Portland State University

PDXScholar

$1-1-2010$

\title{
Cyclic Behavior of Screen Grid Insulated Concrete Form Components
}

Carl Scott Werner

Portland State University

Follow this and additional works at: https://pdxscholar.library.pdx.edu/open_access_etds Let us know how access to this document benefits you.

Recommended Citation

Werner, Carl Scott, "Cyclic Behavior of Screen Grid Insulated Concrete Form Components" (2010). Dissertations and Theses. Paper 364.

https://doi.org/10.15760/etd.364

This Thesis is brought to you for free and open access. It has been accepted for inclusion in Dissertations and Theses by an authorized administrator of PDXScholar. Please contact us if we can make this document more accessible: pdxscholar@pdx.edu. 


\title{
Cyclic Behavior of Screen Grid Insulated Concrete Form Components
}

by

\section{Carl Scott Werner}

A thesis submitted in partial fulfillment of the requirements for the degree of

\section{Master of Science}

in

Civil and Environmental Engineering

\author{
Thesis Committee: \\ Peter Dusicka, Chair \\ Franz Rad \\ William Fish
}

Portland State University

(C)2010 


\begin{abstract}
The principle of sustainability in the built environment has become much more significant in the past decade, resulting in a push to develop building systems that are more energy efficient, durable, and use fewer natural resources. For residential and light commercial buildings, insulated concrete forms (ICF) have enjoyed increasing popularity for their ability to meet these new demands. ICFs are a stay-in-place concrete formwork system for building structural walls that are also highly insulated, among other benefits.
\end{abstract}

Screen-grid ICFs (SGICF) are a small subset of ICFs that tend to use less concrete than standard ICFs and are sometimes made of recycled materials. These traits make SGICFs attractive, but there is a lack of understanding of their structural characteristics due to their irregular internal concrete structure. Because of this, structures using SGICFs are limited to heights no higher than two stories. Further study should show whether SGICFs structures can safely built to greater heights.

This investigation studied two types of SGICFs at a component level in order to gain understanding of their lateral force and drift ratio capacities under cyclic loading. Several variables, including steel reinforcement details, the type of concrete, and the presence of the forms, were altered to measure their impact on the performance of the systems. Test results suggested that the ICF formwork increased lateral strength by up to $100 \%$ and lateral deformation capacity by up $60 \%$ when compared to identical specimens tested with the formwork removed. Results also showed that confinement of the cement, 
either by mesh hoops, spiral wire, or fiber-reinforced concrete improved the drift ratio at failure up to $500 \%$ when compared to specimens with no confinement material.

Computer models were created to gauge their ability to replicate the behavior of the experimental test results. The models typically overestimated the lateral load resistance of the samples by $50 \%-100 \%$, and even more in some cases, depending on the reinforcement. The models were not reliable in determining the drift ratio at which the sample was considered to have failed. In some cases the model failed at $50 \%$ lower lateral deformations than the test specimen, while in others the model did not fail at all.

Future studies should explore refinements of the models to increase their accuracy and usefulness, as well as accounting for the contributions do to the form material. Future studies should also include using spiral wires, mesh hoops, or fiber reinforced concrete in full-scale walls to verify their efficacy in improving overall wall performance. 


\section{ACKNOWLEDGEMENTS}

Thank you to my advisor and thesis chair, Dr. Peter Dusicka, for your support and input throughout my tenure at PSU. Your direction and suggestions proved challenging and invaluable, and undoubtedly improved the quality of my studies and research.

Thank you to my remaining thesis committee members, Dr. Franz Rad and Dr. William Fish, for the excellent suggestions for improving the quality of this paper.

Thank you to all the iSTAR dwellers and especially to Thomas Bennett for all the invaluable help over the past two years. My research would have been impossible without all your contributions.

Thank you also to Apex Construction Systems, Shelterworks Ltd., and Ross Island Sand \& Gravel for the donation and delivery of the ICF forms and concrete used in this research.

Thank you to my parents, whose encouragement and support at every stage of my life proved to be the foundation and catalyst for achieving what I have.

Lastly, thank you to my wife Mica for your inexhaustible strength and patience. This would have not been possible without your love and encouragement. And of course, thank you to my son Elliot for the experience of the irrepressible joy, wonder, and energy of toddlerhood. 


\section{Table of Contents}

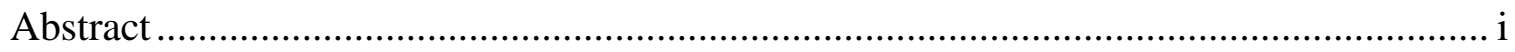

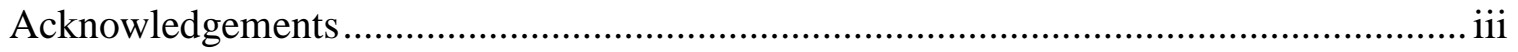

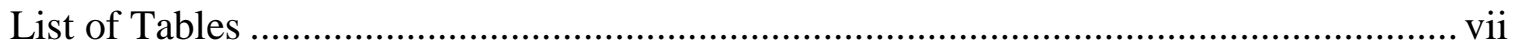

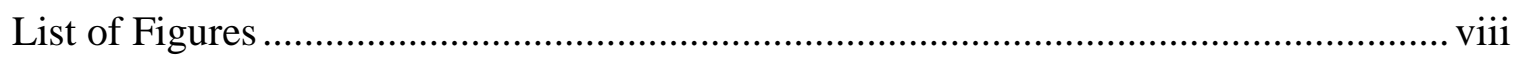

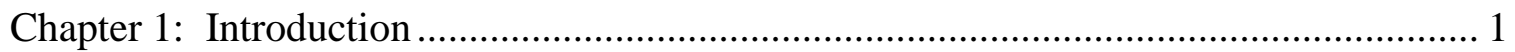

1.1: The Need for Sustainable Engineering .................................................... 1

1.2: Insulated Concrete Forms ........................................................................... 3

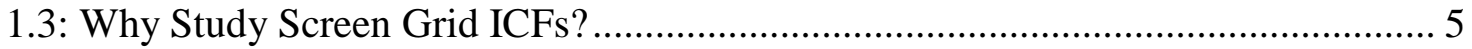

1.4: Review of Literature ................................................................................ 10

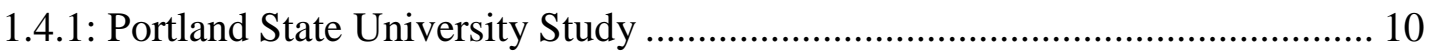

1.4.2: University of California Irvine Study ................................................... 11

1.4.3 National Association of Home Builders Study.......................................... 14

1.4.4: Portland Cement Association Study ........................................................... 15

1.4.5: Apex Construction Systems’ Research ..................................................... 16

1.4.6: Wood Research \& Development, Ltd. Report........................................... 16

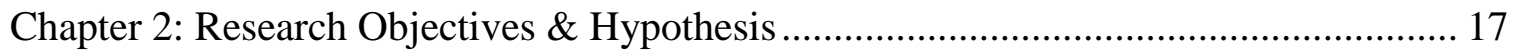

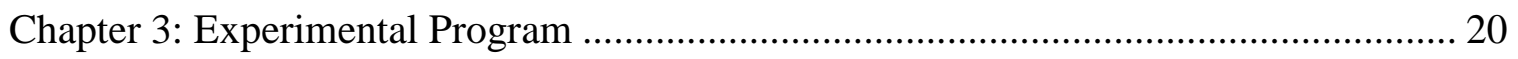


3.1: Specimen Configuration ............................................................................... 20

3.1.1: Apex Block Component Specimens ........................................................... 20

3.1.2: Faswall System Component Specimens ................................................ 24

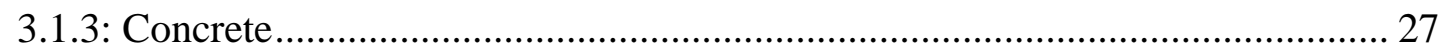

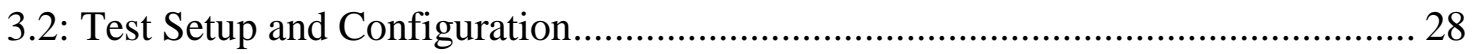

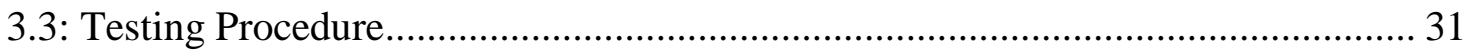

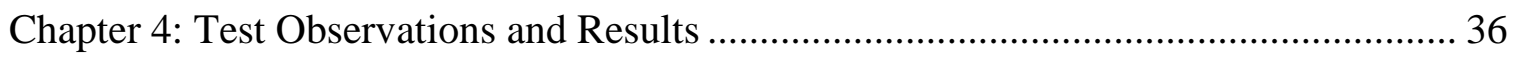

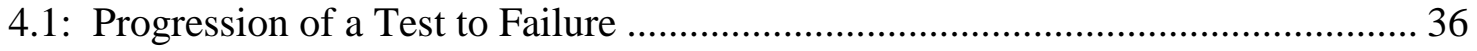

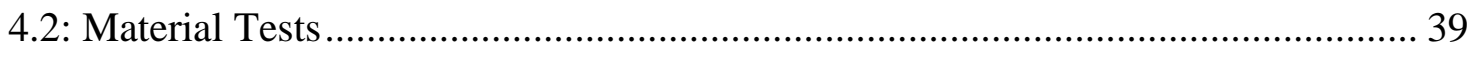

4.2: Apex ICF Test Results ............................................................................ 49

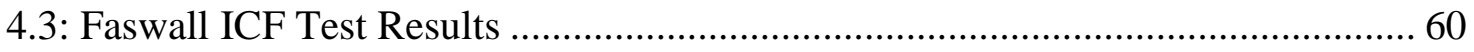

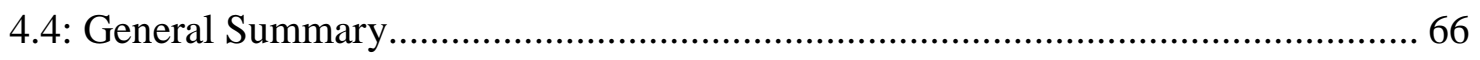

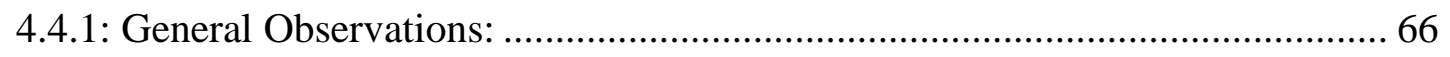

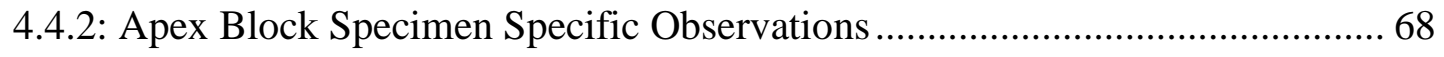

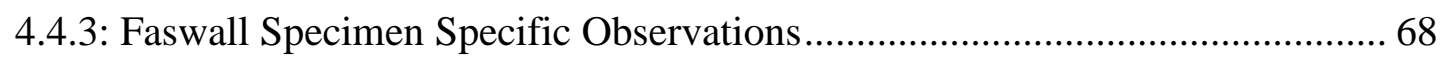

Chapter 5: Numerical Analysis and Computer Modeling.......................................... 69

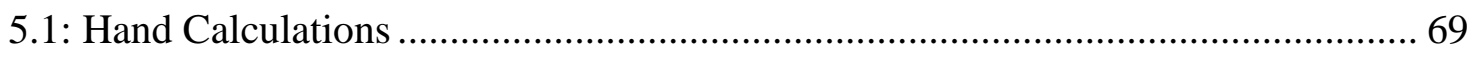

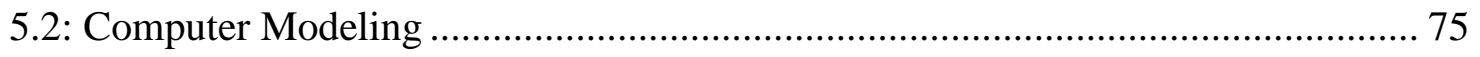




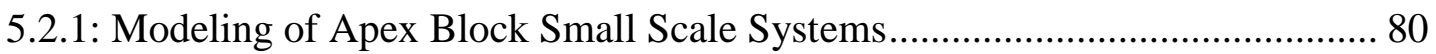

5.2.2: Modeling of Full Scale Apex Walls ............................................................. 87

5.2.3: Modeling of Faswall Small Scale Specimens ............................................ 89

Chapter 6: Conclusions \& Recommendations ......................................................... 96

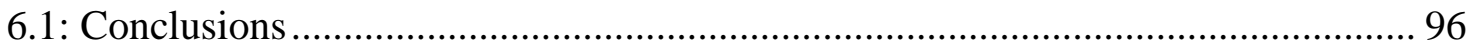

6.1.1: Apex ICF Experimental Test Results ...................................................... 96

6.1.2: Faswall ICF Experimental Test Results ................................................. 98

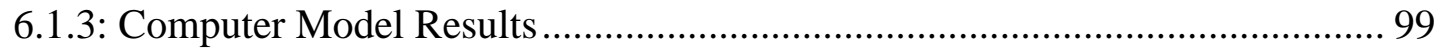

6.2: Suggestions for Future Research.......................................................... 100

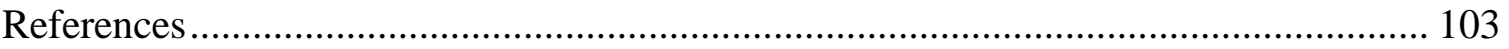

Appendix A: Results of Apex ICF Computer Models without Joint Offsets ................ 105

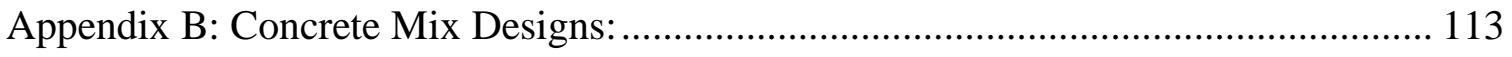

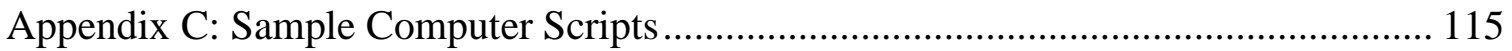

C1: Script for Modeling Small Scale Faswall Test Specimen in OpenSees .............. 115

C2: Script for Modeling Small Scale Apex Test Specimen in Opensees................... 123

C3: Matlab Script for Generating Plots Results of OpenSees Models....................... 130 


\section{LIST OF TABLES}

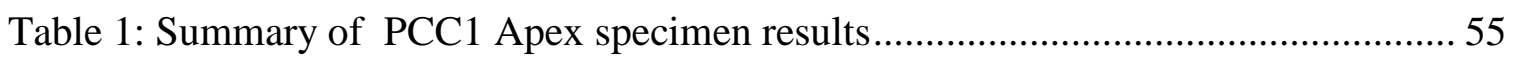

Table 2: Summary of PCC2 and ECC Apex specimen results .................................... 57

Table 3: Summary of Faswall PCC2 and ECC specimen results. * indicates premature

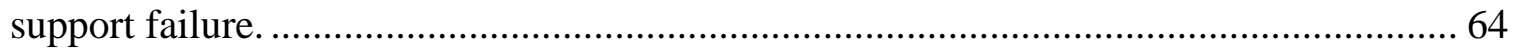

Table 4: Maximum calculated lateral forces in Apex specimen from flexural and shear capacities

Table 5: Maximum calculated lateral forces in Faswall specimens from flexural and shear

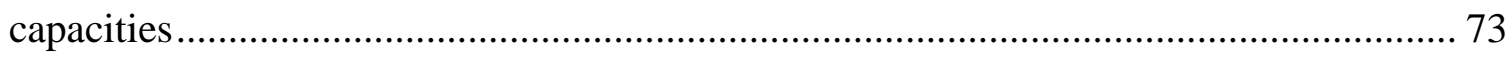

Table 6: OpenSees model results of Apex small scale specimens............................... 81

Table 7: Percent increase or decrease of Apex model results over experimental results . 82

Table 8: Faswall small scale specimen result summary

Table 9: Percent increase or decrease of Faswall model results with respect to experimental results 


\section{LIST OF FIGURES}

Figure 1: ICF Blocks (from left to right): LOGIX flat wall EPS ICF, Apex screen grid EPS ICF, Faswall pseudo-screen grid wood-chip ICF ............................................ 4

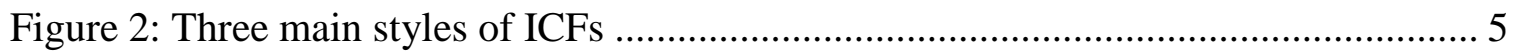

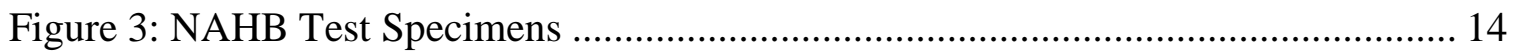

Figure 4: Apex form prior to casting (left); Cured concrete screen specimen grid after casting, curing, and EPS removal, placed in load frame (right). ............................... 21

Figure 5: Apex specimen label convention.......................................................... 22

Figure 6: Apex configurations A11, A12, A13, and A14, with cross-section

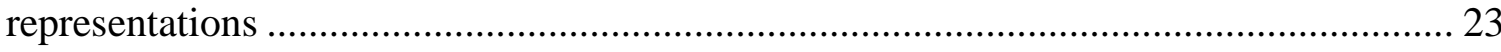

Figure 7: Left to right: Reinforcement configuration for A21, A21, and A25 (also A31,

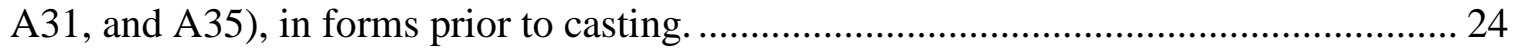

Figure 8: Various stages of Faswall specimen construction ....................................... 25

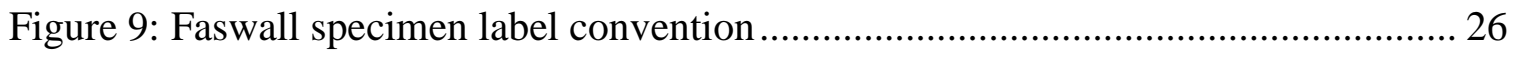

Figure 10:Faswall specimen rebar configuration with representative cross sections ....... 27

Figure 11: Apex Specimen in Reaction Frame …................................................. 30

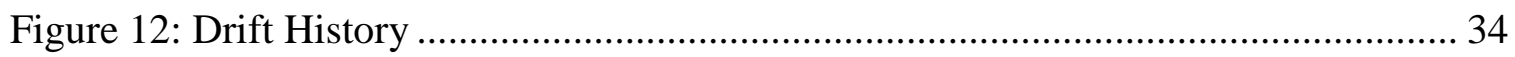

Figure 13: Progression of a typical Apex ICF specimen test....................................... 37 
Figure 14: Progression of typical Faswall ICF specimen test. Arrows indicate new

cracks. 38

Figure 15: Core failure following flexural hinging in Faswall member (diagonal crack, left) and Apex member (axial crack, right) 39

Figure 16: Four compression tests of "red" Apex ICF material 40

Figure 17: Six compression tests of "green" Apex ICF material. 41

Figure 18: compression of "red" Apex forms at small strains 42

Figure 19: compression of "green" Apex forms at small strains 42

Figure 20: Stress-strain diagram of five samples of Faswall wood chip form material ... 43

Figure 21: Stress-strain diagram of five samples of Faswall wood chip form material at small strains 43

Figure 22: Compressive strength test results of PCC1 concrete. 45

Figure 23: Compressive strength test results of PCC2 concrete 46

Figure 24:Four-point bending test results on ECC concrete 47

Figure 25: Compressive strength test results of ECC concrete 48

Figure 26 Apex Block Hystereses, PCC1 Concrete 49

Figure 27: Apex Block Hystereses, PCC1 Concrete 50

Figure 28: Apex Block Small Specimen Backbone Summary: PCC1 Concrete 51

Figure 29: Apex Block Small Scale Specimens: PCC2 (Left) \& ECC (right) concrete... 56 
Figure 30: Apex Block Small Scale Specimen Backbone Summary: PCC2 \& ECC

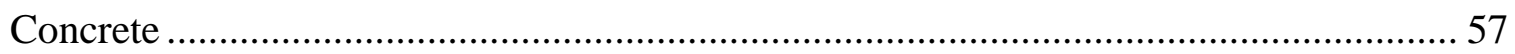

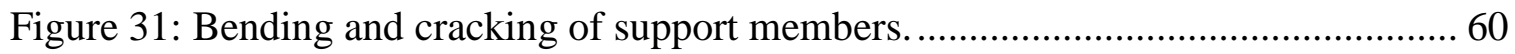

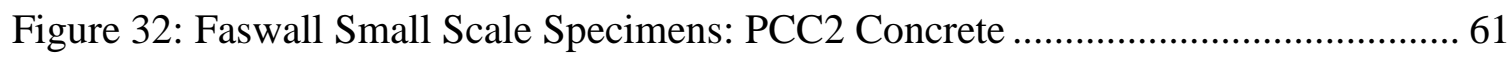

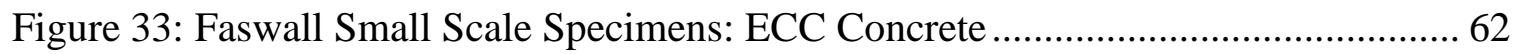

Figure 34 - Faswall Small Scale Backbone Summary, PCC2 Concrete ......................... 63

Figure 35: Faswall Small Scale Backbone Summary, ECC Concrete ............................ 63

Figure 36: Hysteresis cycles from specimen A21R, exhibiting “pinching". .................. 66

Figure 37: Rotation and bearing of vertical member against horizontal members.......... 67

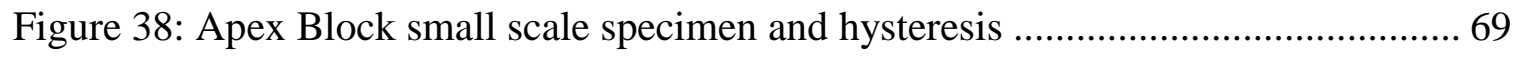

Figure 39: Idealized cross section of Apex core at deflection limits: $\mathrm{f}_{\mathrm{y}}=68 \mathrm{ksi}, \mathrm{f}_{\mathrm{c}}{ }_{\mathrm{c}}=7 \mathrm{ksi}$

Figure 40: Idealized cross section of the reference Faswall core at deflection limits: $f_{y}=$

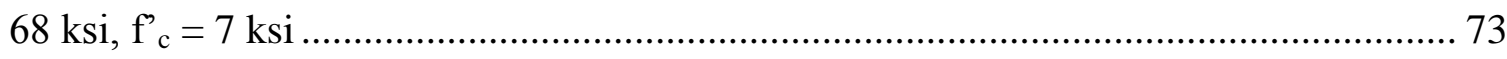

Figure 41: Nodes, members, and supports of Apex model........................................ 76

Figure 42: stress-strain diagram of OpenSees materials "steel02" (left), and "concrete01"

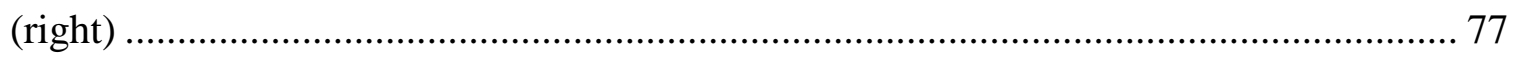

Figure 43: Crack development offset from center of joint for Apex (top) and Faswall

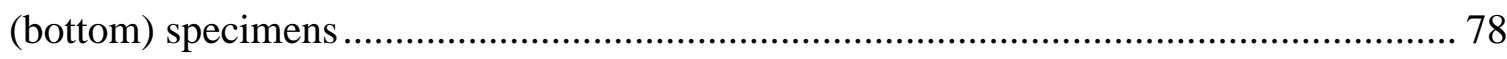


Figure 44: Apex small scale specimen A11R (4 ksi, $63 \mathrm{ksi}$ ): (a) model, (b) experimental result. 82

Figure 45: Apex small scale specimen A21R (7 ksi, 68 ksi): (a) model, (b) experimental result.

Figure 46: Apex small scale specimen A12 (4 ksi, 63 ksi): (a) model, (b) experimental result.

Figure 47: Apex small scale specimen A13 (4 ksi, 63 ksi): (a) model, (b) experimental result. 85

Figure 48: Apex small scale specimen A14R (4 ksi, $63 \mathrm{ksi}$ ): (a) model, (b) experimental result. 85

Figure 49: Apex small scale confined specimens (7 ksi, 68 ksi): (a) model, (b) (c) \& (d) experimental results. 86

Figure 50: Apex full scale 10-ft 8-in x 12-ft wall (4.6 ksi, $60.5 \mathrm{ksi}$ ): (a) model, (b) experimental result.

Figure 51: Peak axial loads in vertical members of 12ft Apex wall model at various drift ratios (compression is positive)

Figure 52: Faswall small scale specimen F21R: (a) model, (b) experimental result........ 91

Figure 53: Faswall small specimen F22R: (a) model, (b) experimental result 92

Figure 54: Faswall small scale specimen F23R: (a) model, (b) experimental result........ 93 
Figure 55: Faswall small scale specimen F31R (ECC): (a) model, (b) experimental result

Figure 56: Faswall small scale specimen F32R (ECC): (a) model, (b) experimental result 


\section{CHAPTER 1: INTRODUCTION}

\section{1: The Need for Sustainable Engineering}

Over the course of the $20^{\text {th }}$ century in the United States, the job of the civil engineer was primarily to produce a national infrastructure to support a rapidly growing nation. Buildings, bridges, utilities, fresh water systems, wastewater systems, and transportation systems were just a few elements of that infrastructure. Natural resources were plentiful, energy was inexpensive, and the population was growing at a healthy, manageable rate. The American dream was driving forward full steam.

Through the late $20^{\text {th }}$ century and into the present, the United States and the world have been drawn into a much closer relationship and deeper awareness of one another, thanks to globalization and leaps forward in technology and communication. Now more than ever we are increasingly cognizant of the affect of our actions in a global context. We are seeing how our actions affect the global population, the environment, and the abundance and availability of resources.

While some of those affects may be positive, we are seeing significant and alarming negative affects as well: we now realize that unchecked growth in a closed system with a finite supply of raw materials, energy, land, and water is wholly unsustainable. The threat to global climate due to emissions of $\mathrm{CO}_{2}$ and other greenhouse gases limits the types of energy sources we can continue to use, further compounding the problem. These factors, coupled with an ever-growing world population (who would 
likely prefer to industrialize and experience the creature comforts of industrialized nations), underscore even more the overarching problem of limited resources.

Thus, the big question becomes that of creating a sustainable world. How do we meet our current needs while preserving the ability of future generations to meet their needs? Fortunately, this question is ringing increasingly louder in educational institutions and professional organizations both domestically and internationally. As of November 2006, The ASCE Code of Ethics' first fundamental cannon mentions sustainability, reading:

Engineers shall hold paramount the safety, health, and welfare of the public and shall strive to comply with the principles of sustainable development in the performance of their professional duties.

The civil and environmental engineer's specific role and ethical duty is therefore to employ sustainability concepts in the built environment in whatever capacity possible.

According to the United States Department of Energy, residential and commercial buildings in the United States are responsible for $40 \%$ of energy consumption in the United Sates, more than for industry or transportation. Buildings are therefore a prime target for improving thermal performance, energy efficiency, water use, and $\mathrm{CO}_{2}$ emissions. Decreasing a building's impact on the environment involves the cooperation of a wide variety of engineers: The mechanical engineer creates efficient HVAC systems; the electrical engineer creates effective and efficient power and lighting systems; the civil engineer creates a site that innovatively deals with water runoff; a chemical engineer creates interior finishes that are low in volatile organic compounds (VOCs); the architect 
situates the building to take advantage of natural lighting, heating, and cooling to further offset energy usage.

What then is the role of structural engineers in this process? A structure has certain requirements to adequately resist gravity and lateral loads, and relatively few materials with which to achieve that goal. Concrete, steel, wood, and masonry have typically been employed to erect sufficient structures. In contributing to the goal of high performance buildings, structural engineers can do but a few things: First, the engineer should — as accurately as is realistically possible — anticipate the forces a building will experience during the building's lifetime, and design building elements to resist those loads, without overdesigning them. Next, engineers can design elements and connections in a way that are less energy-intensive to fabricate and construct. They may also choose to specify materials that use recycled content, are produced locally, or have low embodied energy - energy expended during mining, production, delivery, erection, and recycling. The designer may also design structures with replaceable critical components, such as linked column frames, so that damage is directed to replaceable building elements and the structure is rapidly usable again following a damaging event; lastly, the engineer can design with cognizance of efficient deconstruction and the reuse of materials at the end of a structure's life.

\section{2: Insulated Concrete Forms}

The structural engineer should also be prepared to use new construction materials or methods that may increase the performance of structures. One such relative newcomer that simultaneously uses several common materials and combines important functions is 
the insulated concrete form (ICF). ICF is a broad term that envelopes any system that uses stackable interlocking blocks made from wood chips or expanded polystyrene (EPS) as a stay-in-place form, into the enclosed voids of which steel and concrete are placed to quickly and easily create a structural wall. Several types of ICF are illustrated in Figure 1. The myriad systems on the market are meant to be quick to erect, highly insulating, and durable.
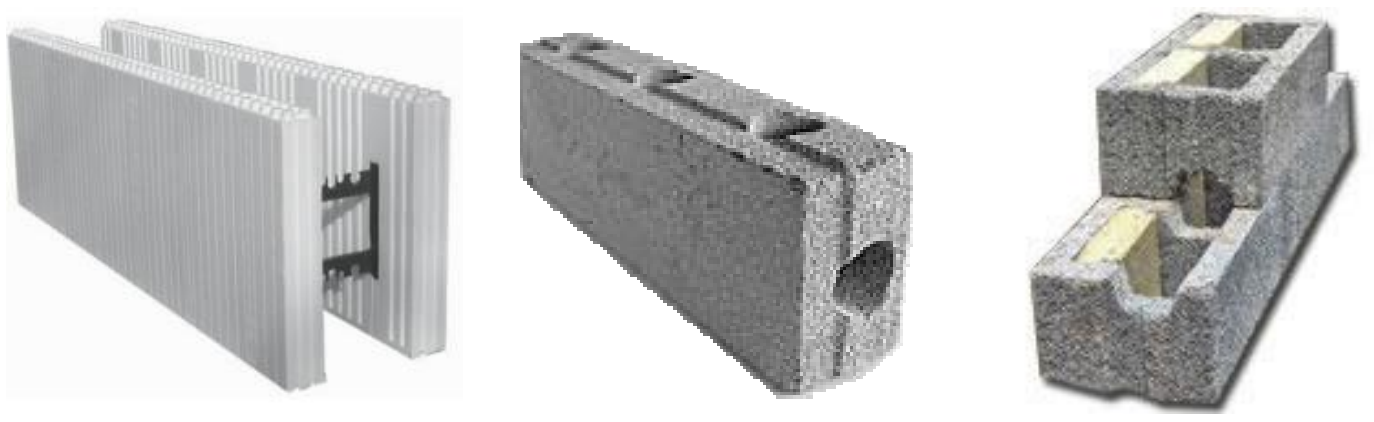

Figure 1: ICF Blocks (from left to right): LOGIX flat wall EPS ICF, Apex screen grid EPS ICF, Faswall pseudo-screen grid wood-chip ICF

The three main types of ICFs are flat, waffle, and screen grid. Flat and waffle grid ICFs create a continuous wall of concrete within the insulating forms. As shown in Figure 2, the concrete within the flat wall ICF has a uniform thickness, while the waffle grid contains a continuous concrete wall with varying thickness. The screen grid wall has discrete concrete post and beam elements, and the space between these elements is filled with the insulating EPS. 


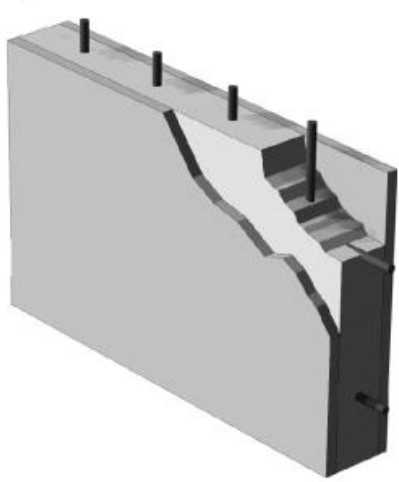

Flat wall core with foam in place

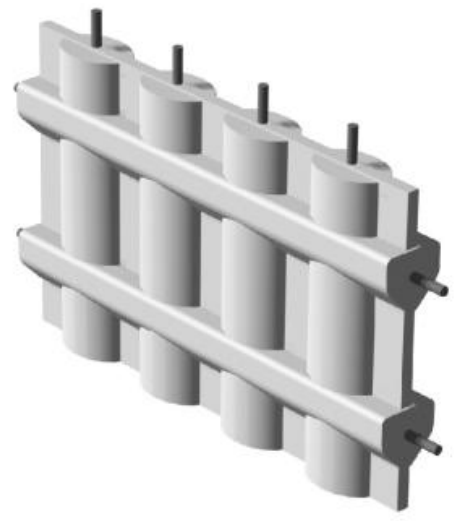

Waffle grid core with foam removed for clarity

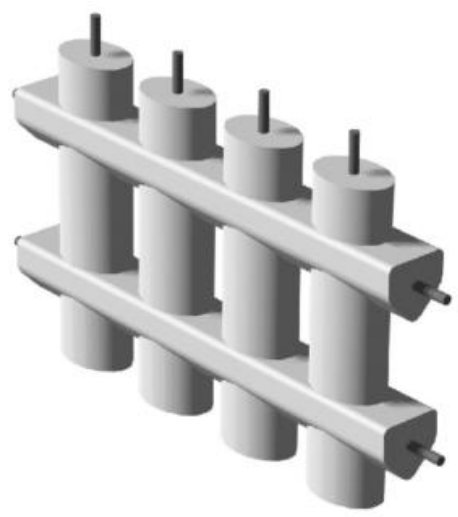

Screen grid core with foam removed for clarity

Courtesy of the Portland Cement Assocation, 2001

Figure 2: Three main styles of ICFs

The design of a wall that utilizes a flat wall ICF is relatively simple in that the concrete core is identical to a typical and familiar continuous concrete wall. In contrast, the intersecting posts and beams of the screen grid ICF (SGICF) is unique from a typical wall, more closely representing a frame with many closely-spaced and relatively stiff elements. The dearth of comprehensive investigative studies into the screen-grid system makes design difficult for designers, as they will find only limited guidance on calculating shear capacity, and even less guidance on flexural, axial, or displacement capacities for the system. There is also very little known about how the form material interacts with the concrete to affect the strength of the system.

\section{3: Why Study Screen Grid ICFs?}

Screen grid insulating concrete forms are worthy of investigation for several reasons. The Apex and Faswall brand SGICFs, which were the focus of this investigation, claim up to $30 \%$ savings in concrete and over flat or waffle grid ICFs. The 
Calculations show that Apex forms use $0.24 \mathrm{ft}^{3}$ of concrete per square foot of wall area, and Faswall uses $0.30 \mathrm{ft}^{3}$ of concrete per square foot of wall. Depending on the interior void width of $4-12$ in, a standard flat wall ICF can use $0.33-1.0 \mathrm{ft}^{3}$ of concrete per square foot of wall. Thus the more commonly used flat ICF form uses at least $37.5 \%$ more concrete than the Apex form, and 10\% more than concrete than the Faswall form. Given that concrete is a highly energy intensive material to produce and that concrete's production contributes approximately $5 \%$ of global anthropogenic atmospheric $\mathrm{CO}_{2}$ emissions each year (Worrell, et al.), reducing the concrete volume for a given wall is preferable for reasons both environmental and economic. An additional sustainability benefit to using Apex and Faswall ICFs is that some use recycled materials; Apex forms are molded using cementitiously bonded $100 \%$ recycled expanded polystyrene (EPS) chips, while Faswall forms are molded using cement-coated crushed recycled pallet wood. Both of these forms have repurposed for constructive use what would otherwise end up as waste in a landfill. Other benefits include a very high claimed R-52 thermal insulating value (thus lower energy costs over the structure's lifetime), four hour flame resistance, high acoustic attenuation, mold and insect resistance, and up to 22 points in the US Green Building Council’s Leadership in Energy and Environmental Design (LEED) program, version 2.0.

The benefits of building with SGICFs are compelling, but a major hurdle of doing so is the design process. First, the SGICF walls consist of intersecting beams and columns surrounded by the ICF form material. Engineers rarely, if ever, deal with such tightly spaced frame-like structures of relatively robust beams and columns, and don't 
know how the form material and concrete interact. Secondly, the required Grade 60 No.4 reinforcing steel is placed haphazardly in the horizontal and vertical cores; the horizontal bars rest directly upon the form at the bottom of each channel, so adequate clear cover of concrete is not provided, and thus full bonding between steel and concrete is unlikely to be achieved. Additionally, the vertical reinforcement is not precisely placed within the vertical cores either - the rebar is not required to be centered in the core, and is allowed to "merely fall as it does", according to the Apex Block building guide (LaManna, et al., 2007). Due to these factors, idealizations of the system must include inherent uncertainty in order to attempt to calculate the in-plane shear and moment capacities of a screen grid ICF wall.

Apex Block SGICF system has been evaluated by International Code Council Evaluation Service, INC. (ICC-ES), which tests building systems and develops design methods for compliance with the Uniform Building Code (UBC) and the International Building Code (IBC). The evaluation service produced a design method that assumes that a wall made of Apex block can be idealized as a nominally reinforced concrete wall of identical length and height and an effective thickness of 4.5 in (ICC Evaluation Service, Inc., September 2008). The ICC report suggests a nominal shear strength of the wall's concrete as

$$
V_{c}=2 * \phi * \psi * b_{e q} * d * \sqrt{f_{c}^{\prime}}(p s i)
$$

where :

$b_{\text {eq }}=$ Width of an equivalent rectangular section equal to 4.5 in, 
$\mathrm{d}=$ Distance from extreme compression fiber to centroid of tension reinforcement (inches),

$\mathrm{f}^{\prime}{ }_{\mathrm{c}}=$ Specified compressive strength of concrete (psi),

$\phi=$ Strength reduction factor in accordance with Section 1901.2 of the IBC or Section 1909.3 of the UBC.

$\Psi=$ Grid-factor equal to 0.85 .

Comparatively, the shear strength of a typical concrete wall from the American Concrete Association concrete building code, ACI 318-08, is

$$
V_{c}=2 \lambda \sqrt{f_{c}^{\prime}} b_{w} d(p s i)
$$

where:

$\lambda=1.0$ for normal-weight concrete,

$\mathrm{b}_{\mathrm{w}}=$ Wall thickness (inches),

$\mathrm{d}=$ Distance from extreme compressive fibers to centroid of tension reinforcement, typically assumed to be $80 \%$ of the wall length.

Thus the calculated nominal shear strength for the Apex SGICF wall can is approximately $35 \%$ lower than that of a flat 4.5 in thick reinforced concrete wall. This assumes strength reduction coefficient of $\phi=0.75$ for members in shear (ACI318-08, Section 9.3.2.3) in the ICF shear equation.

The ICC-ES report gives guidance for calculating nominal shear capacity only; that is, there are no equations for determining moment capacity of screen grid ICF walls. 
Instead, the report provides prescriptive design methods for compliance with the UBC and also refers to the Portland Concrete Association's manual PCA EB212. The prescriptive methods limit the allowable height of Apex ICF structures to no more than two $10 \mathrm{ft}$ stories above grade. The report also provides a table for in-plane shear capacity on a per-lineal-foot (plf) basis, depending on the length of the wall (Table 2 of the ICCES report).

Previous investigations of ICF walls subject to in-plane cyclic forces have generally shown pinched hysteresis loops at drift levels above $2 \%-3 \%$, which indicate a lower capacity for energy dissipation relative to more conventional and well-established building systems. The pinched hystereses also indicate highly reduced system stiffness after large deformations, which is detrimental to the overall stability of the structure and dangerous for any occupants within it.

By providing little guidance on flexural, ductility, or stiffness characteristics, or failure mode of SGICFs, the available design guides leave a designer to ponder the system's true capabilities and the SGICF's potential for safe and economic use in structures that are taller than two stories. Since SGICFs can use significantly less concrete than a flat or waffle grid ICF, in addition to other benefits, further investigation into the system's performance capabilities should help to determine SGICF's suitability for use in taller structures. 


\section{4: Review of Literature}

The following studies represent most of the relevant research on screen grid insulated concrete forms. Their scopes illustrate the need for further study, especially for in-plane cyclic loading characteristics.

\subsection{1: Portland State University Study}

A report by Thomas Kay and Peter Dusicka, of Portland State University's (PSU) Infrastructure Testing and Research (iSTAR) laboratory in Portland, OR, investigated several full scale SGICF walls constructed with the Apex system (Kay, et al., 2009) . The walls were subject to in-plane static cyclic loading, and used an identical loading pattern to that used in the tests performed for this study. The height-to-length ratios of the walls they investigated were 0.9:1 and 2.7:1 (128 in tall and either 144 in or 48 in length, respectively). The walls were tested with and without gravity loads, and in one case the ICF material was stripped away prior to testing in order to investigate only the underlying concrete grid structure. They also constructed and tested nominally reinforced 4.5 in thick continuous concrete walls with identical dimensions to their ICF walls, in order to test the assertion that such walls are equivalent to screen grid ICF walls with regard to in-plane shear strength.

The authors offered several conclusions that will be relevant to the results presented in this report:

When comparing walls tested with the ICF form in place to one with the form material removed, the core-only wall strength was $16 \%$ lower than the wall tested with 
the form in place. Additionally, the stiffness was $47 \%$ lower and the ductility $31 \%$ lower in the core-only wall. That result showed that the EPS form material has a positive effect on strength, stiffness, and ductility. The specific mechanism for this improvement is thus far unknown.

The failure of the test walls were consistently due to diagonal shear cracking through the vertical cores along a single horizontal plane.

Between similar ICF test walls, values of peak strength deviated no more than $7 \%$ from the mean, while stiffness and deformation performance were more widely variable, falling in a range of $28 \%$ of the average.

Failure of the ICF walls typically occurred in a range from $1.75 \%-3 \%$ drift. The point of failure of a wall was defined as the drift ratio at which the peak force of a cycle had been reduced to $80 \%$ of the largest observed force of any prior cycle.

For walls without applied gravity loads, low aspect ratio walls failed consistently at drift ratios of approximately $1.75 \%$, while high aspect ratio walls failed at higher drift ratios of approximately $3.0 \%$.

The ICF walls and their comparable benchmark continuous concrete walls had similar drift ratio capacities, though the concrete walls often reached peak forces up to $30 \%$ greater than the ICF walls.

\subsection{2: University of California Irvine Study}

Another academic investigation was completed in 2000 by UC Irvine doctoral candidate Carla V Yland (Yland, 2000). Like the PSU study, Yland's investigated the 
response of screen grid ICF walls to in-plane cyclic loading. Her walls included three each with height-to-length ratios of 1:1, 2:1, and 3:1. Yland used a slightly different ICF product that yielded a more compact joint spacing of 15 in on-center, as opposed to the 16 in spacing of the Apex product. Both products used 6 in diameter cores and were reinforced with one No.4 grade 60 steel in each core. As with the PSU investigation, Yland's test walls were cyclically loaded with increasing displacements, and she reported results for peak forces, displacements, story drift, ductility ratios, and failure modes. Yland also performed a variety of material test on the EPS material, including the material's confinement effect upon the concrete during compression tests.

Regardless of height-to-length ratios, failure of the ICF walls often occurred at drift ratios of approximately $1 \%$. The point of failure is at lower drifts than were observed in the PSU study, and may be attributed to lower concrete strength (3.1 ksi versus nearly $4 \mathrm{ksi}-5 \mathrm{ksi}$ at PSU) or the slightly more compact 15 in grid spacing.

The mode of failure typically observed was diagonal shear cracking of the vertical members, located along a single horizontal plane. The plane of failure was located 30 in above the footing, just above the end of Grade 60 No.4 lap splices that joined the wall to the footing. This mode and location of failure was identical to that observed in the PSU investigation.

Compression tests on the EPS material by itself exhibited an average compressive stress of only 9 psi at a strain of 0.003 (noted due to strain compatibility with concrete at failure). The compressive stress reached a maximum of 170 psi at $30 \%$ strain, and the test terminated with a stress of 150 psi at $55 \%$ strain. 
Concrete compression tests were performed on 2-in diameter, 4-in tall concrete specimens. Three specimens were cured in air, three were cured in standard plastic molds, and six were poured into molds created from the ICF EPS material. Each EPS mold was 6-in square and 4-in tall, with a 2-in diameter by 4-in tall cylindrical void down through the center for the concrete. At 28 days all the samples were tested, with three of the six ICF-mold specimens stripped of the surrounding EPS material, while the EPS was left in place for the remaining three. The air-dried and plastic mold-cured samples had nearly identical compressive strengths of $1800 \mathrm{psi}$ and $1870 \mathrm{psi}$, respectively. Meanwhile, the three specimens that were cured in the EPS mold but were tested with the EPS form removed exhibited a $31 \%$ increase in average compressive strength of 2410 psi. The specimens tested with the EPS material still in place showed an increase of compressive strength of $102 \%$, failing at 3710 psi. The increase in strength cannot be attributed to the very small compressive strength of the EPS, so Yland concluded that some unknown mechanism of the EPS material must have provided significant confinement to the concrete. This observation is congruent with PSU test results that show additional force resistance and drift capacity of the 1:1 aspect ratio wall with form in place when compared to the 1:1 aspect ratio wall with the form removed.

Lastly, Yland noted that the maximum loads sustained by a specimen subjected to cyclic loading were typically $60 \%-70 \%$ of a monotonically applied load on an identical wall. 


\subsubsection{National Association of Home Builders Study}

A third study of ICF systems that included screen grid systems was performed by the National Association of Home Builders (NAHB) Research Center, Inc., for the U.S. Department of Housing and Urban Development (NAHB Research Center, Inc., 2001) . The study investigated screen-grid walls with 4:1 and 2:1 height-to-length ratios, either alone or joined via lintels to simulate window or garage door openings. Figure 3: NAHB Test Specimens illustrates the test subjects.
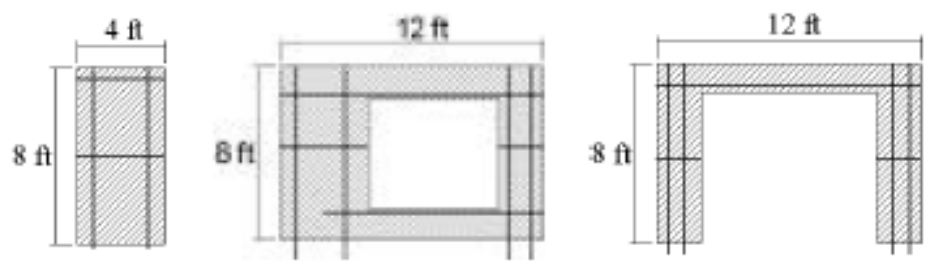

Figure 3: NAHB Test Specimens

The NAHB built and tested only one of each specimen, and applied monotonic loads rather than cyclic. The researchers' intent was to determine an equivalent continuous wall thickness to relate to the screen grid ICF system. They also sought to determine the aspect ratios of screen grid ICF walls for which shear failure or flexural failure were likely to occur. In addition, they compared their results to the shear strength predicted by the prescriptive design guidelines for ICF walls.

Due the lack of testing multiple identical specimens, and that the sample with the window opening may have failed prematurely, the NAHB study ultimately concluded that further study of screen grid ICFs with more specimens were necessary to validate their initial observations and equations for in-plane shear capacity. 
Based on the results from the 8-ft x 4-ft wall, the observed shear strength of the SGICF wall is equivalent to that of a 4.39-in thick solid concrete, which is nearly the same as $b_{\text {eq }}$ determined by and stated in the ICC-ES report.

The cracking pattern through the $2: 1$ aspect ratio screen grid wall under monotonic loading was diagonal, extending from the upper corner nearest the hydraulic actuator, down to the middle of the wall at the opposite side, through joints and members alike. This contrasts with the cyclically loaded walls in the PSU test, where failure occurred along a horizontal plane, 30 in above the footing, through the vertical members.

For walls with aspect ratios greater than $4: 1$, the two theoretical models employed were nonconservative, overstating the actual strength of a wall by up to $66 \%$.

For walls with aspect ratios of 2:1 or less, the two theoretical models employed were conservative, understating the actual strength of the wall by $73 \%$.

\subsection{4: Portland Cement Association Study}

Screen grid ICFs were also studied by Mehrabi in 2000 for the PCA (Mehrabi, 2000). Mehrabi compared wood-frame, steel-frame, ICF flat wall, ICF waffle-grid wall, and ICF screen-grid wall panels. The 8-ft tall x 4-ft wide panels were tested for shear resistance with the intension of comparing their adequacy in earthquake zones 1 or 2 and for 70 mph minimum wind speeds. Similar to the NAHB test, only one wall of each type was tested, and each wall was subject to increasing monotonic static in-plane loads from a hydraulic ram. 
They found that the wall exhibited a diagonal cracking pattern, which extended down from 29 in above the footing on the loaded side to the footing/wall intersection on the opposite side. Peak displacement of 1.7 in, which equates to a drift ratio of $1.77 \%$, and a peak force of 27.9 kip were observed during the test. Comparatively, the screen-grid wall was up to 6.5-8 times stronger and stiffer than wood-frame and steel-frame panel walls of identical dimensions.

\subsection{5: Apex Construction Systems' Research}

As reported by Apex Construction Systems (LaManna, et al., 2007), several material properties of the EPS form material include: material density of $17.5 \mathrm{pcf}$; material tensile bending strength of $28 \mathrm{psi}$; material compressive strength of $40.1 \mathrm{psi}$;

[in-plane] shear capacity for $10.7 \mathrm{ft}$ wide walls of $60.6 \mathrm{kip} \pm 5.2 \mathrm{kip}$; and [in-plane] shear capacity for $4 \mathrm{ft}$.wide walls of 16.6 kip \pm 5.2 kip.

\subsection{6: Wood Research \& Development, Ltd. Report}

Material tests performed by Wood Research and Development Ltd. (Tingley, 2008) for Shelterworks (the producers of Faswall) found: material density of 35-40 lb/ft; average maximum compression stress of $192 \mathrm{psi}$ (at unknown strain); average maximum shear stress resistance of $135 \mathrm{psi}$; and no reported data on tensile strength. 


\section{CHAPTER 2: RESEARCH OBJECTIVES \& HYPOTHESIS}

The general objective of this investigation is to gain further understanding of the strength capacity, deformation capacity, and failure modes of screen grid ICF systems at the component level. More specific objectives are as follows:

- To understand and quantify the effect of varying the reinforcement and confinement details within the concrete cores.

- To understand and quantify the contribution of the ICF form material to the strength and deformation capacity of the system.

- To understand and quantify the effect of ECC concrete versus standard PCC in the ICF system.

- To compare the results of laboratory experiments to computer models, with regard to altering variables of reinforcement, confinement, concrete type, and form inclusion.

- To compare small scale specimen tests to Kay \& Dusicka's results and observations of large scale walls.

- To test the scalability of computer models of small scale specimens to large scale walls and compare with Kay \& Dusicka's findings.

Preliminary hypothesis that were explored do not include expected values with respect to in-plane force resistance of small scale test specimens or their drift capacity, but rather the general qualitative behavior of such specimens based on observations of prior investigations. 
Based on prior investigations (of the Apex ICF specifically), the drift capacity the screen grid ICF (SGICF) specimens is not expected to exceed approximately $2.5 \%$, and the peak resisted forces are as yet unknown. However, since the objective of the investigation is to improve the performance of the SGICF system, several variables were introduced to help achieve those goals. Past investigations showed that the Apex ICF walls had low deformation capacity and generally saw the complete and abrupt failure of the vertical concrete members of the grid.

If confinement is introduced into the sample specimens in the form of spiral wire, mesh wire hoops, or fiber-reinforced concrete, the beam and column members should have increased compressive strength. Thus the drift capacity should increase as the concrete in the members is more likely not to fail catastrophically as in observed in prior tests.

The current recommended ICF reinforcement is one Grade 60 No.4 bar in each vertical and horizontal member - or "core" - of the ICF structure. Additional rebar, whether located in the center of each core or near the outer edges of each core, should provide additional flexural capacity in each core, and thus provide additional flexural capacity and overall in-plane lateral force resistance to the ICF system. Previous investigations have shown pinched hysteresis loops at larger drift levels, indicating dramatically decreased system stiffness. Additional rebar may also serve to delay the degradation of both strength and stiffness in the system.

Finally, previous studies of the ICF have shown a strength increase of approximately $25 \%$ when an ICF wall is tested with the formwork in place as compared 
to the having the formwork removed. This phenomena may be due more to confinement due to the formwork than the material's compressive strength. The investigation explord whether that was the case. 


\section{Chapter 3: Experimental Program}

\section{1: Specimen Configuration}

As previously stated, the objective of this program was to test small units of screen grid ICF systems under full reversal static cyclic loading. While several types of forms exist on the market, the Apex forms and Faswall forms shown in Figure 1were used due to local availability. A variety of variables were altered to test their effect on the strength and ductility of the system.

\subsection{1: Apex Block Component Specimens}

A single Apex Block measures 16 in tall, 48 in wide, and 10 in thick. When stacked, the interior 6 in diameter hollow cores that run both horizontally and vertically at 16 in on center were aligned. Stacking two blocks therefore resulted in a 32-in x 48-in specimen comprised of two horizontal cores and three vertical cores. A limitation of 38 in imposed by the width of the load frame necessitated trimming each side of the stack by 6.25 in, resulting in a 32-in x 35.5-in sample which still retained the same number of cores, though reduced the outer cores' cross section by their outer-most $1.25 \mathrm{in}$. The form and the resulting interior screen grid concrete cores are shown in Figure 4. 

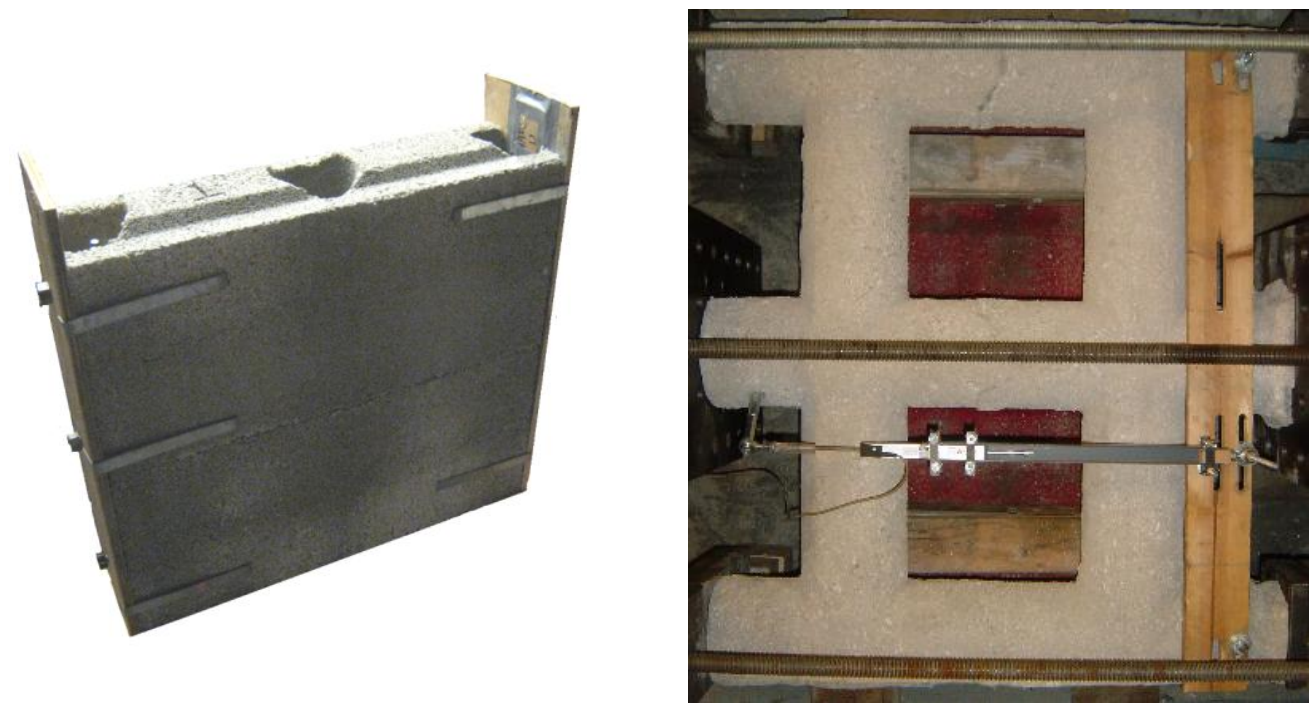

Figure 4: Apex form prior to casting (left); Cured concrete screen specimen grid after casting, curing, and EPS removal, placed in load frame (right).

The Apex Block samples consisted of several different testing configurations.

Common to all configurations were the reinforcing steel in the three cores parallel to the load application (which simulated the horizontal members in a wall), while the steel in the cores perpendicular to the force (which simulated the vertical members in a wall) was varied. The outer horizontal cores (or "support" cores, which were fixed in place) each contained two Grade 60 No.4 rebar centered in each core. The central horizontal core, which was attached to the actuator and carried the cyclic load application, contained one centered No.4 rebar.

The vertical cores were reinforced and denoted as follows, where the member in parenthesis indicates the number of samples built, 'A' denotes the use of the Apex block; the first digit denotes the concrete mix design used; and the second digit is a number assigned to that specific reinforcement configuration. An ' $R$ ' denotes that the form was removed for testing; the omission of a fourth character signifies the test was done with 
the form in place. Figure 5 illustrates the label convention for the Apex specimens, and Figure 6 and Figure 7 illustrate the specimen reinforcement configurations.

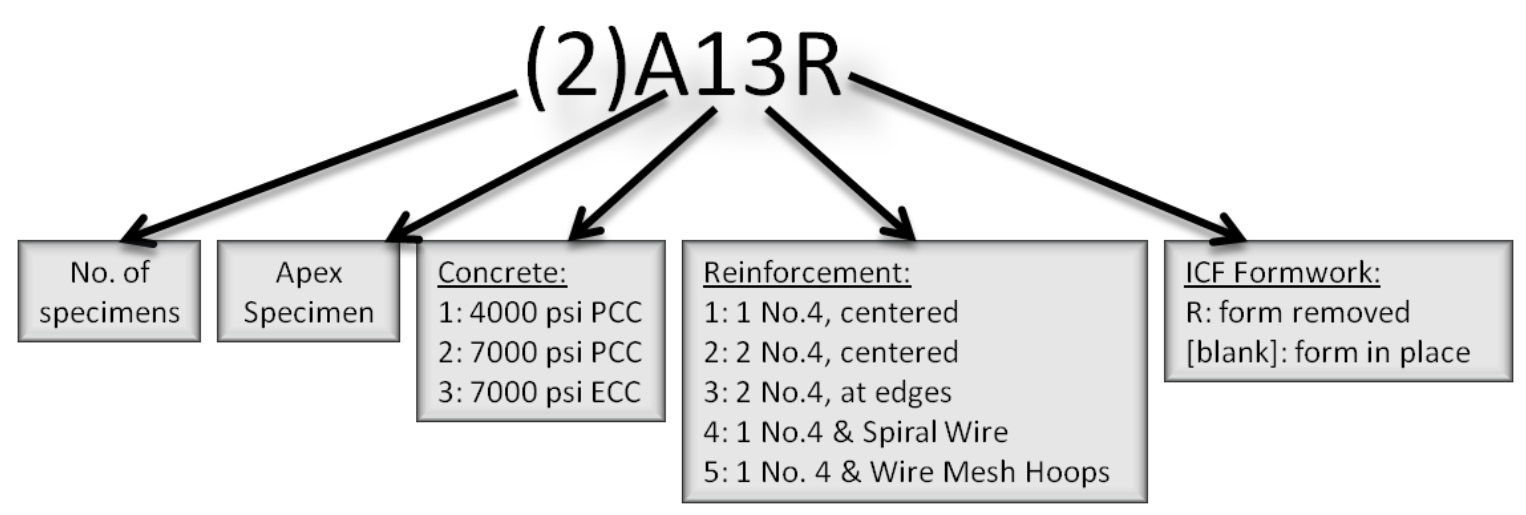

Figure 5: Apex specimen label convention

- (2) A11 - One No.4 reinforcing bar centered in each core.

- (2) A11R -A11 with the EPS removed.

- (2) A12 - Two No.4 reinforcing bars centered in each core.

- (2) A13 - Two No.4 reinforcing bars, each located at the edge of the core along the plane parallel to the length and height of the screen grid wall, with 1 in concrete cover.

- (1) A14 - One No.4 reinforcing bar centered in each core, accompanied by 3/16 in steel wire formed into a spiral of 5.5-in diameter and 2-in pitch.

- (1) A14R -A14 with the EPS form removed.

- (1) A21 - One No.4 reinforcing bar centered in each core.

- (1) A21R -A21 with the EPS form removed. 
- (1) A25R - One No.4 reinforcing bar centered in each core, accompanied by 6-in diameter closed steel wire mesh hoops in all cores. EPS form is removed.

- (1) A31 - One No.4 reinforcing bar centered in each core.

- (1) A31R - A31 with the EPS form removed.

- (1) A35R - One No.4 reinforcing bar centered in each core, accompanied by 6-in diameter closed steel wire mesh hoops in all cores. EPS form is removed.
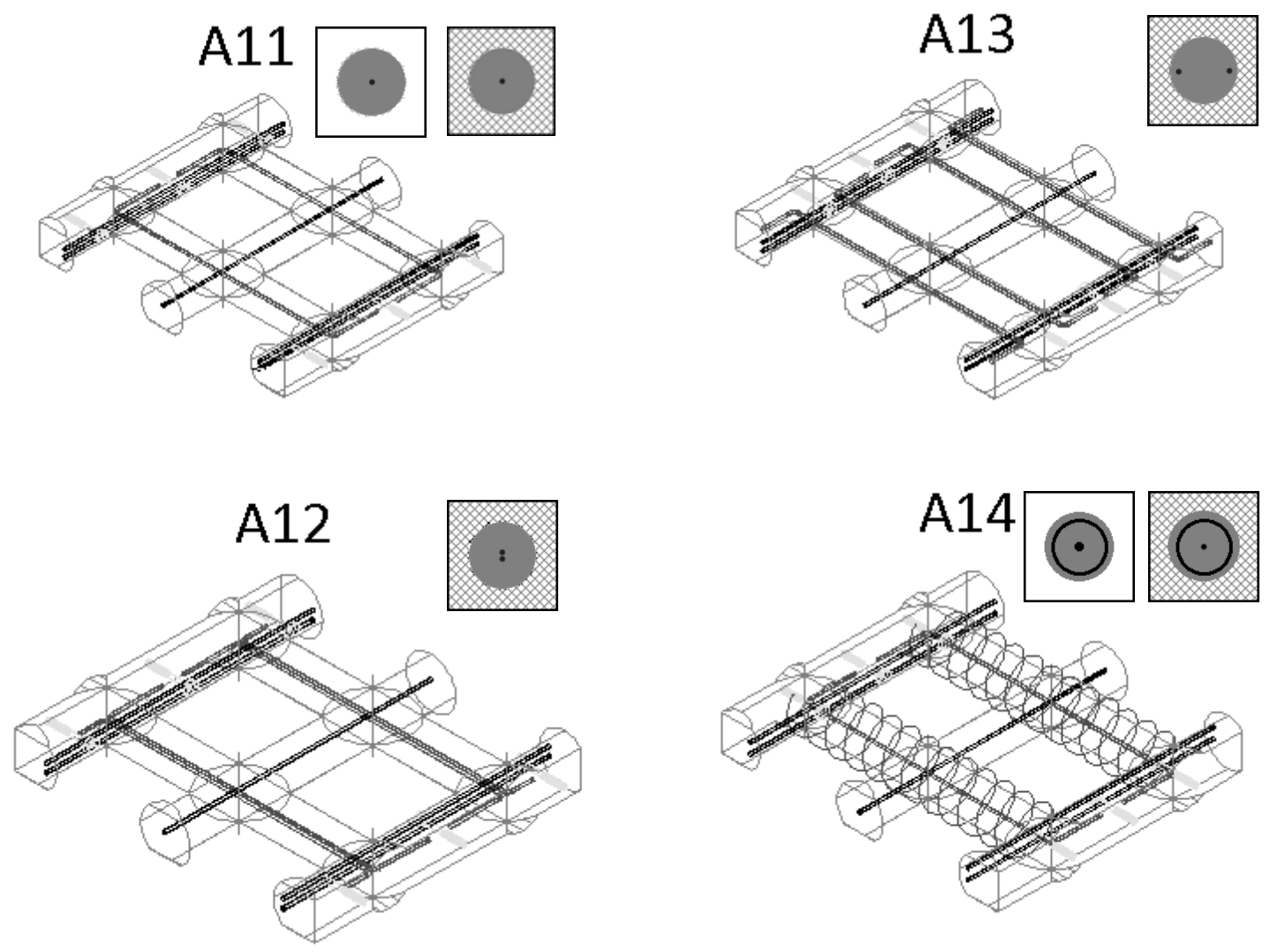

Figure 6: Apex configurations A11, A12, A13, and A14, with cross-section representations 


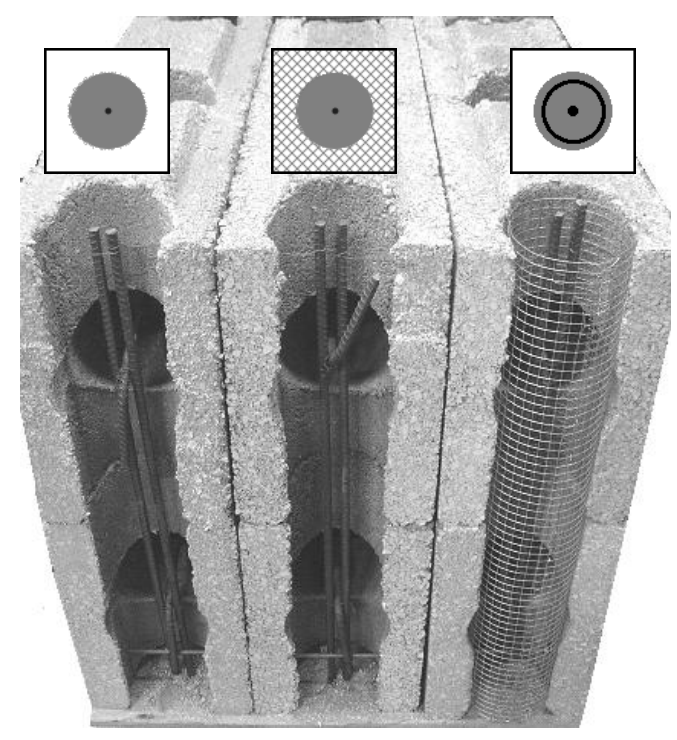

Figure 7: Left to right: Reinforcement configuration for A21, A21, and A25 (also A31, A31, and A35), in forms prior to casting.

\subsection{2: Faswall System Component Specimens}

The Faswall ICF forms are $85 \%$ crushed and mineralized waste pallet wood with $15 \%$ cementitious material, molded into the blocks shown in Figure 4. Similar to the Apex Block, the Faswall forms create an interior concrete screen grid, but the vertical concrete cores are 5-in deep x 9-in wide rectangular columns, with 2 in of space between adjacent cores. Vertically, the cores are connected to one another every 16 in by a reinforced 4-in x 4-in section of concrete. Each individual Faswall block measures 24-in wide $\mathrm{x}$ 12-in deep x 8-in tall and yields two columns and two connections. A cutaway view of the form and the resulting core system after form removal are shown in Figure 8. Stacking four Faswall blocks yields a specimen 24-in wide x 32-in tall, which fits the load frame similarly to the Apex specimens. The frame width of 38 in allowed for additional concrete at both sides of the Faswall specimen to increase their cross-sectional and thus strength for their roles as static supports during the test. The additional concrete 
can be seen protruding from the top of the cured form in Figure 8B. Figure 8A shows the interior reinforcing prior to the addition of concrete, and Figure 8C shows the cured concrete with the forms removed.

Three configurations of reinforcement were used for the Faswall specimens. The horizontal cores (used for support and applying the cyclic loading) were reinforced similarly to the Apex specimens; the two outer support cores each contained two parallel lengths or Grade 60 No.4 rebar, while the central core contains only had one length of rebar.

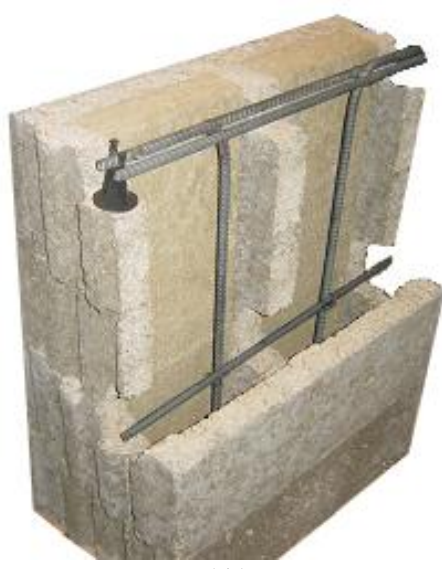

(A)

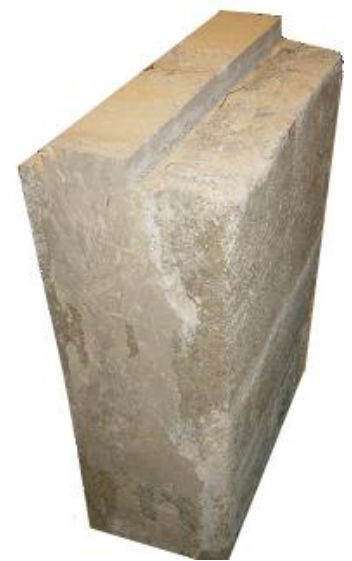

(B)

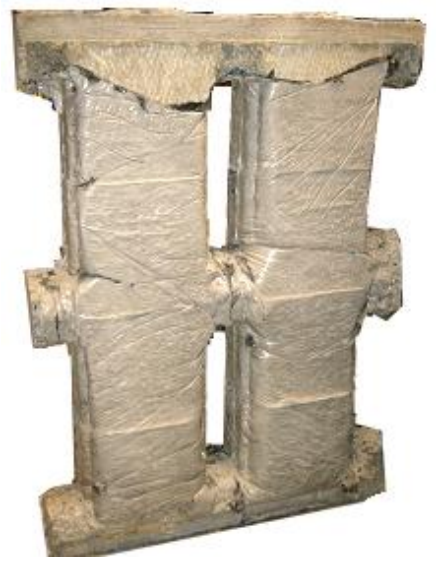

(C)

Figure 8: Various stages of Faswall specimen construction

The vertical cores were reinforced and denoted as follows: the number in parenthesis indicates the number of samples built; 'F' denotes the use of the Faswall ICF form; the first digit denotes the concrete batch used; and the second digit is a number assigned to that specific reinforcement configuration The addition of ' $R$ ' signifies that the Faswall woodchip form was removed for testing. Figure 9 illustrates the Faswall specimen naming convention and Figure 10 illustrates the reinforcement configuration. 


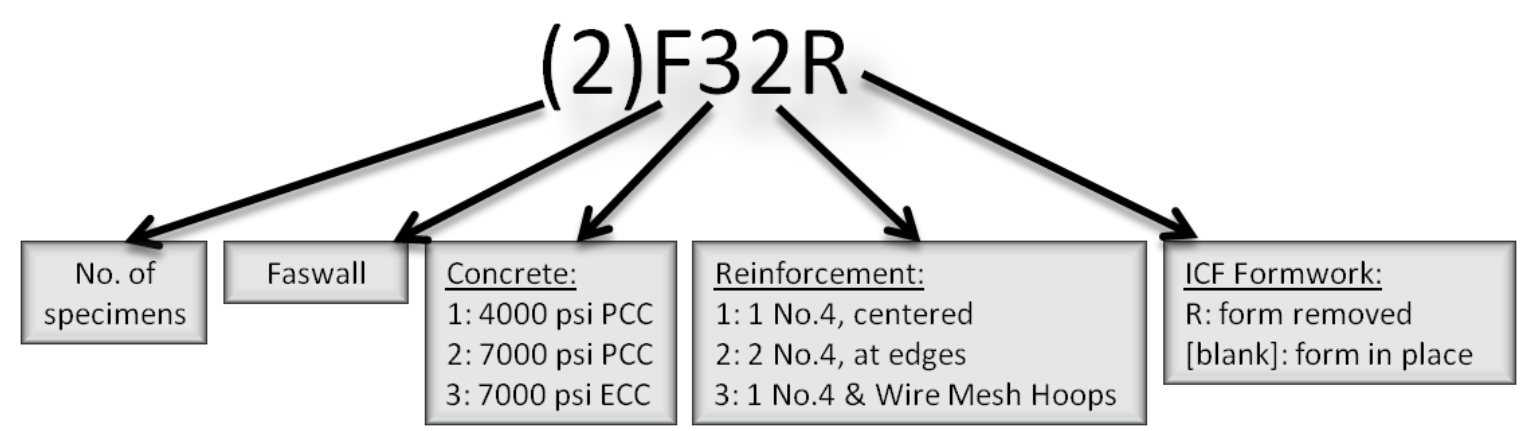

Figure 9: Faswall specimen label convention

- (1) F21 - One centered No.4 rebar per transverse core.

- (2) F21R - F21 with Faswall form removed.

- (1) F22R - Two No.4 rebars per transverse core, each centered depth-wise but separated width-wise to opposite sides of the core, 1 in concrete cover. Faswall form is removed.

- (1) F23 -One centered No.4 rebar per transverse core, like F21, but with the addition of 4.5 in diameter close mesh wire hoops centered in each core.

- (1) F23R-F23 with the form removed.

- (1) F31 -Same configuration as F21, but with ECC concrete.

- (2) F31R-F31 with form removed.

- (1) F32 - Same configuration as F22, but with ECC concrete.

- (1) F32R - F32 with form removed. 


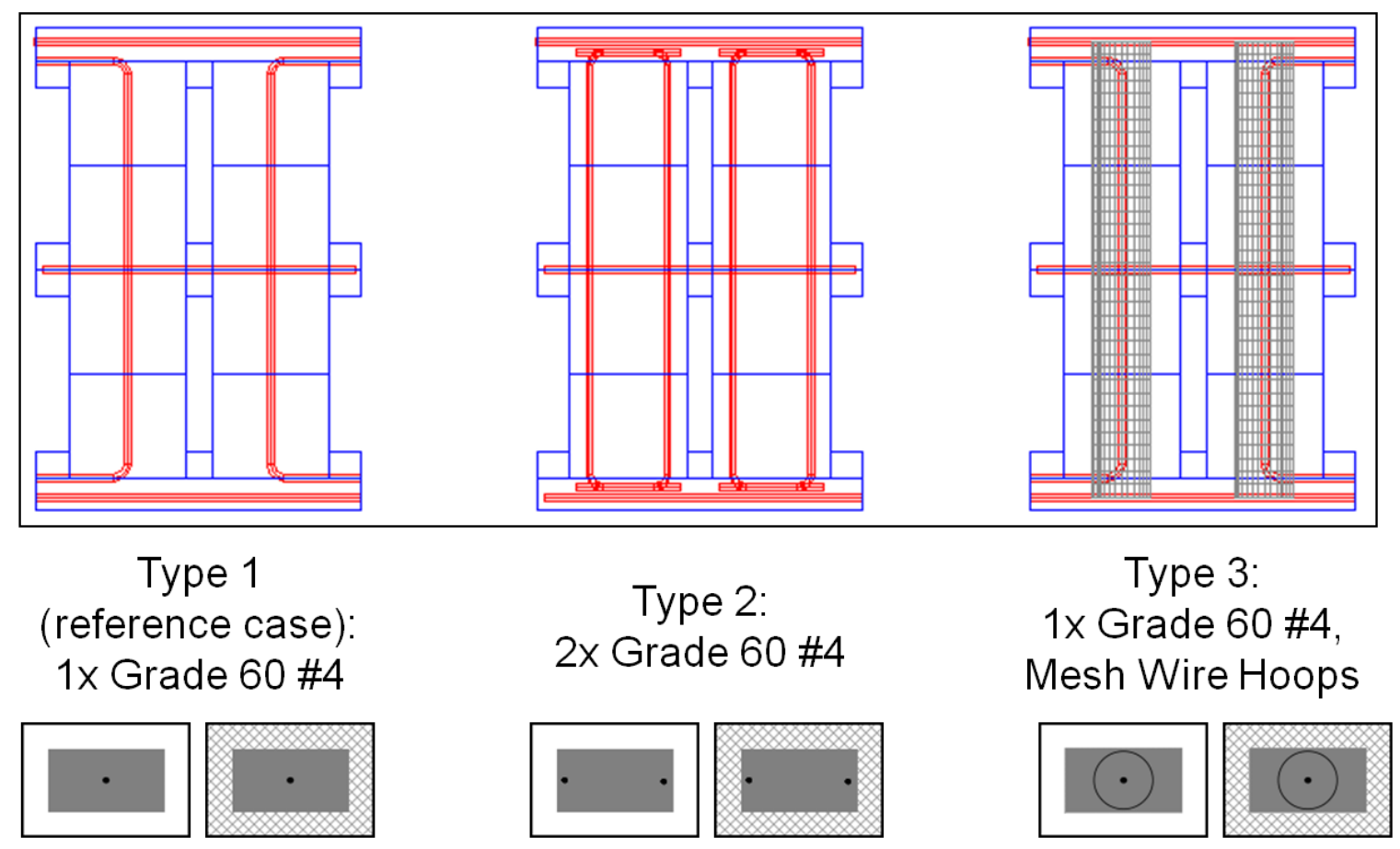

Figure 10:Faswall specimen rebar configuration with representative cross sections

\subsection{3: Concrete}

As previously mentioned, three concrete castings were performed during the investigation of several ICFs. The first mix, denoted as 'PCC1', was cast in August 2008 and used in the first ten Apex specimens listed above (A1XX series). The mix design specified $30 \%$ coarse aggregate (3/8 in pea gravel), $70 \%$ clean sand, 8.5 in slump, and a 28-day compressive strength of 4000 psi. The concrete mix was provided Bella Green Contractors and tested by Mayes Testing Engineers, both of Portland, OR. The test specimens were cast onsite at the iSTAR laboratory

The second casting of concrete, denoted 'PCC2', was similarly designed to PCC1, but was found to have a 28-day compressive strength of 7000 psi. PCC2 was used in both 
Apex and Faswall test specimens (A2XX and F2XX series above), was cast in November 2009, and provided by Ross Island Sand \& Gravel of Portland, OR. Compressive strength tests were performed by the author in the iSTAR laboratory.

The third casting of concrete was a fiber reinforced engineered cementitious composite (ECC) concrete. ECC employs 8mm long polyvinyl alcohol fibers at a rate of $2 \%$ by volume of a concrete mix that contains only clean sand as aggregate- there is no coarse aggregate. The fibers chemically bond with the cement to prevent pull-out prior to reaching their $270 \mathrm{ksi}$ tensile strength. Inclusion of the fibers has been shown to increase the tensile strength of the concrete by two orders of magnitude, effectively improving the concrete's strain capacity from nearly non-existent to $4 \%-6 \%(\mathrm{Li}$, et al., 2005). The ductility of ECC is promoted as being 500 times that of standard Portland cement concrete (Li, 2003). The mix design was based on University of Michigan's Dr. Victor Li's standard published mix (Li, et al., 2005). The fibers used in the mix were Kuralon brand RECS15 sourced from NyCon of Westerly, RI. The mix was delivered by Ross Island Sand \& Gravel of Portland, OR. The ECC test samples were found to have a 28day compressive strength of $7 \mathrm{ksi}$ in tests performed by the author in the iSTAR laboratory.

\section{2: Test Setup and Configuration}

Portland State University’s Infrastructure Testing and Applied Research (iSTAR) lab is equipped with a horizontal load frame containing a 100 kip hydraulic actuator with \pm 3 in stroke. The frame consisted of two parallel $20 \mathrm{ft}$ long W10x24 beams separated by 43.75 in and connected by two reaction girders. One girder acts as a reaction support for 
the actuator assembly, while the other acts as a reaction support for the ICF specimen as shown in Figure 11. The specimen is laid flat on a rolling dolly and centered in the frame. The outer support cores are held in place statically by two pairs of threaded rods pulling on 2 in thick steel plates, keeping the specimen snug against the aforementioned girder.

The central core, which is to be cycled relative to the outer cores, is similarly attached to the actuator via threaded rods and steel plates. Figure 11 shows the frame with the specimen in place.

The instrumentation consisted of the following:

Force data was collected from the actuator's built-in load cell, which was calibrated from an Omega LC 101 30-kip reference cell.

Deformation of the central core relative to the static support cores was monitored using a linear variable differential transformer (LVDT) with 4 in stroke. The LVDT was connected on one end to the a threaded rod protruding from the central horizontal core, while the other end was connected to a wooden cross beam that was affixed to the horizontal support cores, thus measuring the deformation of the active core relative to the supports.

The actuator was controlled by an MTS Model 407 digital servocontroller. The signals from the LVDT and load cell were collected by a National Instruments NCXI1000 data acquisition unit (DAQ). The DAQ signals were sent via USB interface to a Dell 6400 notebook computer running National Instruments' Labview 7.1 software. The software was programmed to collect load and deformation data at a rate of ten samples per second. 


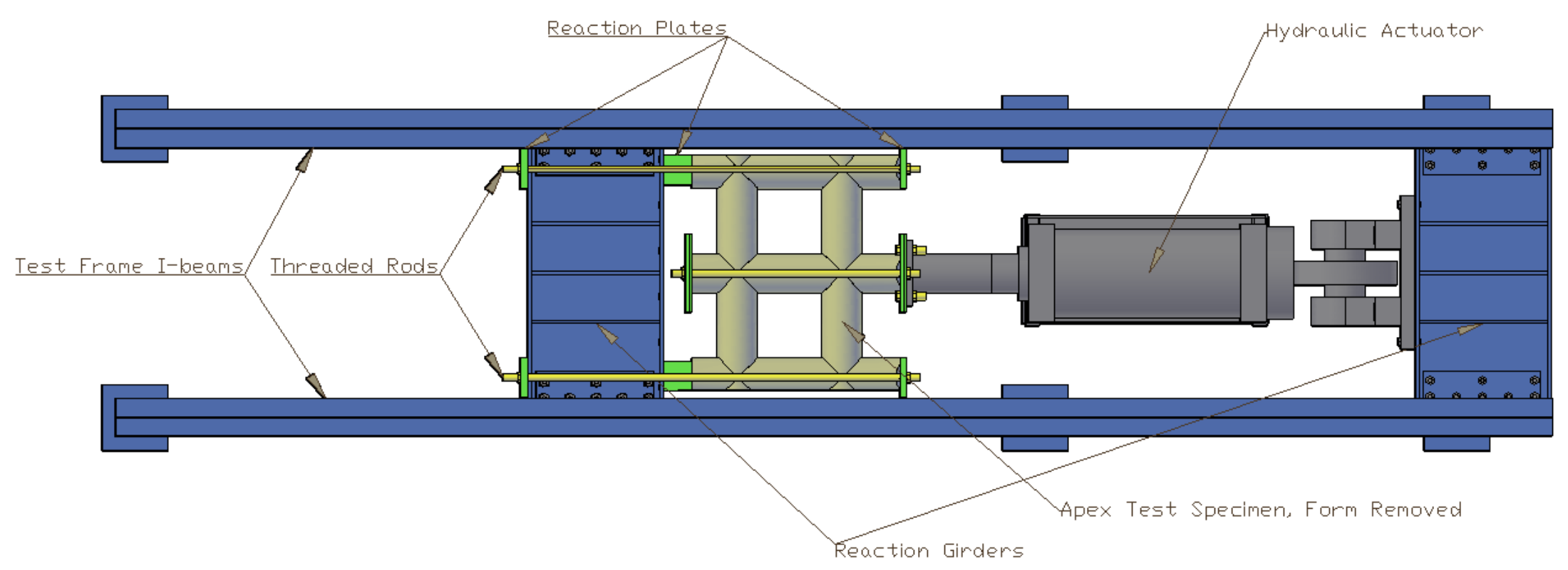

Figure 11: Apex Specimen in Reaction Frame 


\section{3: Testing Procedure}

On the day of the test, the following checklist was adhered to in preparation for experimentation:

$\checkmark$ Clear frame area of floor debris

$\checkmark$ Verify proper position of frame cross-beam, from fully retreated actuator:

○ Faswall: 31 in

- Apex: 39 in

$\checkmark$ Prepare dolly with appropriate wooden supports:

○ Stripped Apex specimen: 6.75 in

$\circ$ Unstripped Apex specimen: 4.75 in

○ Stripped Faswall specimen: 7.25 in

○ Unstripped Faswall: 2.25 in

$\checkmark$ Flatten all surfaces of test specimen that will be in contact with actuator or reaction supports.

$\checkmark$ Place test specimen into frame, with dolly properly aligned.

$\checkmark$ Attach the LVDT mounting beam to the wall specimen, verifying that the beam will not be struck by any plates or threaded rods during experimentation.

$\checkmark$ Turn on computer, DAQ, and 407 controller:

- Set the 407 to run back to 3 in position (fully retracted), at rate of $0.1 \mathrm{in} / \mathrm{min}$.

Turn on pump to low pressure:

- Verify that the actuator is under control, and backed out to 3 in. 
$\checkmark$ Secure specimen to frame:

- Place reaction-plate carriers on the frame's reaction beam.

- Place 3.5 in of steel reaction plates into the carriers, laterally aligned with the wall specimen.

- Ensure that the test specimen is centered laterally in the frame.

- Place blocks between specimen base and load frame for lateral alignment:

- Apex specimen: 3.5 in

- Faswall Specimen: 4.25 in

- Secure the test specimen firmly against the reaction plates, using the $11 / 8$ in threaded rods to pull the 2 in thick steel plates against the opposite ends of each support member of the test specimen.

Turn pump up to high pressure.

$\checkmark$ Slowly advance the actuator until light contact is made with the test specimen's central core.

$\checkmark$ Affix the central core to the actuator via threaded rods and 2 in plate:

- The far plate is supported by the end of a second dolly to prevent vertical displacement during the test.

- With the 407 controller, slowly release any resulting tension from the attachment process.

- Retighten threaded rod nuts as needed.

$\checkmark$ Ensure that no collisions will occur:

- LVDT setup and actuator plates require 2 in clearance. 
- LVDT setup and outer threaded rods must not be in contact.

- Actuator plate $\&$ threaded rods must not contact the cross-beam support (2 in clearance).

$\checkmark$ Adjust LVDT to mid-stroke position (2 in).

$\checkmark$ Print out test procedure worksheet, after inputting:

○ Initial force reading from actuator load cell.

○ Actuator LVDT reading.

○ External LVDT reading.

○ Apex: Height: 35.5 in, Width: 32 in.

○ Faswall: Height: 35 in Width: 25 in.

$\checkmark$ Take pictures of test setup.

$\checkmark$ Commence Testing.

The static cyclic loading history performed in the tests was identical to that used previously in the PSU study, which was adopted from a method described by Hawkins (Hawkins, et al., 2004) . The test was displacement controlled, where desired displacement during each cycle was devised from a specific drift ratio of interest. The drift ratio was calculated as the ratio of the lateral deformation of the loaded core to the distance between the loaded core and the adjacent support cores: $\operatorname{Drift}(\%)=100 \% *(\Delta / \mathrm{h})$. As a cyclic test, the central core underwent three fully reversed in-plane cycles for each prescribed drift level. The drift level, as shown in Figure 12, began with a drift of $\pm 0.04 \%$ - which equates to a deformation of \pm 0.007 in - and then increased by $40 \%$ after 
each set of three complete cycles, continuing until the specimen failed or an instrumentation limit was reached. The LVDT's stroke of 4 in limited the experiment to a drift level of $\pm 10 \%$ drift. Being a static test under non-automatic control, the actuator was moved slowly, at rates that ranged from 0.02 in per minute to 2 in per minute, depending upon the prescribed drift level.

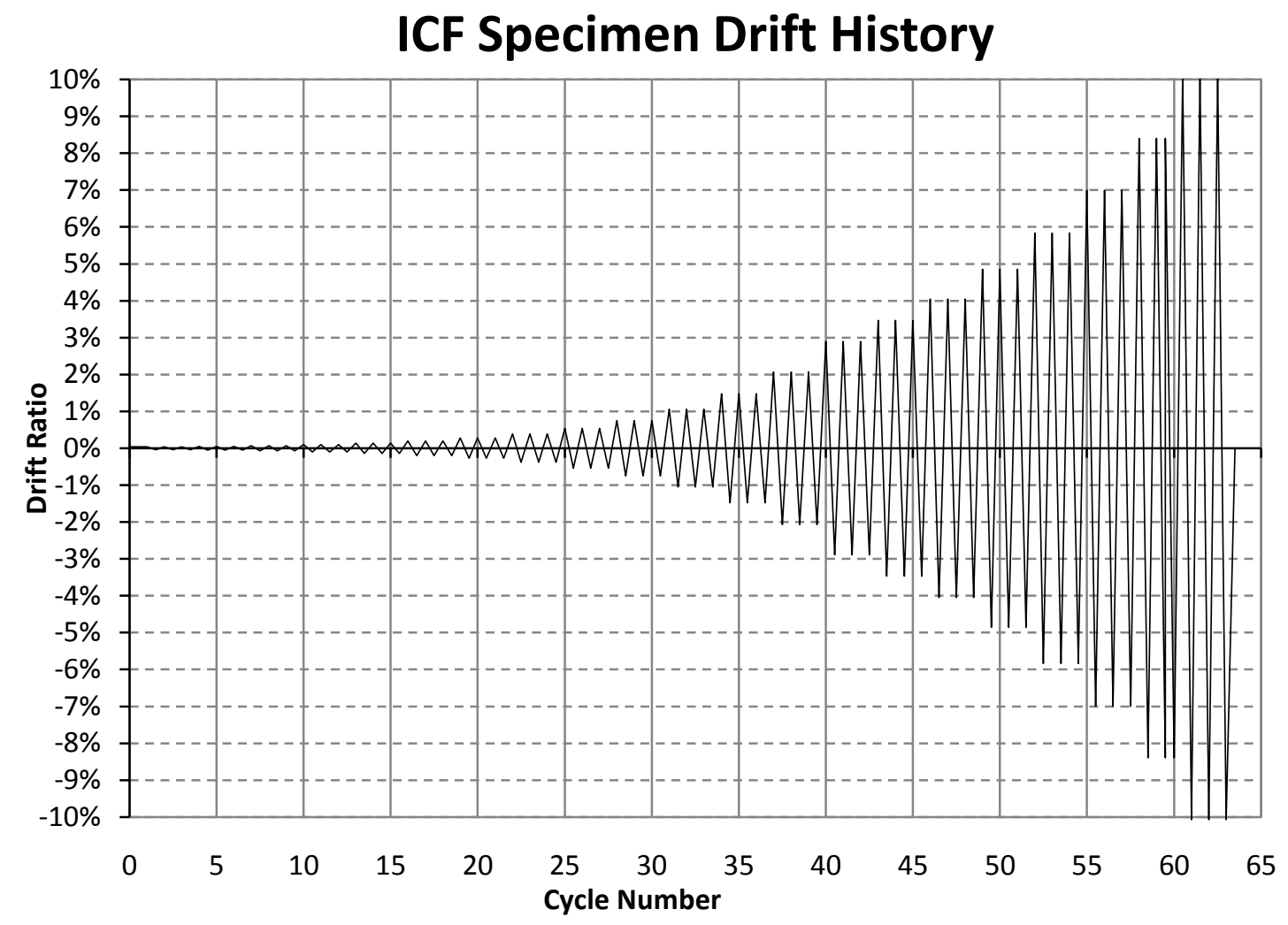

Figure 12: Drift History

After completing three full reversals at each drift level, each test specimen was inspected for damage, and permanent marker was used to note the development of cracks. Photographs were taken to document crack propagation, and ultimately the failure mode. For test specimens where the ICF form was removed and the concrete was exposed, crack development was easily inspected and often detected early in the test. For specimens 
tested with the ICF form in place, development of cracks on the surface of the forms were more difficult to detect, and often were presented later than the cracks in their formless counterparts. For specimens tested with the forms in place, the forms were removed after the test to inspect the failure of the concrete cores. 


\section{Chapter 4: TEST OBSERVATIONS AND RESUlTS}

\section{1: Progression of a Test to Failure}

Many of the tests performed on both the Apex and Faswall ICF samples proceeded in similar ways, as shown below. Flexural cracks often appeared first at the joint between the vertical (perpendicular to the direction of loading) and the horizontal (parallel to the direction of loading) cores; as the cyclic loading program advanced, those flexural cracks eventually appeared at both ends of each vertical core, completely severing the connection of concrete between perpendicular members, leaving them connected only by the rebar they shared. Shortly after the development of all eight flexural cracks, or 'hinges', one of the four vertical cores would typically fail catastrophically. The failure would take the form of a diagonal shear crack, or an axial crack along a plane containing the rebar and parallel to the direction of loading. Both types of core failure were immediately followed by a large reduction in lateral force resistance, and the test was deemed complete soon thereafter. Figure 13 and Figure 14 show the progression of Apex and Faswall tests, respectively, on specimens where the form has been removed. Crack propagation is marked in red. Arrows are added where cracks are difficult to see. Figure 15 shows the two types of most commonly observed failures.

For specimens tested with the ICF form in place, cracks appeared on the form surface at higher drift levels when compared to the formless specimens, but appeared to follow the same pattern of propagation. 


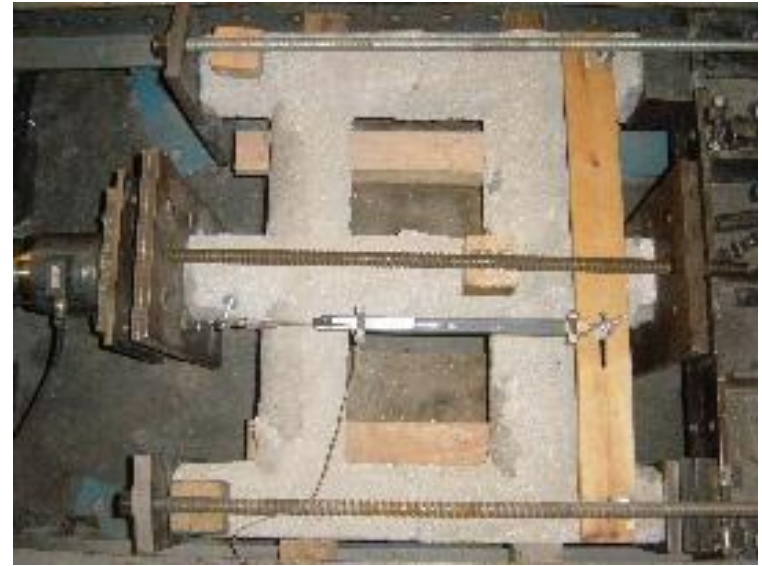

(A) $0.0 \%$ Drift

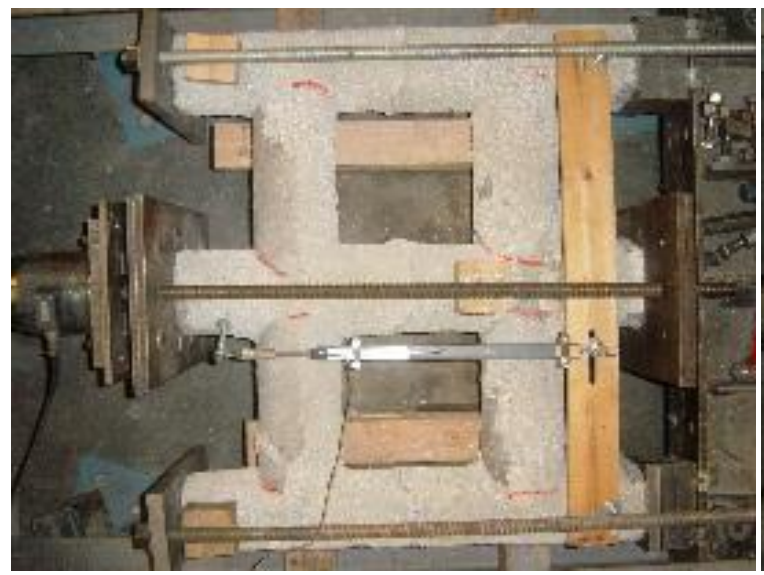

(C) $0.54 \%$ Drift

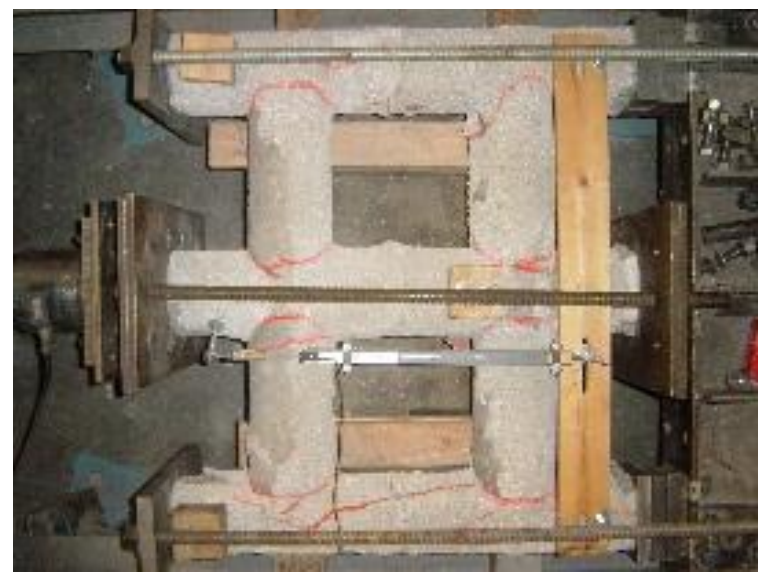

(E) $2.07 \%$ Drift

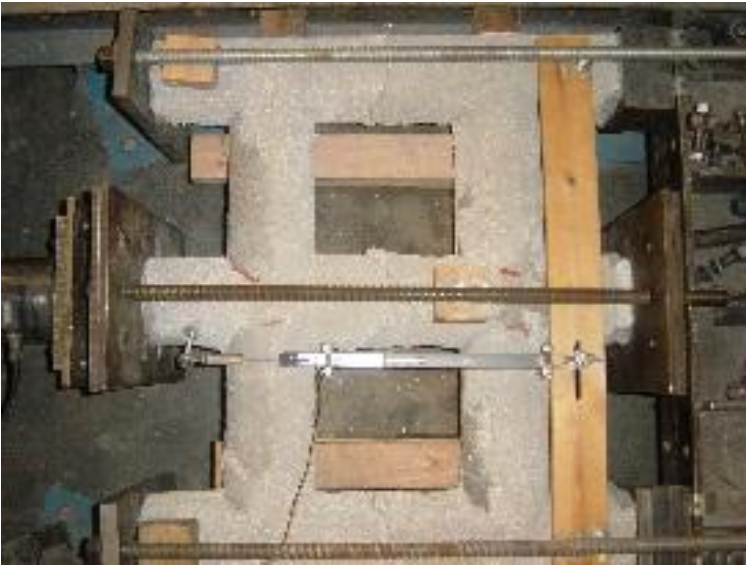

(B) $0.27 \%$ Drift

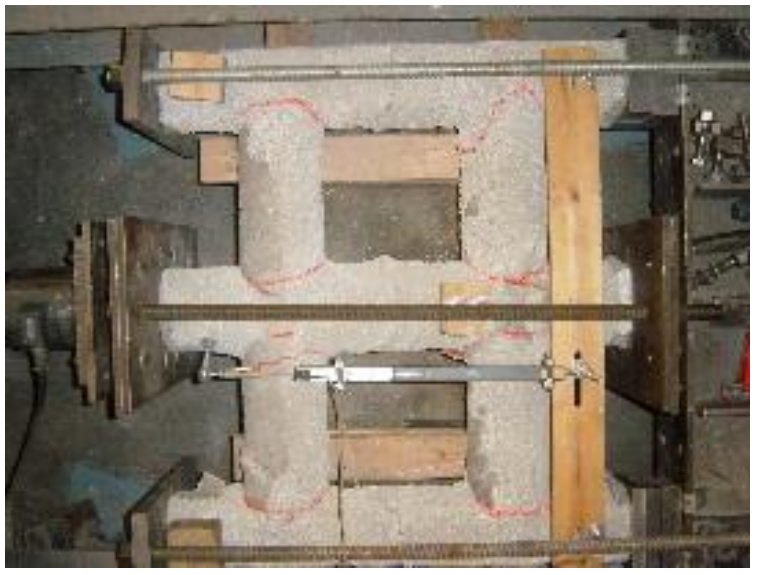

(D) $1.05 \%$ Drift

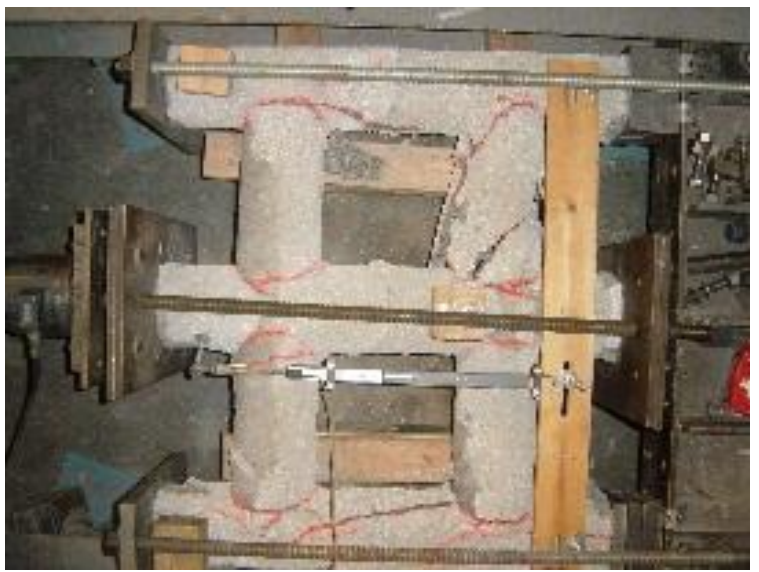

(F) $-4.05 \%$ Drift

Figure 13: Progression of a typical Apex ICF specimen test. 


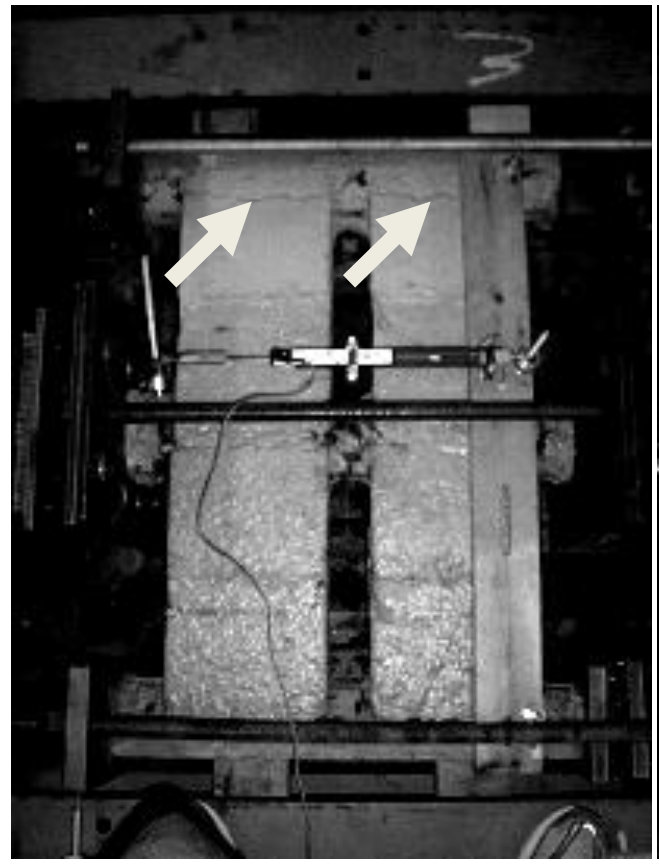

(A) $0.1 \%$ Drift

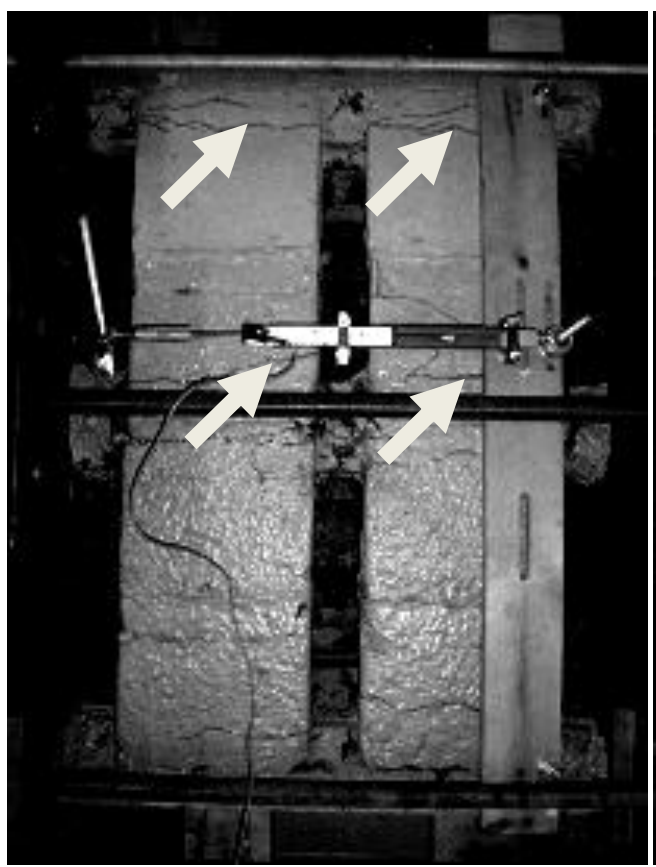

(C) $0.75 \%$ Drift

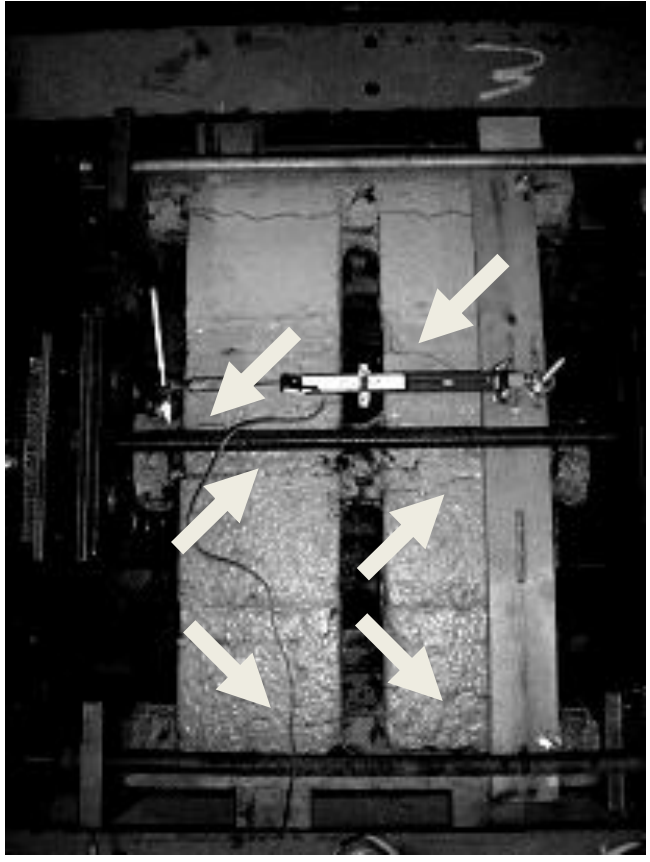

(B) $0.38 \%$ Drift

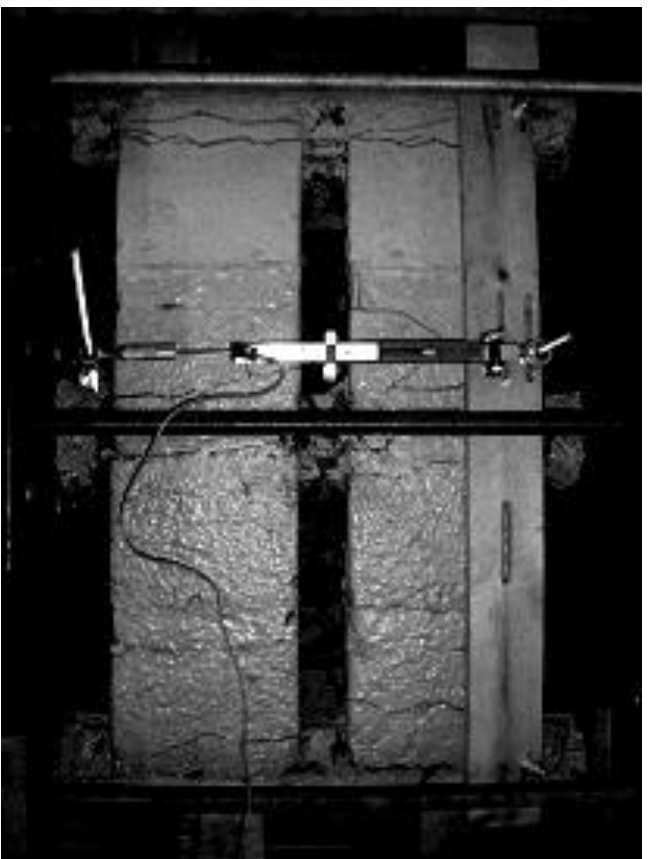

(D) $1.05 \%$ Drift

Figure 14: Progression of typical Faswall ICF specimen test. Arrows indicate new cracks. 

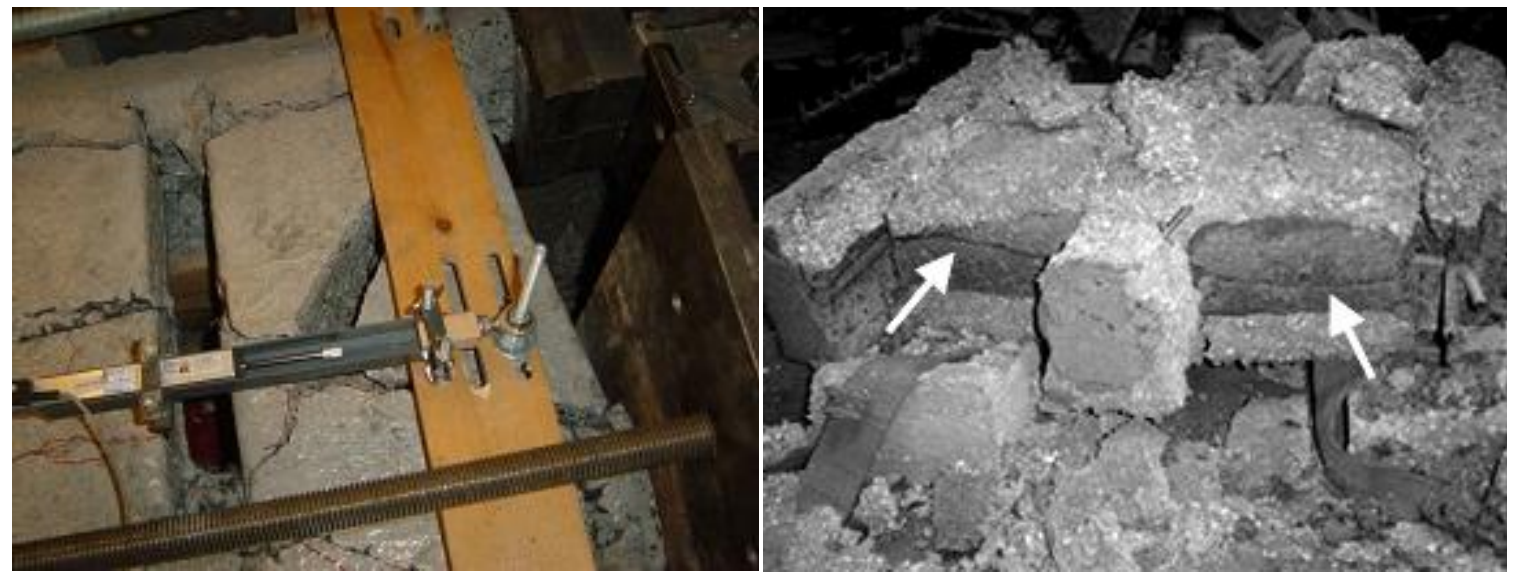

Figure 15: Core failure following flexural hinging in Faswall member (diagonal crack, left) and Apex member (axial crack, right)

\section{2: Material Tests}

Basic strength tests were performed on each of the materials used in the investigation. Compressive strengths of the concrete, Apex block, and Faswall were all measured. The tensile properties of the reinforcing steel was tested and reported by the rebar suppliers (Rose City Rebar and Harris Rebar, both of Portland, OR).

The Apex EPS foam material was tested using a hand-pumped hydraulic ram mounted in a vertical load frame. The largest circular cross-section of material obtainable from a production Apex block was 3.75-in diameter by 7-in tall. A handpumped actuator in a vertical load frame was used to test twelve of these Apex cylinders. The data was collected via National Instrument's (NI) Automation Explorer 4.0 software for Windows via a USB data acquisition unit (NI USB-6008). The displacement data was produced by a Trans-Tek 355 LVDT, calibrated with a reference steel block of known thickness. The LVDT was in contact with a steel plate placed between the 
hydraulic ram and the top of the specimen. The load signal was produced by a Kulite 1000lb-capacity load cell, and was conditioned and amplified by a Pacific Instruments SA1B. The signal was calibrated with known reference weights up to 200 pounds, and assumed to be linear to the $1000 \mathrm{lb}$ rated limit. Steel plates supported each test sample from below, with another atop the sample to interface with the hydraulic ram. The load was applied statically until the LVDT's limit was reached. Two rounds of testing were performed for what were possibly two different production runs of ICF material, as suggested by different coloring of the Apex brand label painted on each block. The resulting stress and strain relationships of each sample are shown in the plots of Figure 16 and Figure 17.

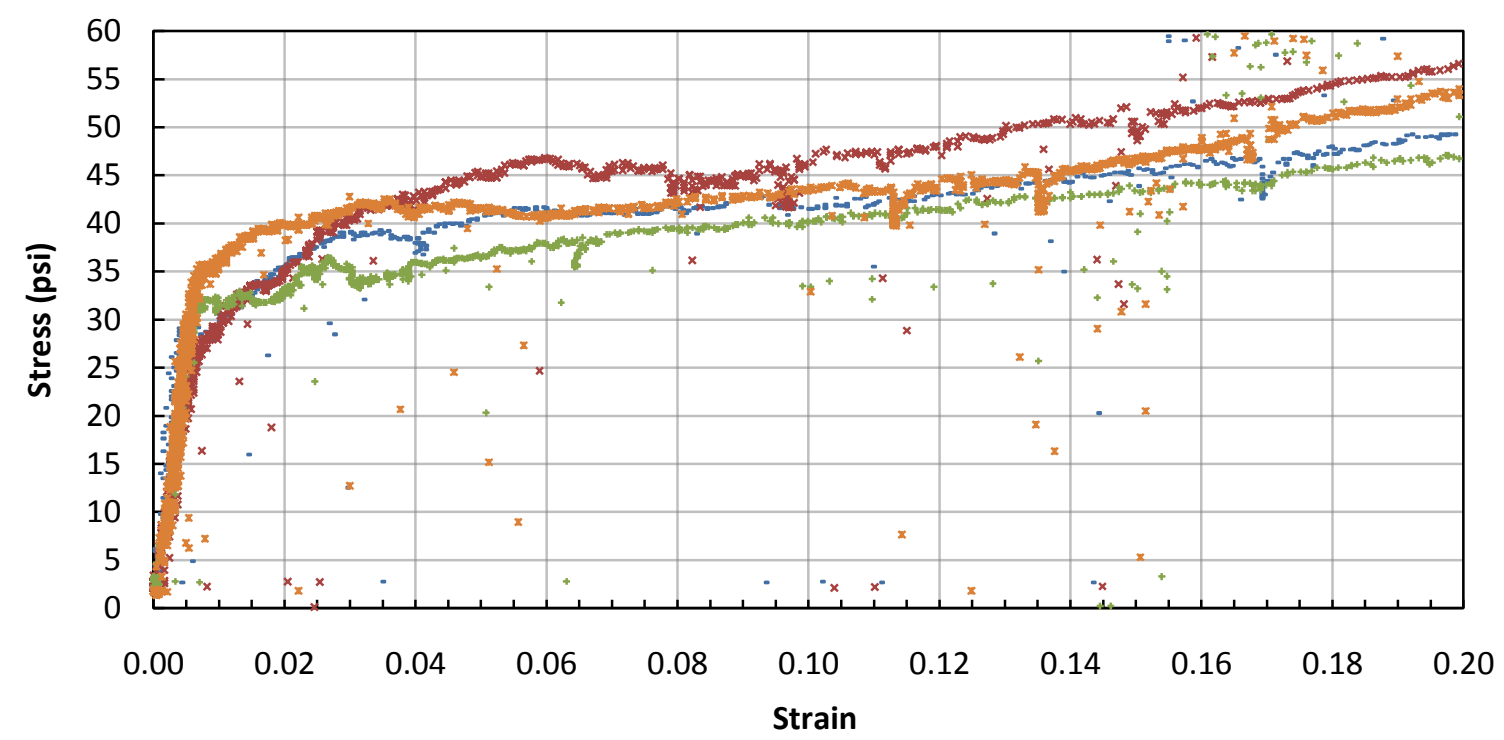

Figure 16: Four compression tests of "red" Apex ICF material 


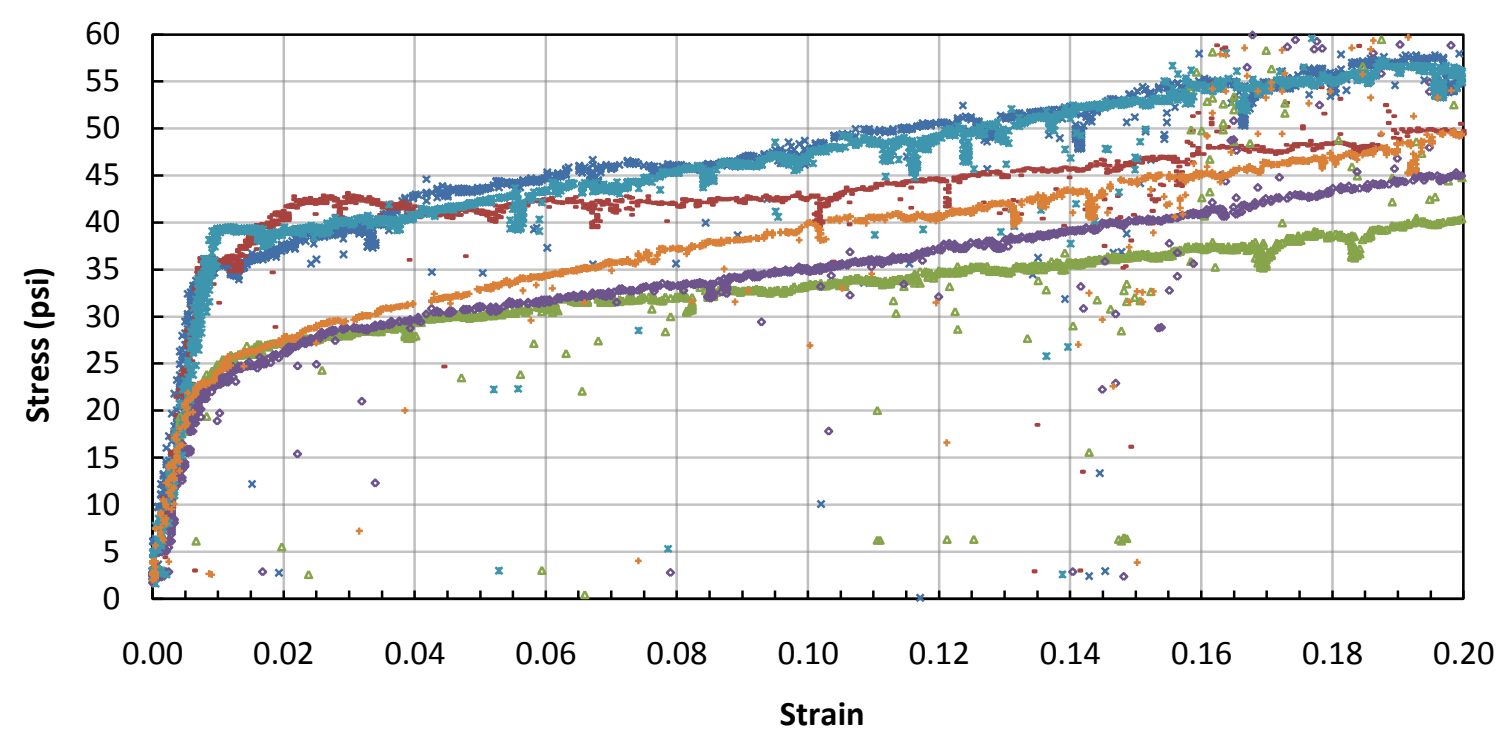

Figure 17: Six compression tests of "green" Apex ICF material

Compared to concrete or steel, the foam exhibited very high strain levels concurrent with very low stresses. For the purpose of investigating the contribution of the ICF formwork to wall strength, the region of interest is assumed to have strain compatibility with concrete. Since concrete is normally assumed to fail in compression at a strain of 0.003 , Figure 18 and Figure 19 portray the previous results in a more appropriate range. At the strain limit of concrete of 0.003, the Apex EPS material exhibits a compressive resistance of 5 psi -20 psi. Although the range of results is relatively wide, the fact remains that the material is at least two orders of magnitude weaker than concrete. Based on the cross-sectional area ratio of Apex material to concrete (4.7:1), the material may account for $0.3-3 \%$ of the vertical force resistance of an Apex wall, based on 5 psi -20 psi Apex form material and 3 ksi - 7 ksi concrete compressive strength. 


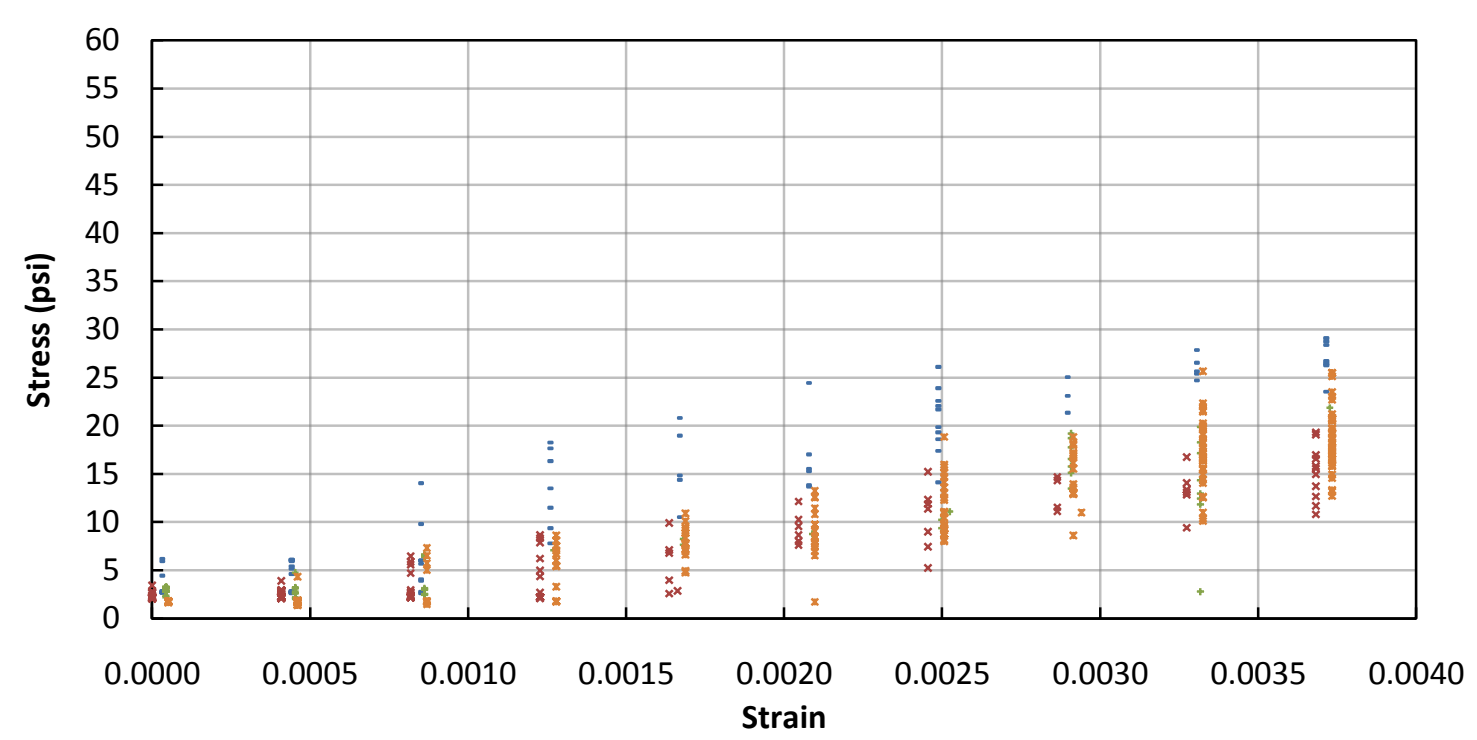

Figure 18: compression of "red" Apex forms at small strains

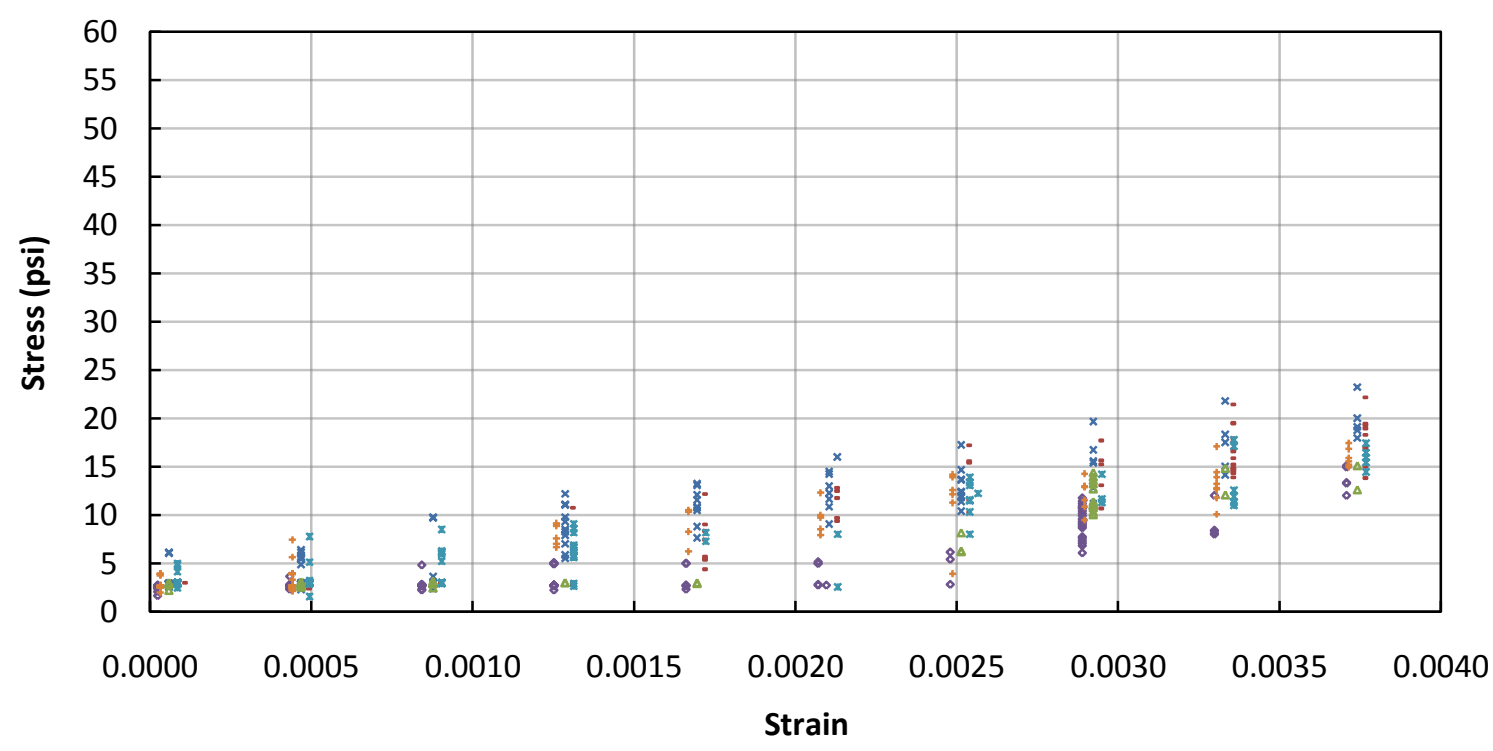

Figure 19: compression of "green" Apex forms at small strains

The Faswall formwork material was measured in the same way as the Apex material, however the largest whole piece of material that could be removed from a Faswall block was 2-in x 2-in square in cross-section, and 6 in long. Similar results to the Apex block were found where the peak stress coincided with large strains - strains 
which the formwork would not be likely to experience if the formwork is assumed to be strain-compatible with the contained concrete. The complete tests, shown in Figure 20, found that the Faswall material readily resists at least twice as much peak stress as the Apex,

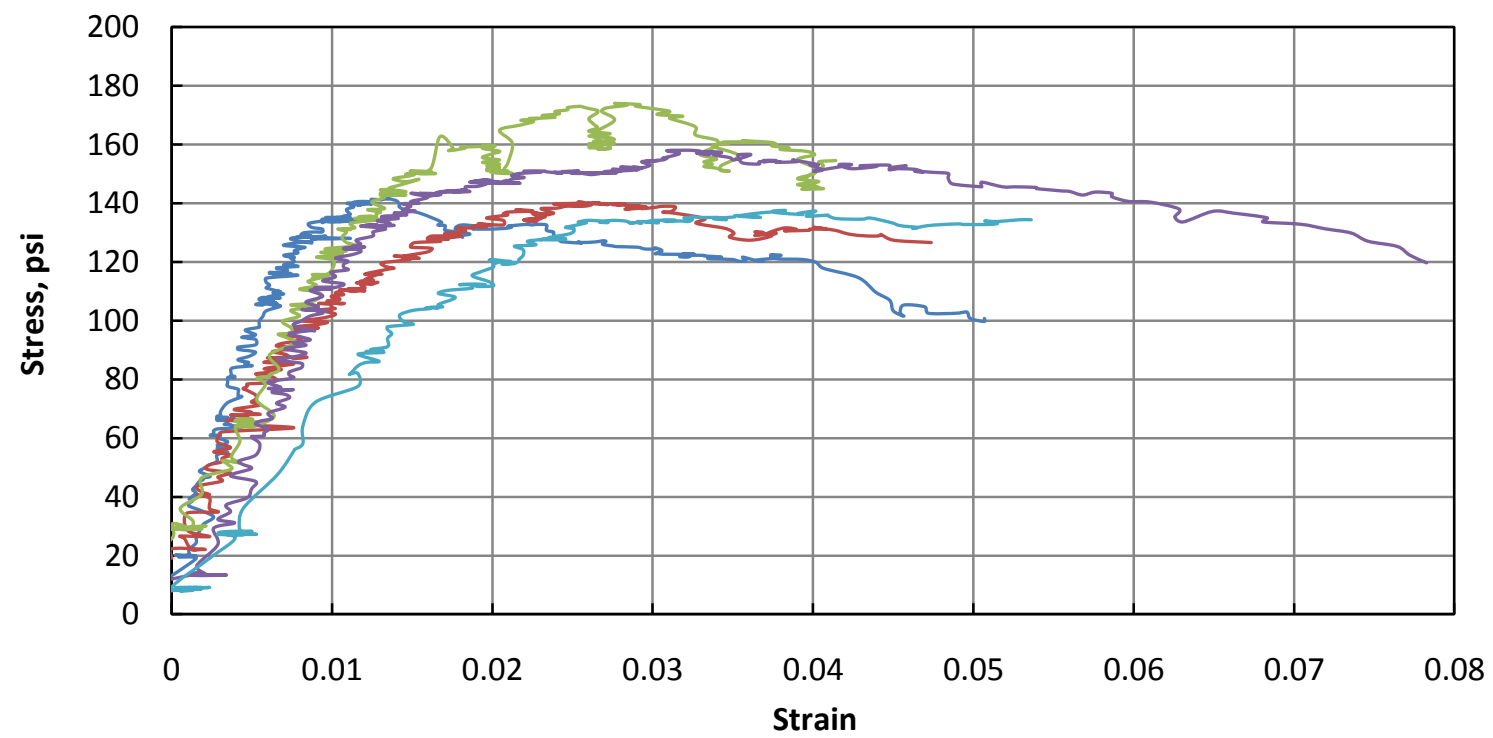

Figure 20: Stress-strain diagram of five samples of Faswall wood chip form material

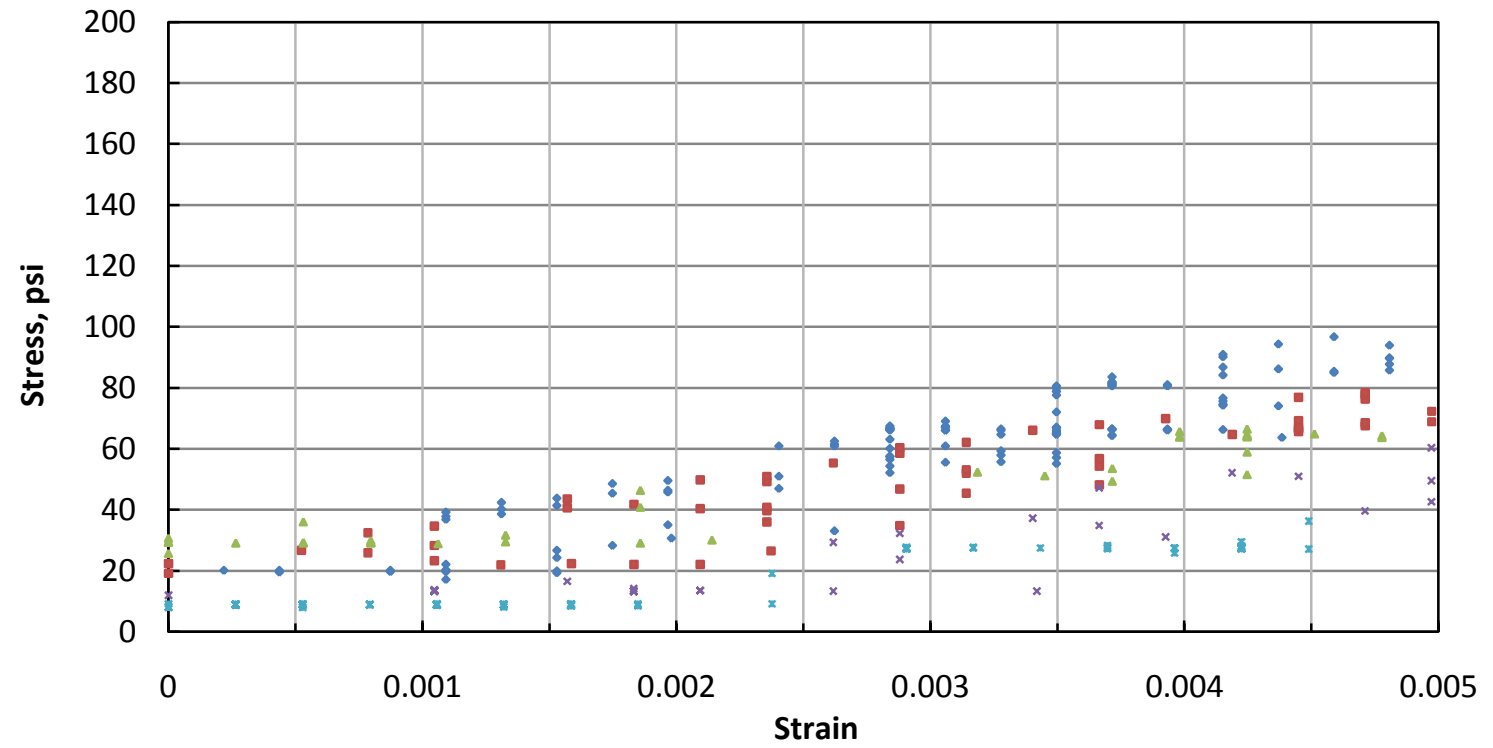

Figure 21: Stress-strain diagram of five samples of Faswall wood chip form material at small strains 
at nearly one tenth of the strain. When viewed at the range more appropriate for straincompatibility with concrete, the data showed a range of stress resistance of only $20 \mathrm{psi}$ 70 psi. While the Faswall material was somewhat stronger than Apex material, the stress resistance of the Faswall material was still two orders of magnitude smaller than the surrounded concrete. The cross-section of the Faswall form was such that the material would only account for $0.3 \%-2.2 \%$ of any compression resistance of a wall, based on strength ranges of 20 psi -70 psi for Faswall and 3000 psi -7000 psi for concrete.

As mentioned previously, three different batches of concrete were used in the ICF small scale experiments: The first series of ten Apex samples utilized 'PCC1' concrete; the next series of three Apex samples and six Faswall samples utilized 'PCC2' concrete; and the final series of three Apex samples and five Faswall samples utilized 'ECC' concrete. The mix designs used for PCC2 and ECC concrete are found in Appendix B. The PCC1 concrete was tested by Mayes Testing Engineers of Portland, OR, in accordance with standard ASTM protocols C39, C1231, and C617. PCC1 was cast on August 25, 2008 with a slump of 8.75 in and design compressive strength of $\mathrm{f}_{\mathrm{c}}{ }_{\mathrm{c}}=3000$ psi. The ten small scale Apex specimens were tested between October 16, 2008 and January 29, 2009. Figure 22 shows the results of the tests on PCC1, for which the average value for $\mathrm{f}_{\mathrm{c}}$ after 28 days is 3810 psi. 


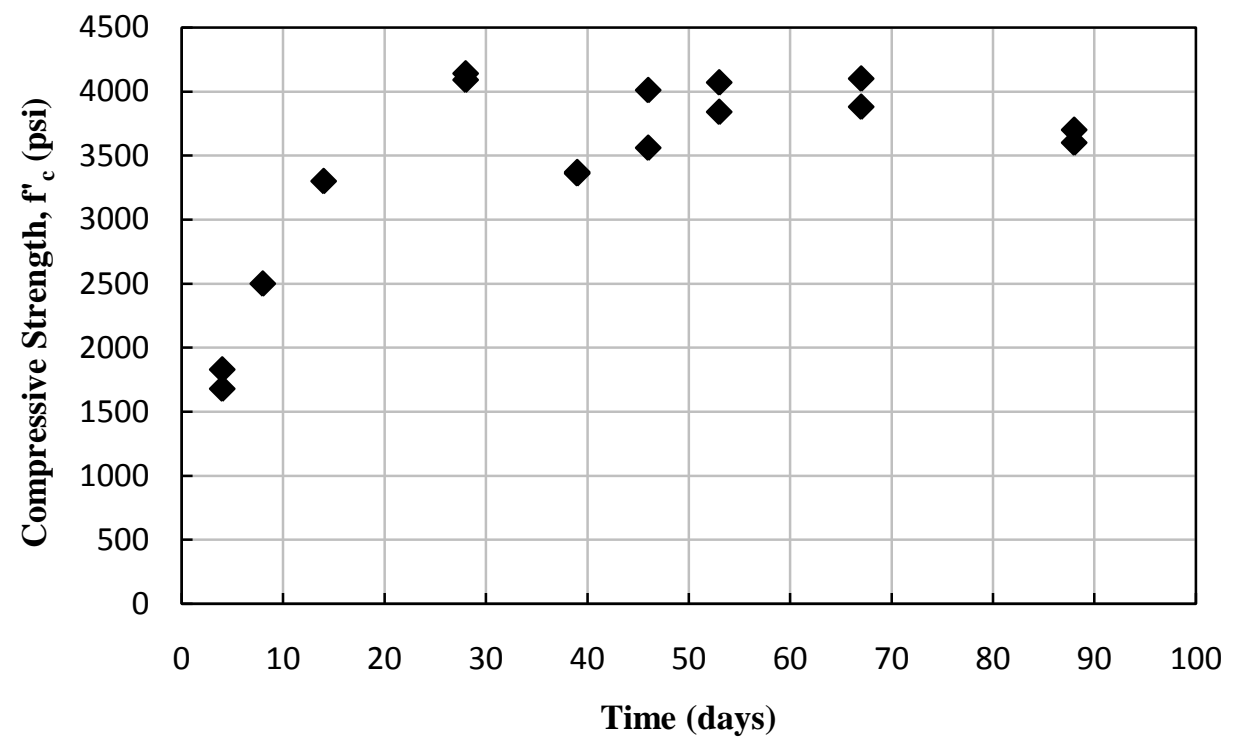

Figure 22: Compressive strength test results of PCC1 concrete

The PCC2 Concrete was poured on November 24, 2009, and was designed for a 28-day compressive strength of $\mathrm{f}_{\mathrm{c}}=4000$ psi. Standard 6-in diameter by 12-in tall cylinders were also cast, and were tested in Portland State University's concrete laboratory. Test data was collected from a pre-calibrated load cell and two LVDTs, again captured through a National Instruments (NI) USB DAQ to a Windows computer running NI's Automation Explorer 4.0. Stress and strain were calculated from load and displacement data. Figure 23 shows the results of the compressive tests through time. The first Apex form specimen with PCC2 concrete was tested on January 12, 2010, 49 days after the pour. The average strength of the concrete was 7131 psi on test cylinders 28 days and older, regardless if they were cured in a moist room or outdoors next to the test specimens. In the individual test results, no PCC2 test cylinder failed at a strain greater than 0.002 , where 0.003 is the typical expected strain for failure. 


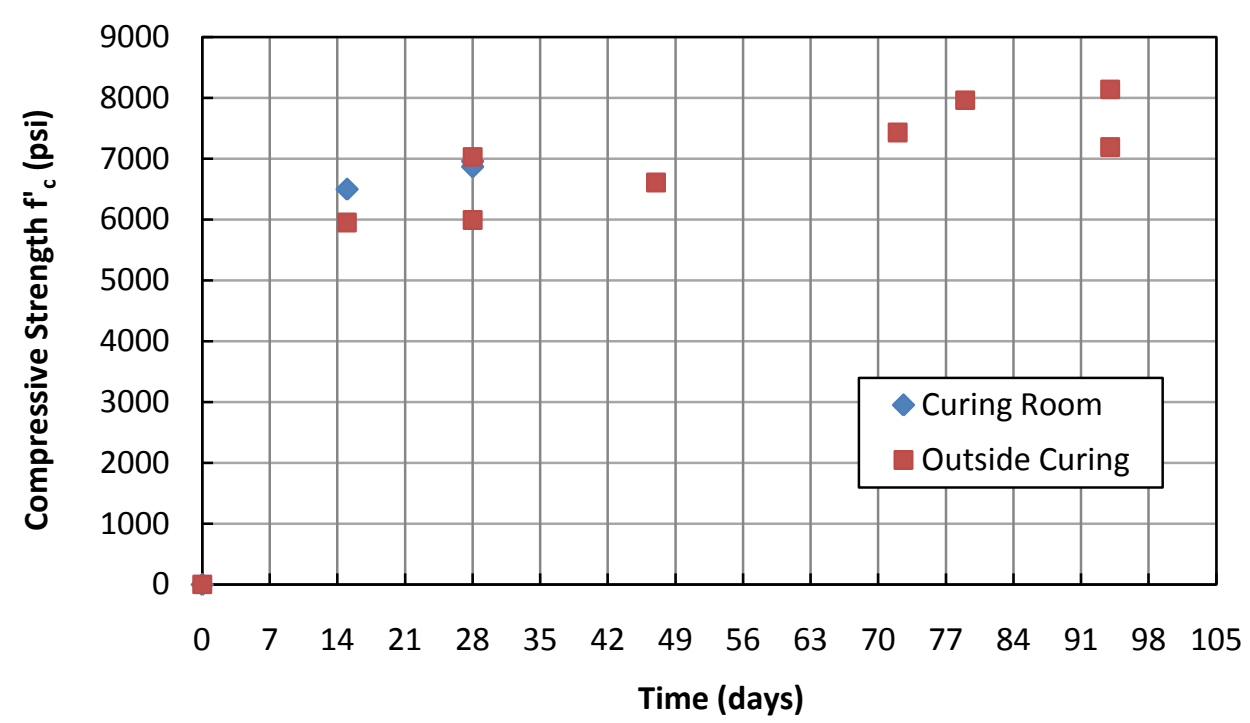

Figure 23: Compressive strength test results of PCC2 concrete

The ECC Concrete was poured on January 14, 2010 into three Apex form specimens, and five Faswall form specimens, which were subsequently tested between March 9, 2010, and April 4, 2010, nearly eight weeks later. Several standard test cylinders were also poured and subsequently tested. The mix design estimate for the strength of the ECC was 4000 psi, however the results shown in Figure 25 reveal a compressive strength of nearly 7000 psi at 28 days. Despite the similar compressive strength to PCC2 concrete, the ECC failed at strains between 0.003 and 0.004 , a marked increase. Tests performed on the ECC cylinders after 28 days were inconclusive due to leaks springing in the hydraulic line fixtures when the load cell approached $220 \mathrm{kip}$, or nearly $8 \mathrm{ksi}$ on the unyielding concrete.

Two ECC beams were subjected to four-point bending tests. The beams were 6-in x 6-in x 20-in. Each beam was placed two knife edges, each 1 in from the end 
of the beam, so they were separated by $18 \%$. The load was applied to the top of the beam at third points -3 in from the both sides of the center. The load was applied while force and vertical deformation data was collected in the same apparatus as was used to crush concrete test cylinders. The data is shown in Figure 24

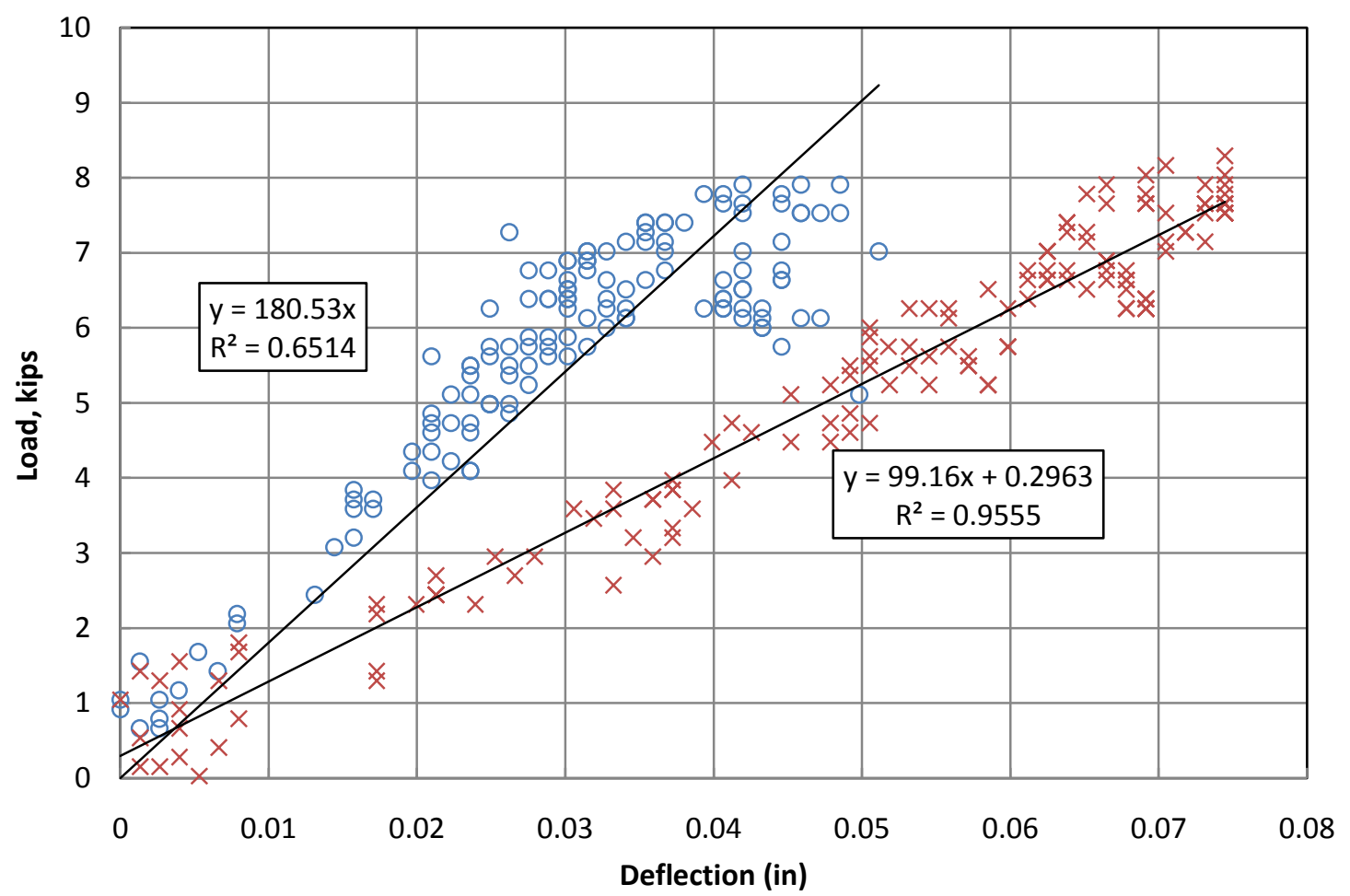

Figure 24:Four-point bending test results on ECC concrete

The modulus or rupture is calculated by the equation

$$
M=\frac{3 P L}{2 b d^{\wedge} 2}
$$

Where:

$\mathrm{P}=$ the applied load, 
$\mathrm{L}=$ the length between the supports,

$b=$ width of the member,

$\mathrm{d}=$ depth of the member.

The beams resisted 8 kip and 8.29 kip, so $M_{1}=1000$ psi, and $M_{2}=1037$, respectively.

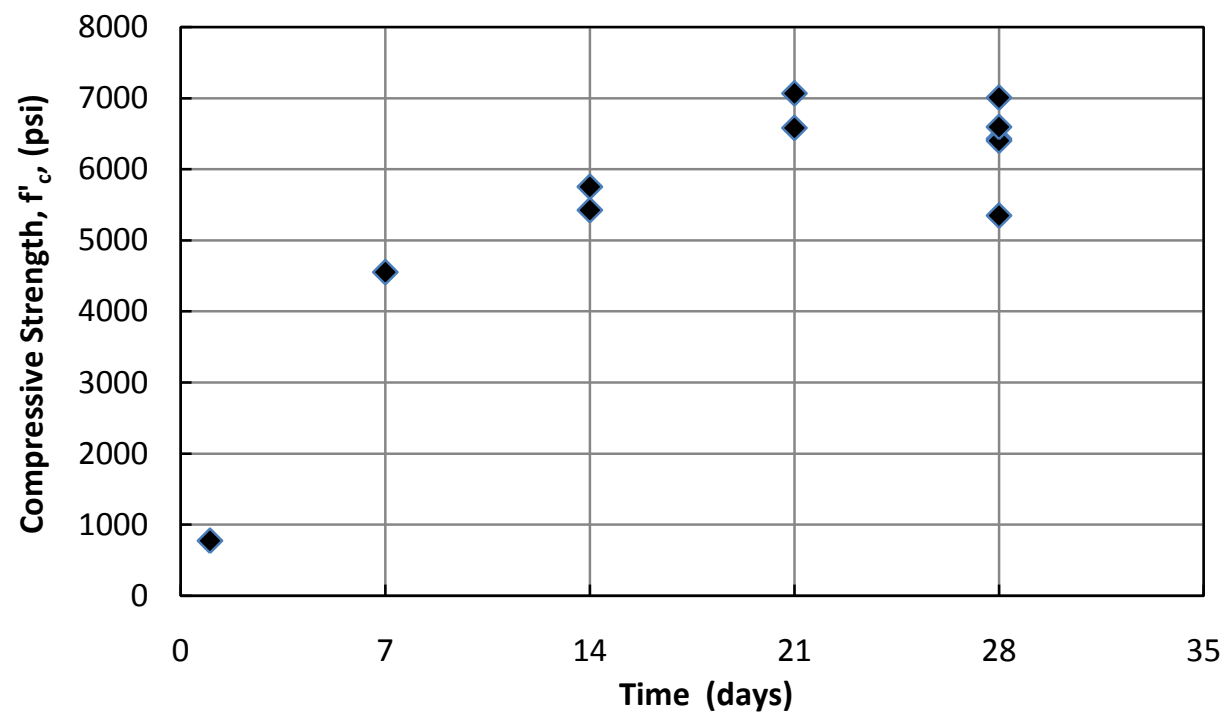

Figure 25: Compressive strength test results of ECC concrete

The steel rebar used in the first ten Apex small scale specimens with the PCC1 concrete had a yielding stress of $f_{y}=62.3 \mathrm{ksi}$, according to the PSU full-scale wall report which used the same steel. The PCC2 and ECC concrete-filled forms were both built with steel having yield stresses ranging from $67 \mathrm{ksi}$ to $69 \mathrm{ksi}$, as certified by Rose City Rebar and Harris Rebar, both of Portland, OR. 


\section{2: Apex ICF Test Results}

The first set of tests was performed on ten Apex Block ICF specimens, which used standard concrete (PCC1) with compressive strength $f_{c}^{\prime}=4000$ psi and reinforcing steel with yield strength $f_{y}=63 \mathrm{ksi}$. The hysteresis plots from the experiments are shown in Figure 26(A) and Figure 26(B). Each plot is accompanied by a representation of the cross section of the core being tested (with loading applied along the left-right direction), as introduced in Figure 6.

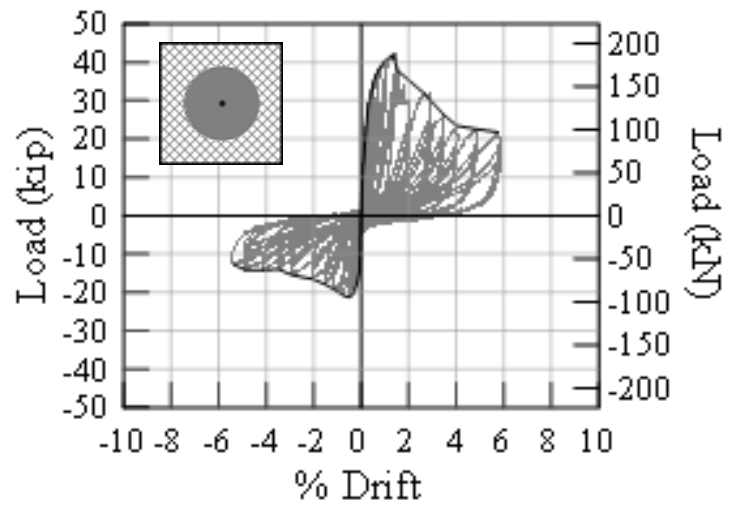

(A) A11

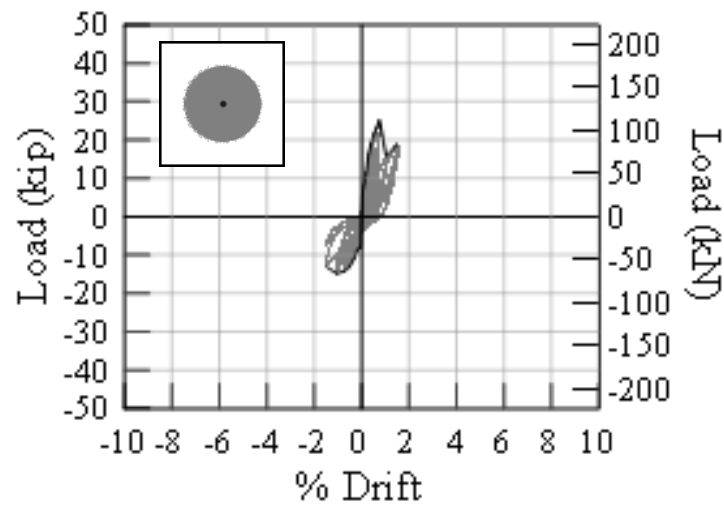

(B) A11Ra

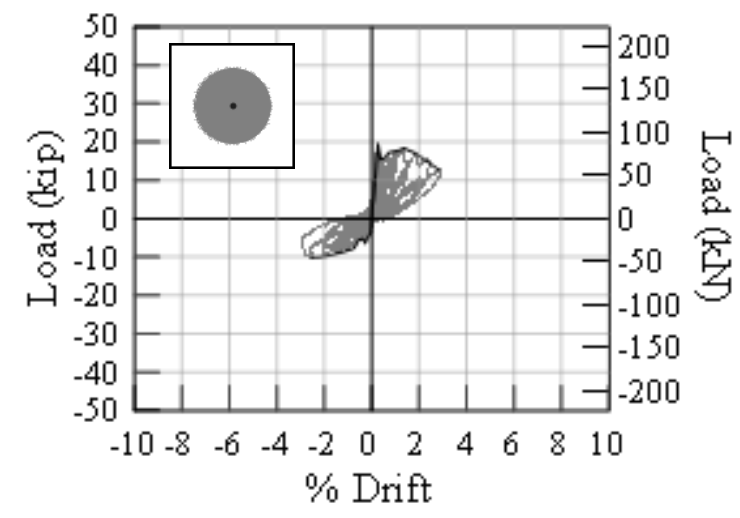

(C) $\mathrm{A} 11 \mathrm{Rb}$

Figure 26 Apex Block Hystereses, PCC1 Concrete 


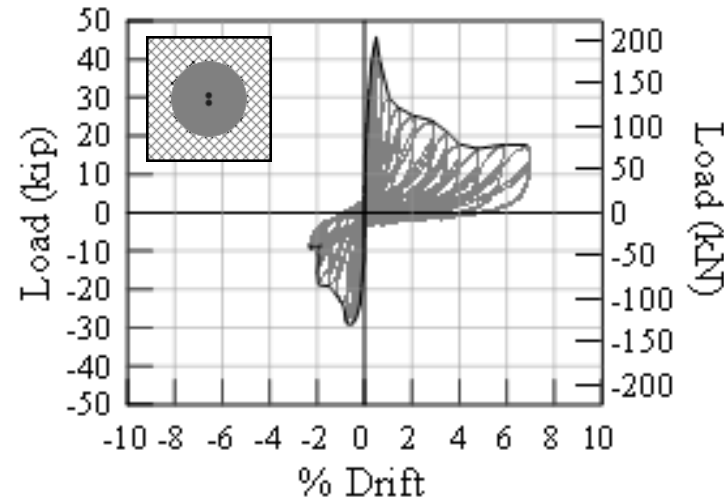

(A) A12a

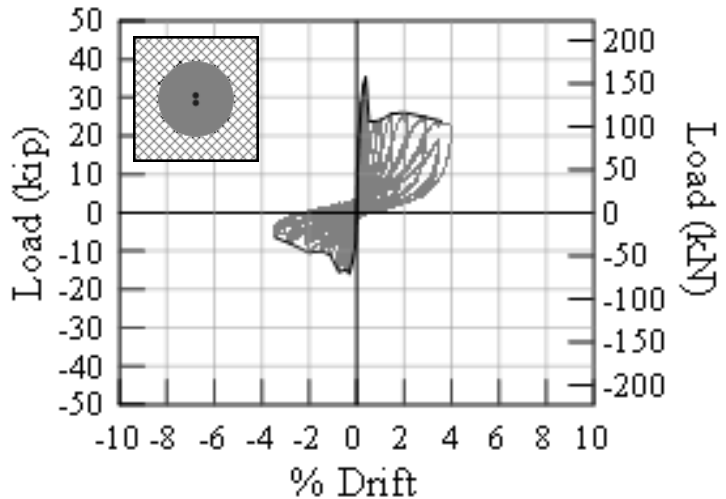

(B) A12b

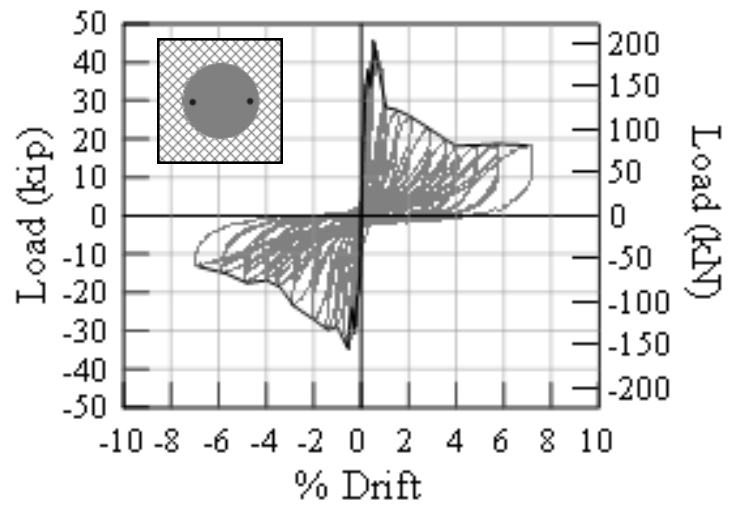

(C) A13

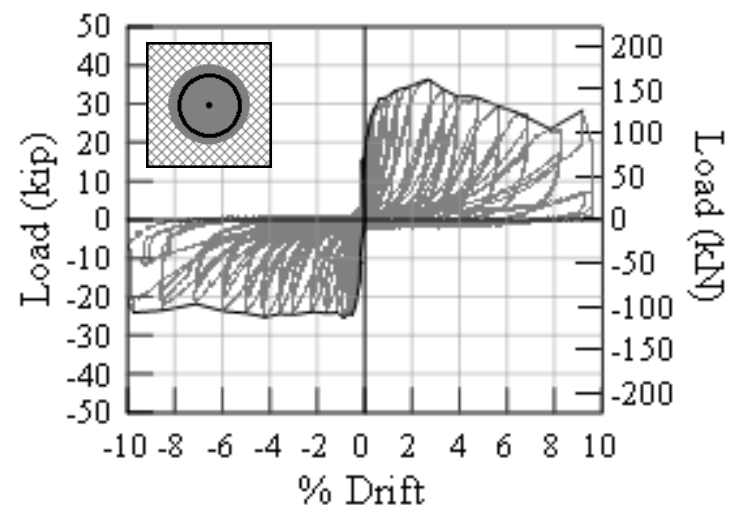

(D) A14

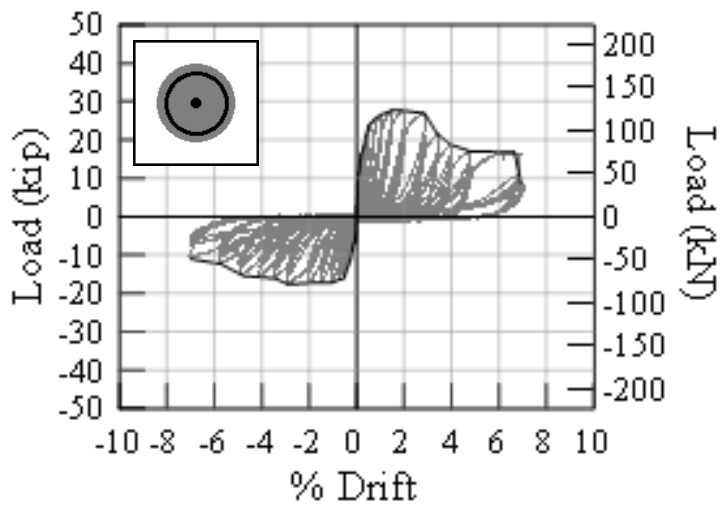

(E) A14R

Figure 27: Apex Block Hystereses, PCC1 Concrete 


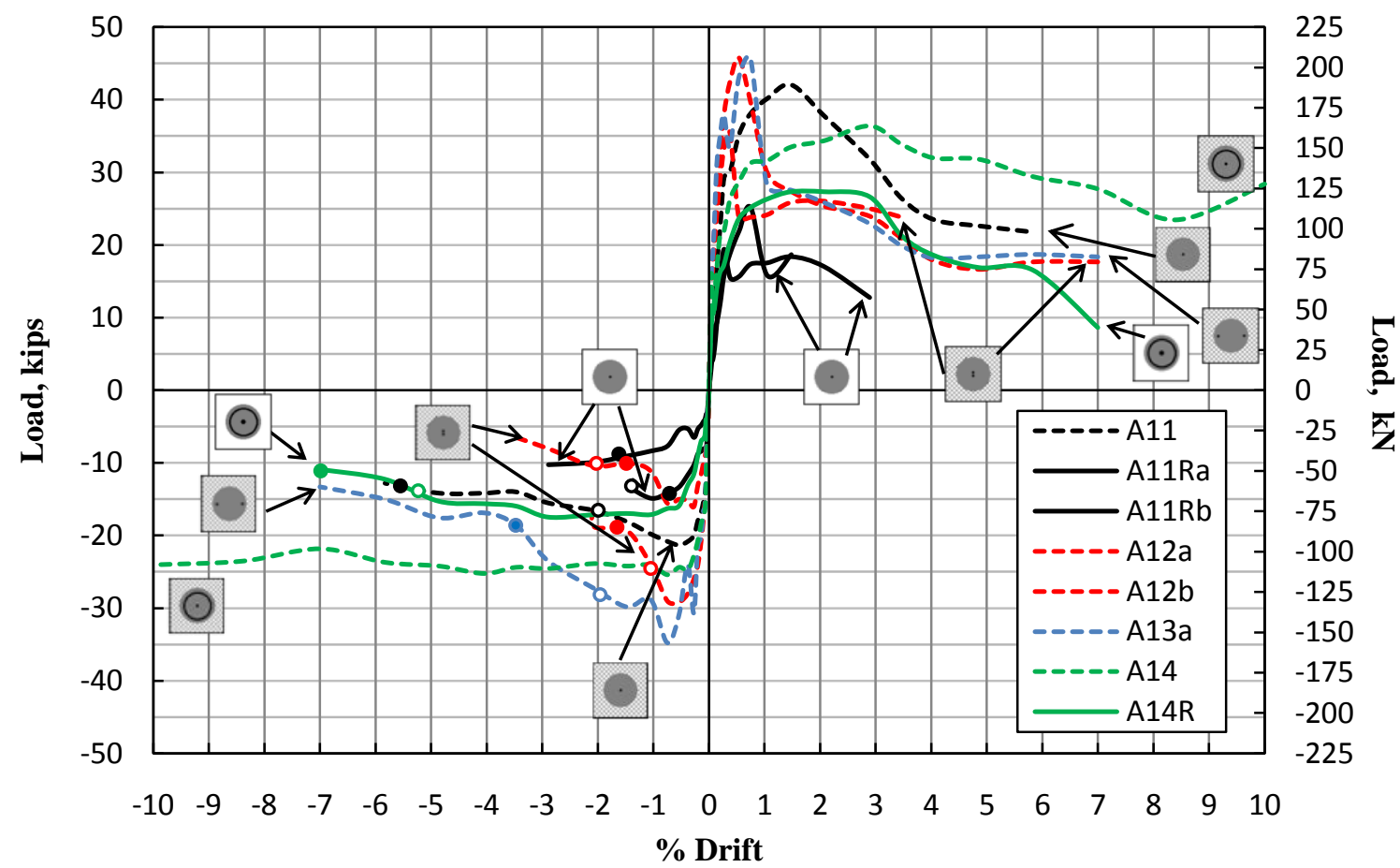

Figure 28: Apex Block Small Specimen Backbone Summary: PCC1 Concrete

Figure 28 consolidates the backbone curves of each hysteresis plot from the PCC1 test of Apex Block ICF samples. Cross-sectional representations are added to aid identification of individual curves. Color coding differentiates the reinforcement type: black signifies single No.4 rebar (A11 \& A11R), red is dual No.4 centered rebar (A12), blue is dual separated No.4 rebar (A13), and green is single No.4 rebar with the spiral wire confinement (A14 \& A14R). Solid lines indicate the presence of the ICF form material during the test, while dashed lines indicate their absence. The unfilled circle along each backbone curve represents $\mathrm{D}_{20}$, the drift ratio at which the backbone value has decreased to $80 \%$ of $\mathrm{P}_{\max }$. $\mathrm{D}_{\text {fail }}$, the point where any one of the cores failed catastrophically, is marked along each line with a solid circle. The absence of those 
markings along any line indicates that the benchmark did not occur prior to the completion of the test.

Each hysteresis graph is not symmetric about the horizontal axis - the force in the forward stroke direction for any given drift percentage level was normally nearly twice that of the magnitude of the force during the reverse portion of the stroke, which was much more than would be expected for normal hysteretic behavior. This behavior occurred regardless of the initial direction of the cycle (positive stroke followed by reversal stroke, or vice versa), and occurred for both Apex and Faswall specimens. Great care was taken in placing the rebar symmetrically within the sample during prior to casting, so the difference is likely not due to internal reinforcement placement. Great care was also taken to ensure that the deflections were measured about the true neutral position, so any errant reading should not be the cause of the discrepancy.

The support members are held in place at one end by steel plates ("tension plates"), from which four threaded rods pull the sample into bearing against the wideflanged cross-member in the test frame at the other end of each support, via 6-in x 6-in steel plates ("bearing plates"), as can be seen in Figure 13. The tension plates were not restrained from movement in the transverse direction (with respect to the direction of loading), while friction alone restrained the bearing plates from moving transversely. Observations during testing revealed that as each test progressed and cracks developed, the test specimen tended to expand and contract, or "breathe", in the direction perpendicular to loading. The breathing appeared to be a complicated combination of several phenomena: 
First, as the active horizontal member is cycled away from the original non-deflected position relative to the support members, the resulting inward force tries to displace the supports inward toward the center member to a degree dependent upon the magnitude of the drift.

Second, the support members were observed to undergo bending during larger drift cycles. This affect was greatest during positive deflection, with the sample bearing against the bearing plates, while the tension plate ends of the support members were unconstrained from lateral motion, and inward bending there was clearly evident.

Lastly, a general lengthening of a specimen along the axis of the vertical members was observed over the duration of each complete test, from start to ultimate failure. This was due to the plastic deformation in the vertical members' steel during each cycle.

The breathing described above is likely responsible for the asymmetry of forces seen in hysteresis charts, as the support conditions are different for the positive deflection portion of the cycle than the reverse portion. During the reverse cycle, the threaded rods that secure the support members invariably experience a some amount of strain (of course depending on the strength of the test specimen), allowing the inward breathing to occur much more easily due to lower friction at the bearing plates. Upon reversal toward the positive direction thereafter, the support members bear again against the plates and encounter lateral friction when outward breathing occurs again. For the rest of the deflection thereafter, and until the subsequent reversal whereby the friction is decreased, the additional force applied by the actuator is possibly due to the transverse breathing of the sample being restricted by friction at the bearing end of the supports. In the reverse 
direction, the friction is heavily reduced and the specimen is allowed to breathe with less restriction. Therefore the force applied during the reverse half of the cycle is regarded as a more accurate representation of the force causing the deformation, since friction effects are less prevalent. Hence, the following discussion regarding peak applied force will be with regard to observations of the reverse direction (negative forces) of the hystereses cycles.

The test matrix used for this experiment allows several factors to be compared, and several trends have become evident for behavior of the specimens due to varying the reinforcing layouts and removing the ICF form material. In the following discussion, $\mathrm{P}_{\max }$ is the maximum force resisted by the test specimen during the entirety of the test for either the positive or reverse portions of the cycle. An envelope curve, or backbone, is developed for each set of results (Figure 28), connecting successive cycle's peak forces; $\mathrm{D}_{20}$ is the drift ratio along that curve for which the test specimen's force resistance capacity has decreased to $80 \%$ of the observed maximum. $\mathrm{D}_{20}$ is considered to be the point at which we consider the sample to have effectively failed, but $\mathrm{D}_{\text {fail }}$ is the drift at which a catastrophic core failure occurs. $D_{\text {end }}$ is the drift ratio at which the experiment is ceased. Not every test necessarily reached every drift benchmark noted above. 


\begin{tabular}{|c|c|c|c|c|c|c|c|}
\hline \multirow[b]{2}{*}{ Specimen } & \multicolumn{2}{|c|}{$\mathbf{P}_{\max }(\mathbf{k i p})$} & \multicolumn{2}{|c|}{$\mathbf{D}_{20}$} & \multirow{2}{*}{$\mathbf{D}_{\text {fail }}$} & \multicolumn{2}{|c|}{ Max Drift $\left(D_{\text {end }}\right)$} \\
\hline & Forward & Reverse & Forward & Reverse & & Forward & Reverse \\
\hline A11 & 42 & 22 & $2.50 \%$ & $2.00 \%$ & $5.80 \%$ & $5.80 \%$ & $5.50 \%$ \\
\hline $\mathrm{A} 11 \mathrm{Ra}$ & 25 & 15 & $1.25 \%$ & $1.25 \%$ & $0.75 \%$ & $1.75 \%$ & $1.75 \%$ \\
\hline $\mathrm{A} 11 \mathrm{Rb}$ & 19.4 & 10 & $2.20 \%$ & $2.50 \%$ & $1.48 \%$ & $2.50 \%$ & $3.00 \%$ \\
\hline A12a & 46 & 29 & $1.00 \%$ & $2.00 \%$ & $2.07 \%$ & $7.00 \%$ & $\mathrm{n} / \mathrm{a}$ \\
\hline $\mathrm{A} 12 \mathrm{~b}$ & 35 & 16 & $0.50 \%$ & $1.00 \%$ & $1.48 \%$ & $4.00 \%$ & $3.50 \%$ \\
\hline A13a & 46 & 35 & $1.00 \%$ & $2.00 \%$ & $3.47 \%$ & $7.00 \%$ & $7.00 \%$ \\
\hline A14 & 36 & 25.4 & $5.90 \%$ & $8.4 \%+*$ & $\mathrm{n} / \mathrm{a}$ & $10.00 \%$ & $10.00 \%$ \\
\hline A14R & 27.5 & 17.5 & $3.30 \%$ & $5.20 \%$ & $4.05 \%$ & $7.00 \%$ & $7.00 \%$ \\
\hline
\end{tabular}

Table 1: Summary of PCC1 Apex specimen results

From the information in the backbone plots and the summary table (Table 1), several trends become apparent:

First, the presence of the ICF forms (dashed lines in Figure 28) during testing increased $\mathrm{P}_{\max }$ by nearly $50 \%$, increased $\mathrm{D}_{20}$ by nearly $60 \%$ and nearly doubled $\mathrm{D}_{\text {fail }}$, when compared to a similarly reinforced specimen tested with the ICF form removed (solid lines).

Second, the addition of rebar beyond the nominal single No.4 rebar appeared to result in a near doubling $\mathrm{P}_{\max }$, while $\mathrm{D}_{20}$ was virtually unchanged. In each specimen with additional reinforcement (blue and red dashed lines) $\mathrm{D}_{\text {fail }}$ was decreased by at least $2 \%$ drift when compared to the nominally reinforced specimen (black dashed line).

Third, when compared to the nominally reinforced specimen, the spiral reinforced specimens added little additional to $\mathrm{P}_{\max }$, but improved $\mathrm{D}_{20}$ drift percentage by up to 300\%. Specimen A14 (green dashed line), was the only specimen for which no core failure occurred prior to test completion at $10 \%$ drift. 
Figure 29 shows the second set of Apex ICF tests, using PCC2 and ECC concrete.

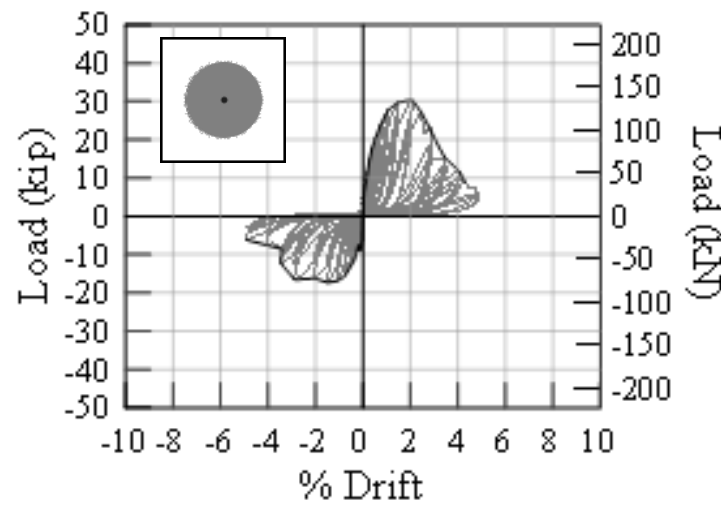

(A) A21R

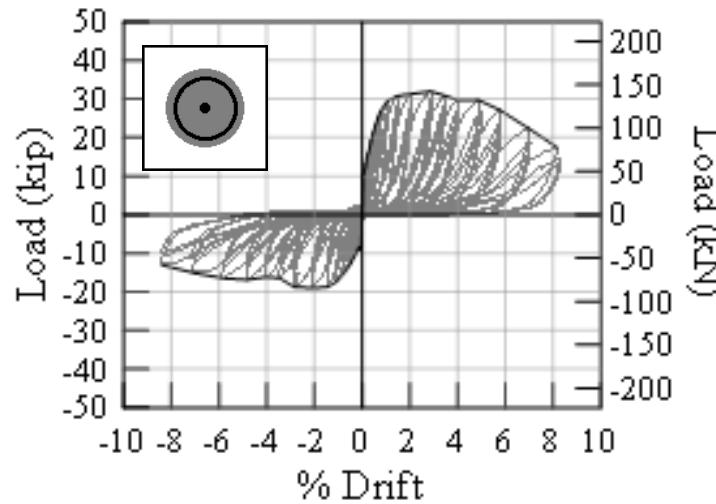

(C) A25R

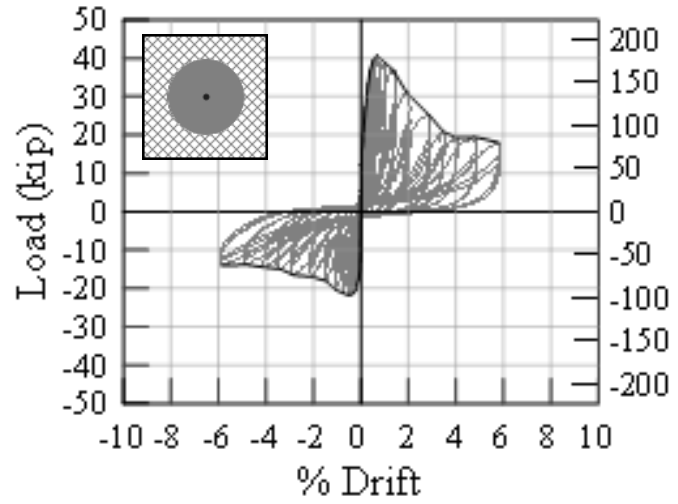

(E) A21

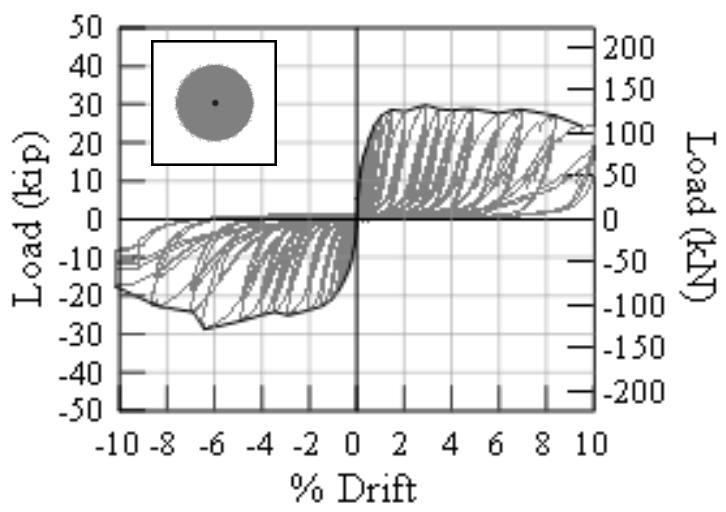

(B) A31R

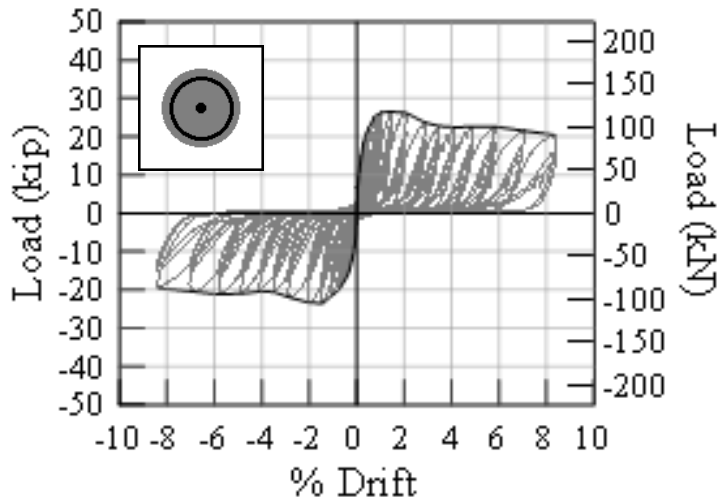

(D) A35R

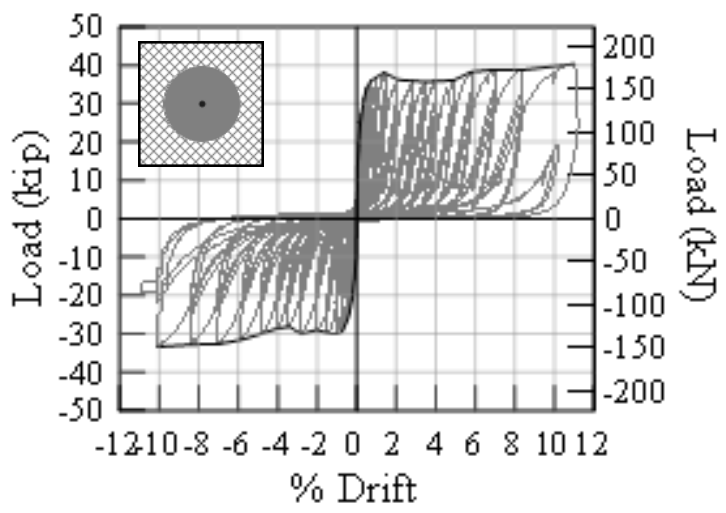

(F) A31

Figure 29: Apex Block Small Scale Specimens: PCC2 (Left) \& ECC (right) concrete. 


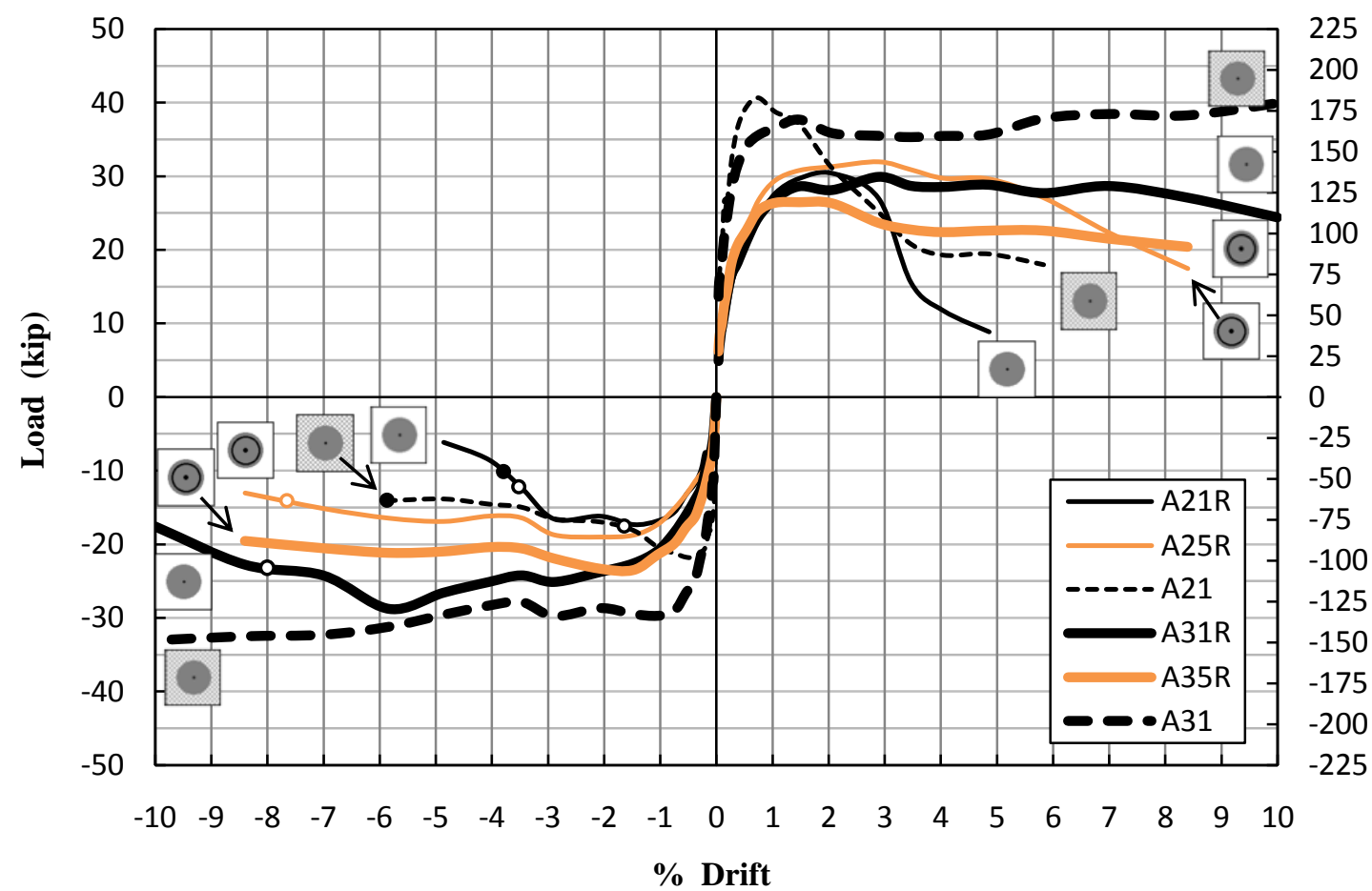

Figure 30: Apex Block Small Scale Specimen Backbone Summary: PCC2 \& ECC Concrete

Figure 30 summarizes the backbone curves for the PCC2 and ECC Apex specimen tests, with cross-sectional representations added to aid in identification of individual curves.

\begin{tabular}{|c|c|c|c|c|c|c|c|}
\hline \multirow[b]{2}{*}{ Specimen } & \multicolumn{2}{|c|}{$\mathbf{P}_{\max }(\mathbf{k i p})$} & \multicolumn{2}{|c|}{$\mathbf{D}_{\mathbf{2 0}}$} & \multirow{2}{*}{$\mathbf{D}_{\text {fail }}$} & \multicolumn{2}{|c|}{ Max Drift $\left(D_{\text {end }}\right)$} \\
\hline & Forward & Reverse & Forward & Reverse & & Forward & Reverse \\
\hline A21 & 40.6 & 21.7 & $2.00 \%$ & $1.50 \%$ & $5.90 \%$ & $5.90 \%$ & $5.90 \%$ \\
\hline$A 21 R$ & 30.4 & 17.3 & $2.80 \%$ & $3.40 \%$ & $3.47 \%$ & $4.80 \%$ & $4.80 \%$ \\
\hline$A 25 R$ & 40.6 & 19 & $6.20 \%$ & $7.50 \%$ & $\mathrm{n} / \mathrm{a}$ & $8.40 \%$ & $8.40 \%$ \\
\hline A31 & 40 & 33.5 & $10.00+\%$ & $10.00+\%$ & $\mathrm{n} / \mathrm{a}$ & $10.00 \%$ & $10.00 \%$ \\
\hline A31R & 30 & 29 & $9.50 \%$ & $8.00 \%$ & $\mathrm{n} / \mathrm{a}$ & $10.00 \%$ & $10.00 \%$ \\
\hline A35R & 26.5 & 23.5 & $7.50 \%$ & $8.5+\%$ & $\mathrm{n} / \mathrm{a}$ & $8.40 \%$ & $8.40 \%$ \\
\hline
\end{tabular}

Table 2: Summary of PCC2 and ECC Apex specimen results

Some of the general trends that arise from the second set of Apex specimen tests are similar to those observed following the first set. 
First, regardless of the alteration of the given variables, bias of the magnitude of $\mathrm{P}_{\max }$ between positive and reverse directions in the cycle, as discussed earlier, is still present and is still likely due to the test setup.

The presence of the ICF form material (dashed lines in Figure 30) still appeared to increase $\mathrm{P}_{\max }$ by approximately $25 \%$, but where $\mathrm{D}_{20}$ was increased in prior tests, a $56 \%$ reduction was observed in the PCC2 case. The ICF form material did however delay the ultimate core failure, $\mathrm{D}_{\text {fail }}$, which occurred at $2 \%$ higher drift than the specimen with the form removed.

The wire mesh hoop reinforcement (solid orange lines) seemed to have effectively confined the concrete, as neither specimen experienced ultimate core failure, especially notable because the form had been removed. Also, $\mathrm{D}_{20}$ for the PCC2 case was much improved, occurring at a drift nearly twice that of the unconfined specimen.

The ECC (thick lines) appears to provide confinement similar to that provided by the mesh hoops or spiral reinforcements. The ECC tended to increase $\mathrm{P}_{\max }$ by $24 \%-68 \%$ over the PCC2 concrete (despite both having 7000 psi compressive strength), while $\mathrm{D}_{20}$ was extended up to at least the $8 \%$ drift cycle, an increase of $3 \%$ drift. Each ECC test specimen was still intact at $10 \%$ drift, with little to no signs of any impending shear failure. The comparison of samples A21R (Figure 29A) and A31R (Figure 29B) clearly shows the contribution of ECC to the behavior of a nominally reinforced sample with the ICF form material removed. 
Comparing the first and second sets of test, the nominally reinforced samples with the form in place - A11 (Figure 26A) and A21 (Figure 29E) - are nearly identical, despite a 3000 psi difference in concrete compressive strength. This may indicate that the in-plane cyclic load resistance $\left(\mathrm{P}_{\max }\right)$ is tension-controlled by the steel reinforcement in the transverse cores, and not highly sensitive to the concrete strength. 


\section{3: Faswall ICF Test Results}

As noted previously, the Faswall ICF samples were tested with various configurations of reinforcement, concrete, and the presence of absence of forms. The Faswall setup was identical to that used in the Apex specimen tests, so the specimens were again susceptible to the bias in applied force between the positive and reverse directions of each cycle.

In general, unanticipated failure of the horizontal support cores was more commonly the cause of the termination of a test, due to the in-plane stiffness of the 5-in $\mathrm{x}$ 9-in rectangular vertical cores relative to the less robust horizontal support cores.

Bending and cracking of the support cores were often evident, as well as a crushing and cracking due to transverse movement against friction near the bearing plate contacts, as shown on the right in Figure 31. The damage sometimes loosened the threaded rod which secured the LVDT apparatus, making any further cycling impossible.
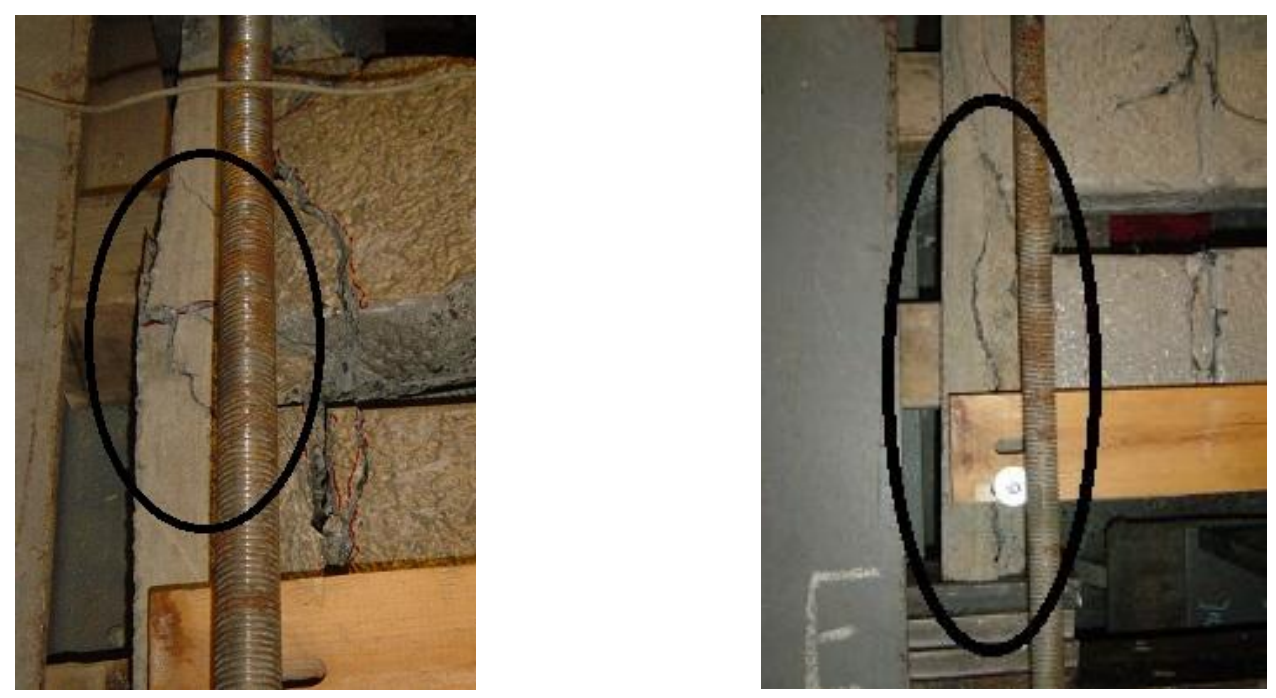

Figure 31: Bending and cracking of support members. 
Figure 32 and Figure 33 show the individual hysteresis plots for all eleven Faswall tests.

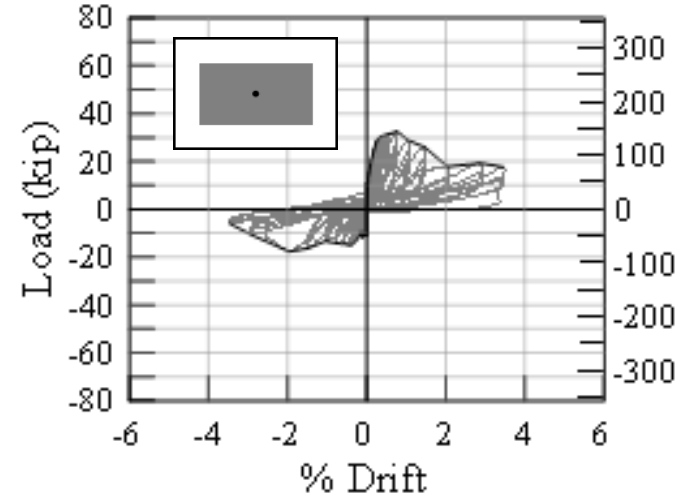

(A) F21Ra

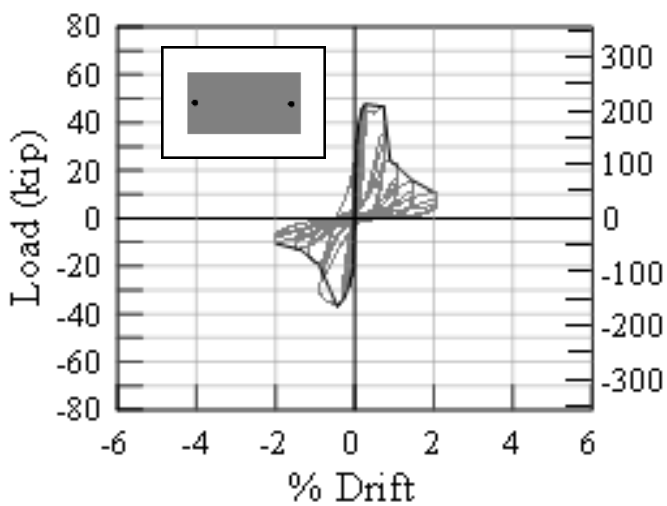

(C) F22R

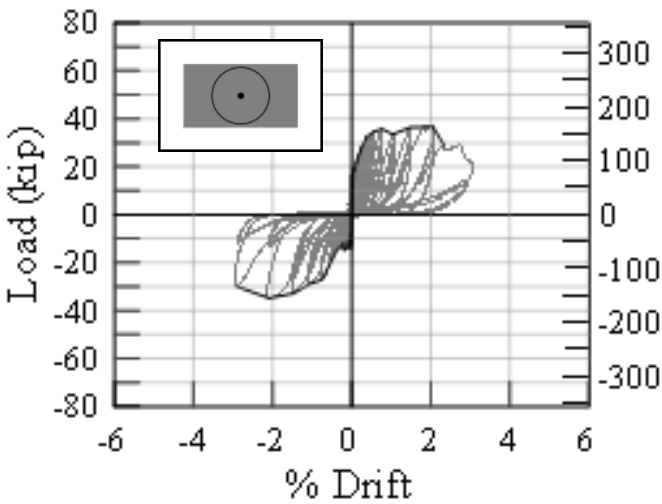

(E) F23R

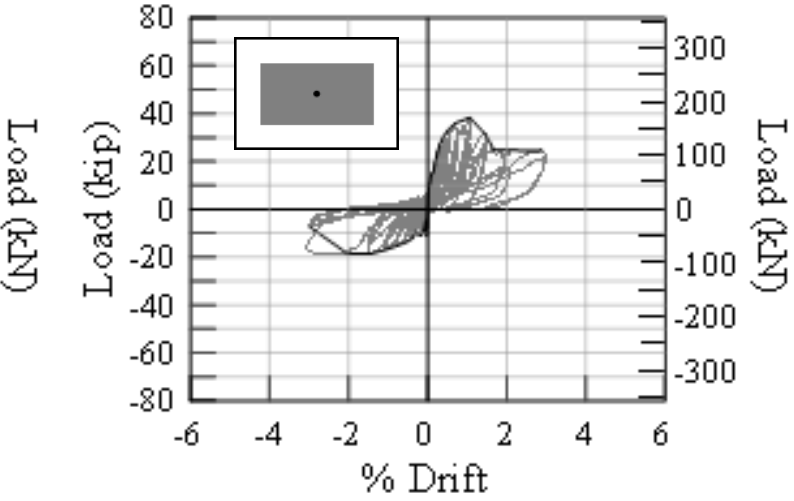

(B) $\mathrm{F} 21 \mathrm{Rb}$

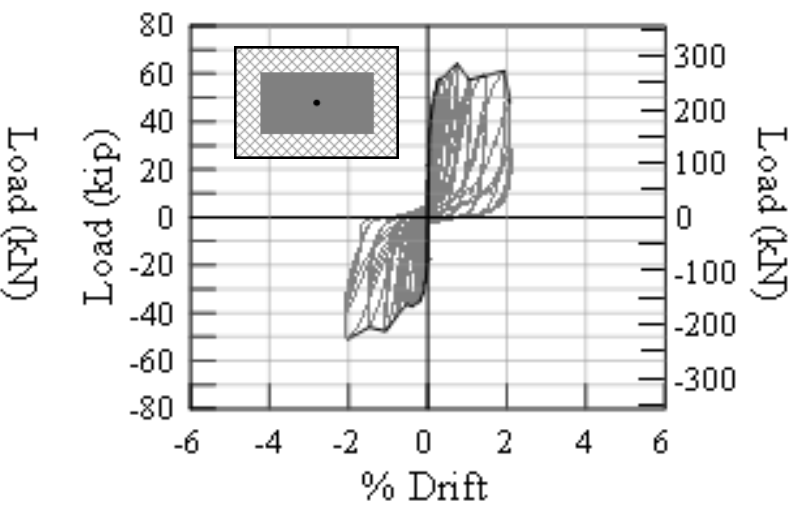

(D) F21

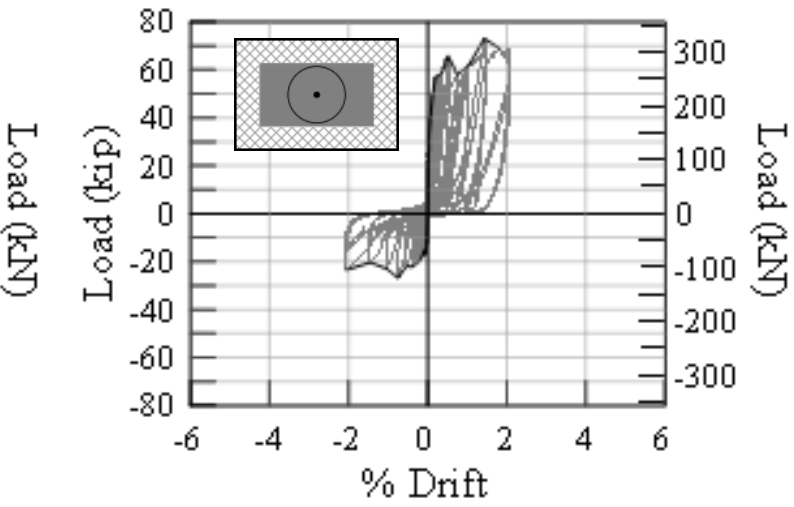

(F) F23

Figure 32: Faswall Small Scale Specimens: PCC2 Concrete 


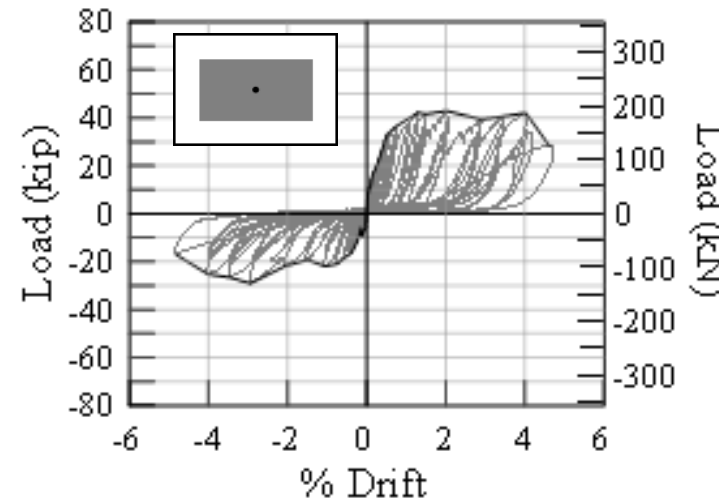

(A) F31Ra

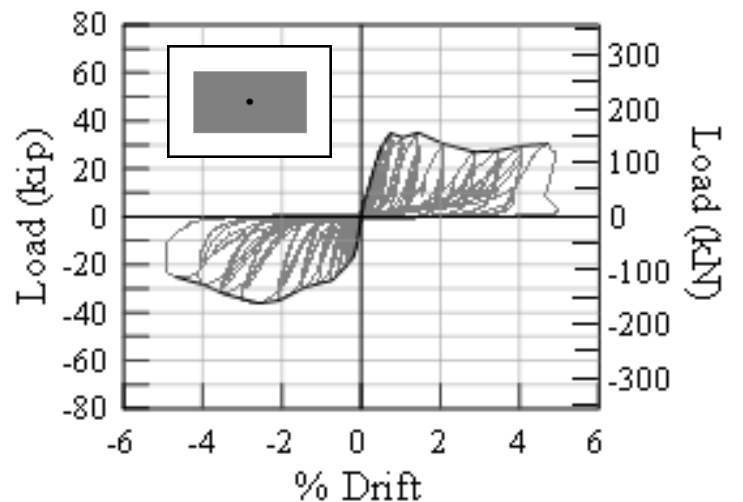

(B) F31 Rb

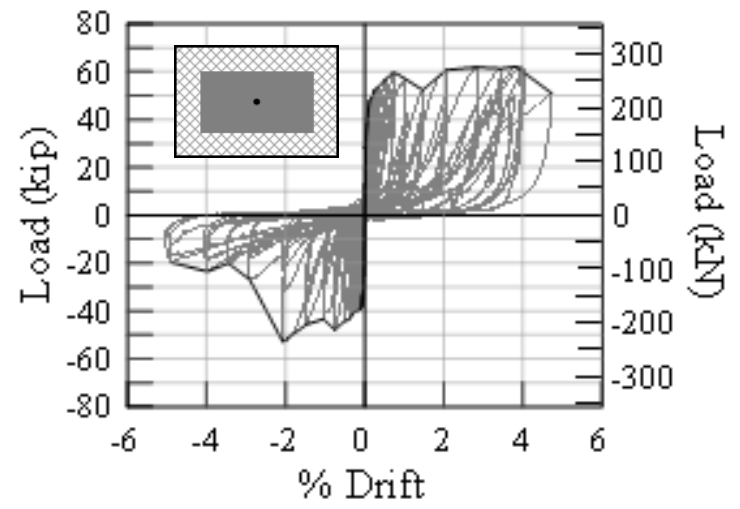

(C) F31

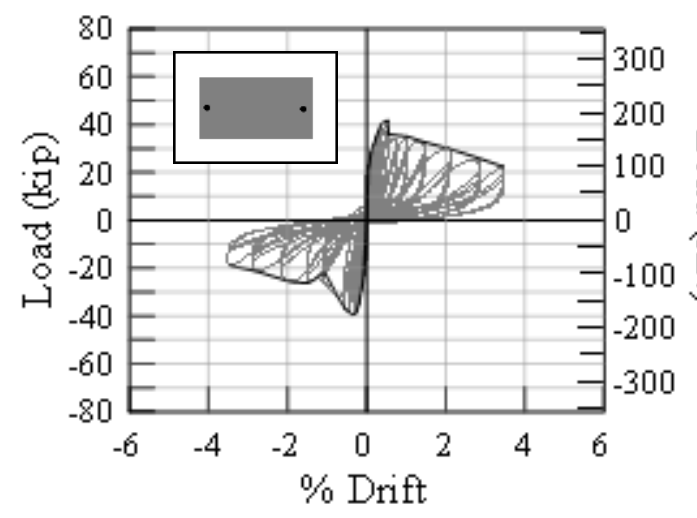

(D) F32R

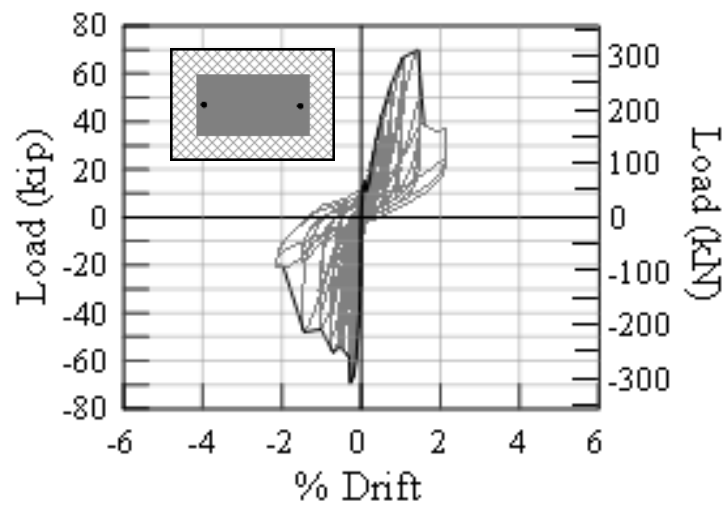

(E) F32

Figure 33: Faswall Small Scale Specimens: ECC Concrete 
The Faswall backbone summaries are shown in Figure 34 and Figure 35.

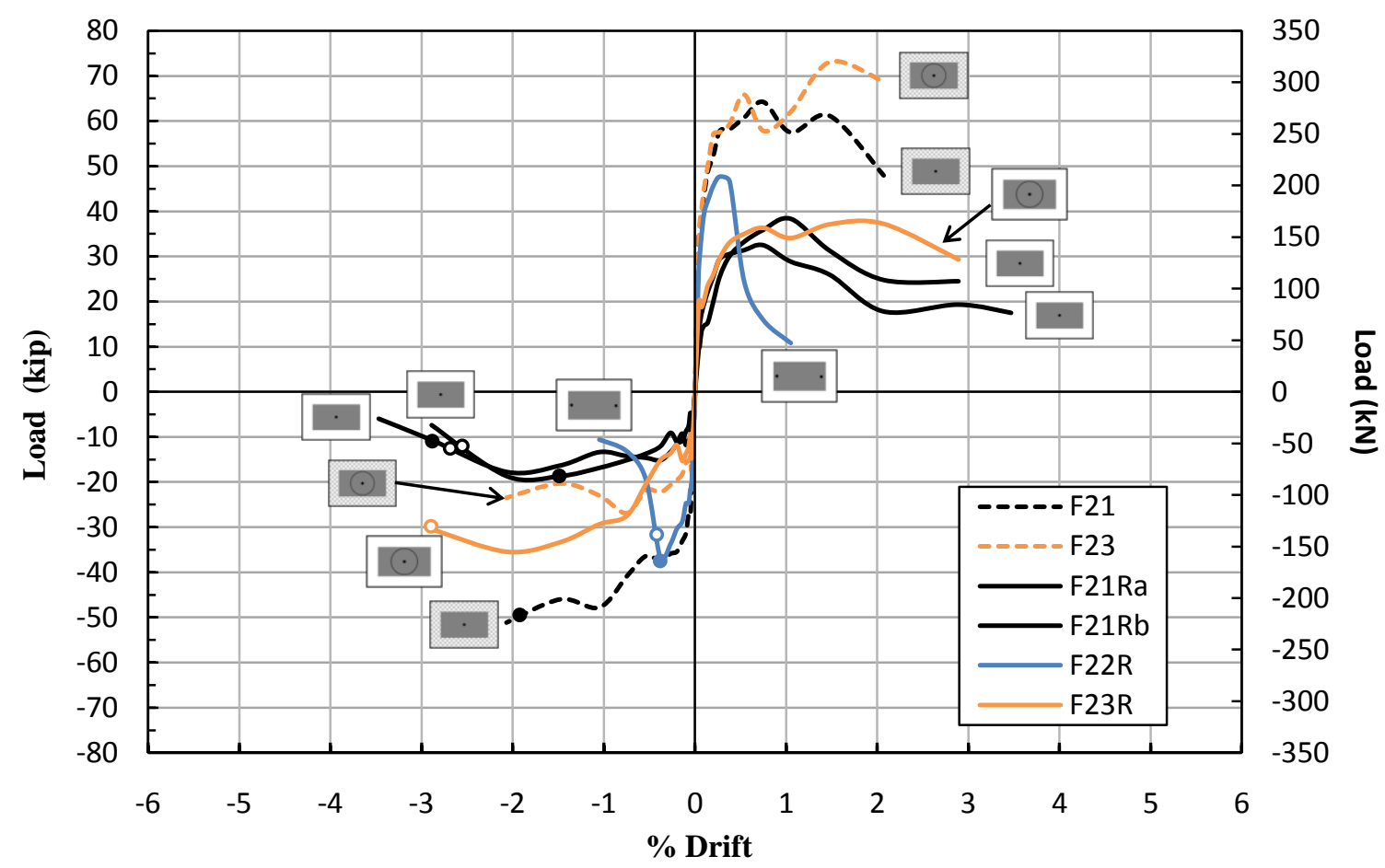

Figure 34 - Faswall Small Scale Backbone Summary, PCC2 Concrete

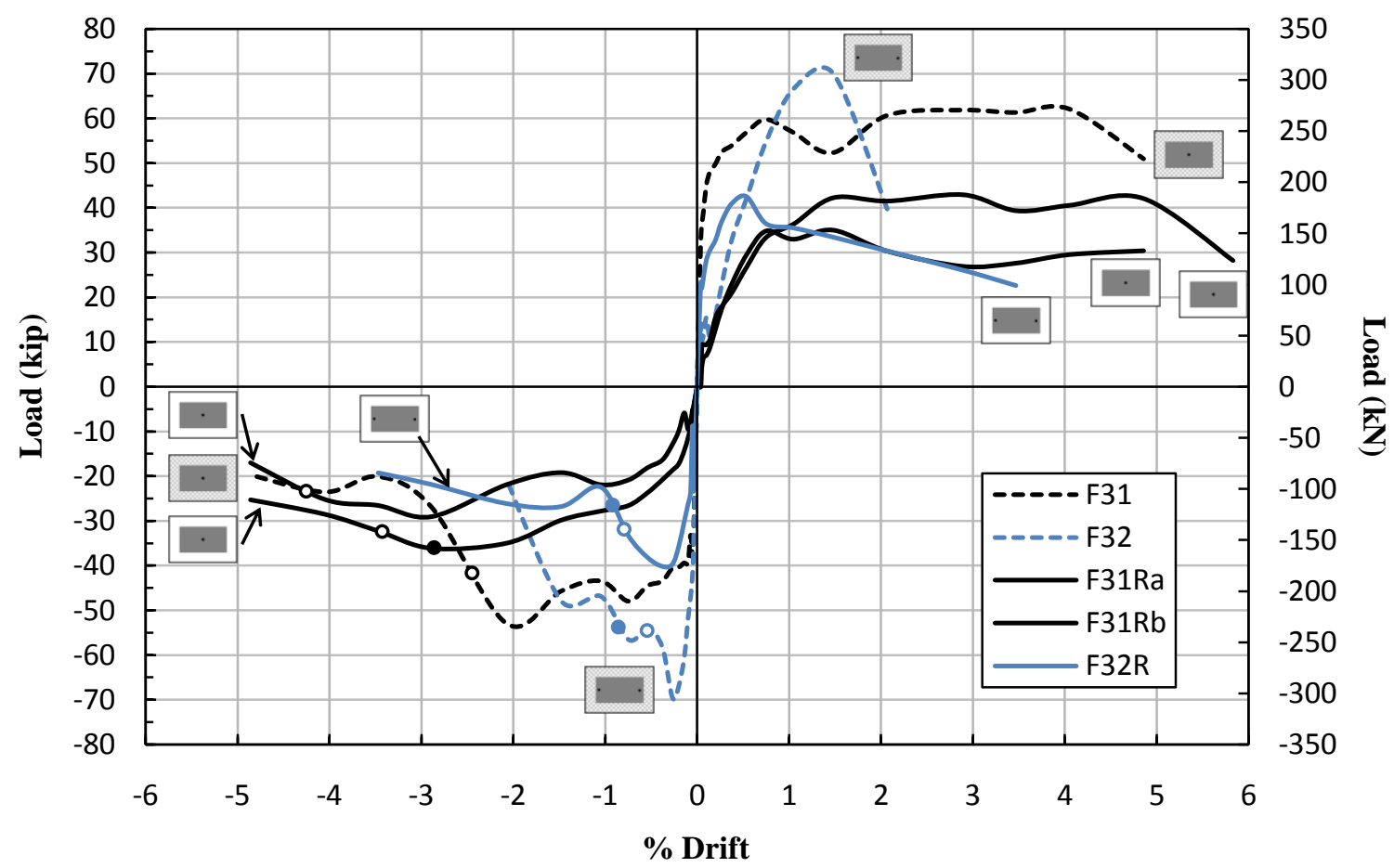

Figure 35: Faswall Small Scale Backbone Summary, ECC Concrete 


\begin{tabular}{|c|c|c|c|c|c|c|c|}
\hline \multirow[b]{2}{*}{ Specimen } & \multicolumn{2}{|c|}{$\mathbf{P}_{\max }($ kip) } & \multirow{2}{*}{\multicolumn{2}{|c|}{\begin{tabular}{|c|}
$D_{20}$ \\
Forward Reverse \\
\end{tabular}}} & \multirow{2}{*}{$D_{\text {fail }}$} & \multicolumn{2}{|c|}{ Max Drift $\left(D_{\text {end }}\right)$} \\
\hline & Forward & Reverse & & & & Forward & Reverse \\
\hline F21Ra & 32.5 & 17.7 & $1.50 \%$ & $2.40 \%$ & $2.89 \%$ & $3.50 \%$ & $3.50 \%$ \\
\hline $\mathrm{F} 21 \mathrm{Rb}$ & 38.3 & 18.6 & $1.50 \%$ & $2.50 \%$ & $1.50 \%$ & $2.90 \%$ & $2.90 \%$ \\
\hline $\mathrm{F} 21 *$ & 64.2 & 51 & $2+\% *$ & $2+\% *$ & $2.89 \%$ & $2.00 \%$ & $2.00 \%$ \\
\hline $\mathrm{F} 22 \mathrm{R} *$ & 48 & 36.5 & $0.50 \%$ & $0.50 \%$ & $0.75 \%$ & $1.10 \%$ & $1.10 \%$ \\
\hline $\mathrm{F} 23 \mathrm{R} *$ & 36.5 & 34.8 & $3.00 \%$ & $3.00 \%$ & $3+\%$ & $2.90 \%$ & $2.90 \%$ \\
\hline $\mathrm{F} 23^{*}$ & 68 & 26 & $2+\% *$ & $2+\% *$ & $2.1+\%$ & $2.10 \%$ & $2.10 \%$ \\
\hline F31* & 62 & 53 & $4.5+\% *$ & $2.50 \%$ & $4.5+\%$ & $4.50 \%$ & $4.50 \%$ \\
\hline F32* & 70 & 69 & $1.50 \%$ & $0.70 \%$ & $0.75 \%$ & $2.10 \%$ & $2.10 \%$ \\
\hline F31Ra* & 42.8 & 29 & $4.40 \%$ & $4.25 \%$ & $4.5+\%$ & $4.50 \%$ & $4.50 \%$ \\
\hline F31Rb & 35 & 36 & $2.60 \%$ & $3.90 \%$ & $2.90 \%$ & $4.50 \%$ & $4.50 \%$ \\
\hline F32R & 41.7 & 39.5 & $1.50 \%$ & $0.65 \%$ & $0.75 \%$ & $3.50 \%$ & $3.50 \%$ \\
\hline
\end{tabular}

Table 3: Summary of Faswall PCC2 and ECC specimen results. * indicates premature support failure.

The Faswall results yield some of the same observations made with the Apex Block specimens:

The Faswall form material (solid lines in Figure 34 and Figure 35), despite having dissimilar material and geometry tom the Apex EPS material, appeared to behave similarly to the Apex form by increasing $\mathrm{P}_{\max }$ significantly when compared to similar specimens tested with the forms removed (solid lines). The increase in $\mathrm{P}_{\max }$ ranged from $45 \%$ to $188 \%$, with exception to specimen F23, which saw a $25 \%$ decrease on the reverse cycle backbone. Unlike the Apex forms however, the Faswall samples generally saw more rapid strength degradation from their peak, as evidenced by a reduction of $\mathrm{D}_{20}$ values by $20 \%-50 \%$. Ultimate failure of the transverse elements occurred up to $40 \%$ earlier also.

Compared to the nominally reinforced case, the three Faswall specimens with rebar near both edges of each core doubled $\mathrm{P}_{\max }$. Such forces precipitated a drastic reduction in 
strength thereafter, halving $\mathrm{D}_{20}$ percent values. In both of the dually-reinforced PCC2 and ECC specimens, complete transverse core failure shear occurred at $0.75 \%$ drift, as the rebar broke through the concrete cover and destroyed the core. The drift at failure is lower than the $2 \%-3 \%$ drift failure observed in nominally reinforced specimens, regardless of the presence or lack of the ICF form during the test.

Compared to the nominally reinforced PCC2 Faswall specimens (solid black lines in Figure 34), similarly reinforced ECC specimens (solid black lines in Figure 35) showed increases in $\mathrm{P}_{\max }$ by $56 \%-103 \%, \mathrm{D}_{20}$ values by $1.5 \%-2 \%$ drift, and $\mathrm{D}_{\text {fail }}$ values by $0 \%$ $3 \%$ drift. Surprisingly, the ECC did not appear to increase $\mathrm{P}_{\max }$ of the nominally reinforced specimen with form in place $(\mathrm{F} 31)$, or the dual reinforced specimen with form removed $(\mathrm{F} 32 \mathrm{R})$

When steel mesh hoops were included (orange lines in Figure 34), the strength appeared to double for specimens with the forms removed, and $\mathrm{D}_{20}$ was increased by $20 \%-25 \%$. Failure of the supports of the ECC samples prior to reaching $\mathrm{D}_{\text {fail }}$ makes quantifying any improvement difficult, though improvement does look probable, as little strength deterioration had yet to occur. Strength comparisons for the specimens tested with forms in place were inconclusive (same strength on positive stroke, half strength on reverse stroke). 


\section{4: General Summary}

\subsection{1: General Observations:}

In all cases, Individual cycles of the hysteresis appeared "pinched" through the middle of each stroke, meaning relatively little force was required to displace the central

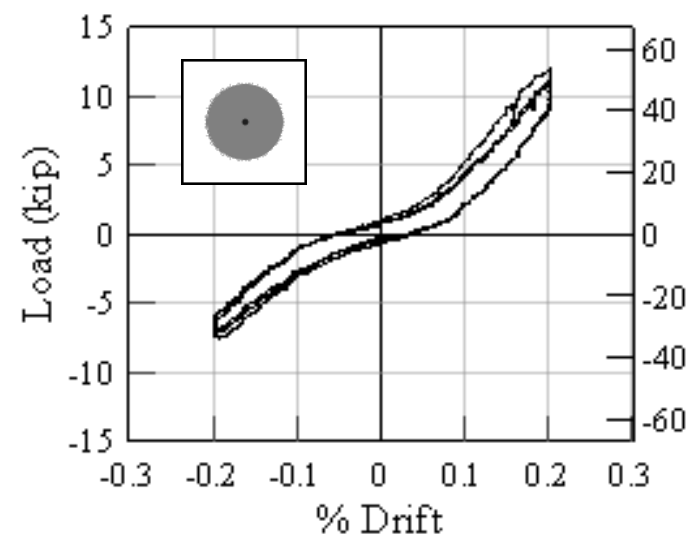

(a) $\pm 0.20 \%$ drift

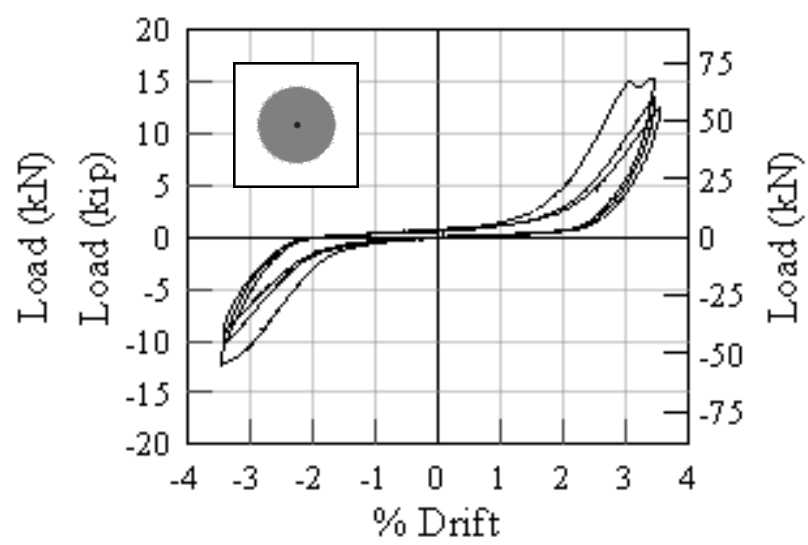

(b) $\pm 3.47 \%$ drift

Figure 36: Hysteresis cycles from specimen A21R, exhibiting "pinching".

core until reaching the extremes of the drift cycles. The area enclosed by the curve is related to the energy dissipated by the system, thus pinched nature of the curve indicates low energy dissipation, which is undesirable. Additionally, the slope of the curve indicates the system's stiffness. Thus during cycles of large displacement such as in Figure 36(b), the nearly-horizontal line through the central $\pm 1.5 \%$ drift indicates very little stiffness, which is also undesirable. A likely explanation for this behavior is that after cracks form at the ends of each vertical core, as in Figure 13(e), the reinforcing steel is the only material connecting the vertical cores to the horizontal cores. Thus the only resistance through the middle of the stroke is due only to bending of eight small sections 
of exposed No.4 rebar at the joints. As the central horizontal core is displaced further, the concrete of the vertical cores bears against the concrete of the horizontal cores, which causes the steel to go into tension, causing a coupling moment that greatly increases the resistance to further displacement. The compression, tension, applied, and reaction forces are illustrated in Figure 37 for displacements to the left, center, and right during a drift cycle.

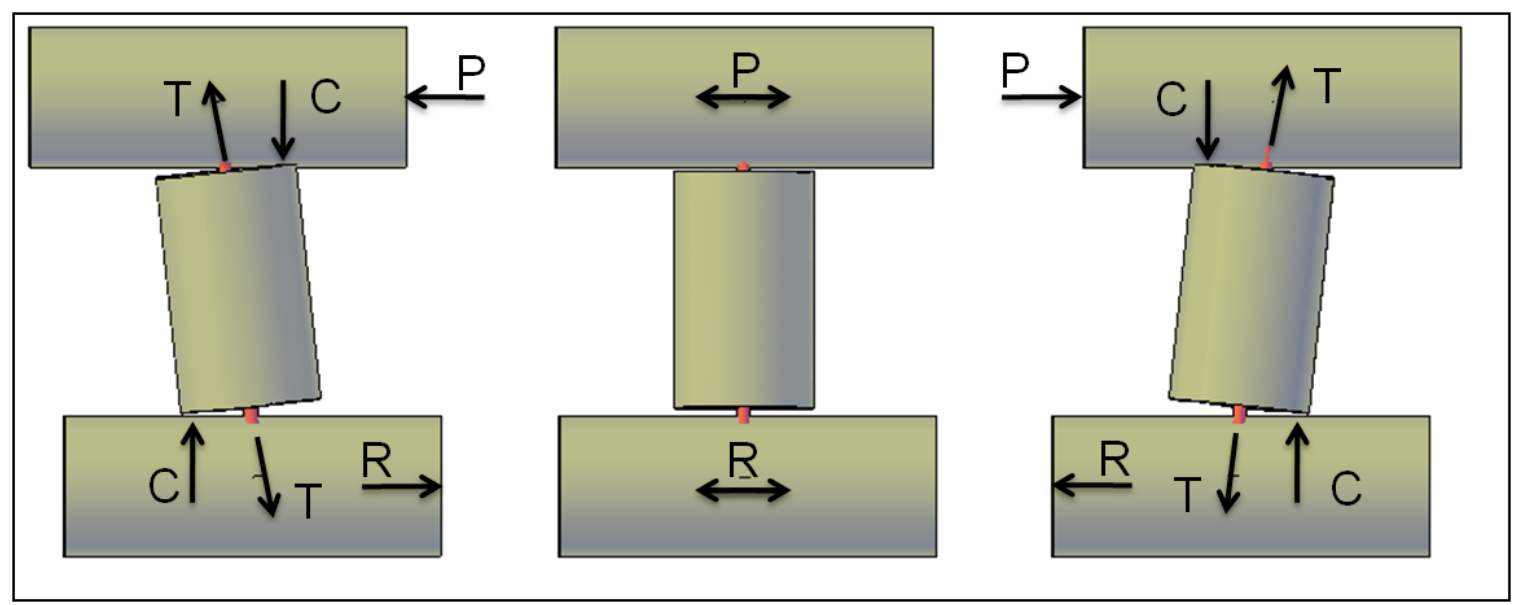

Figure 37: Rotation and bearing of vertical member against horizontal members

In general, additional rebar only forced a different mode of failure in the sample by first developing a larger $\mathrm{P}_{\max }$, followed by a swift degradation of strength and ultimately a premature failure when compared to the reference specimen. Prior to failure however, the additional steel did appear to result in thicker hysteresis loops, indicating higher energy dissipation than the reference case.

When subject to confinement either by spiral wires, mesh hoops, ECC concrete, or the presence of the ICF form, most specimens exhibited a larger $\mathrm{D}_{20}$ and $\mathrm{D}_{\text {fail }}$, though 
those results were marked by pinched hysteresis loops with wide regions of low stiffness as discussed previously.

\subsection{2: Apex Block Specimen Specific Observations}

The presence of the form material tends to increase peak strength by approximately $25 \%$, does not improve $\mathrm{D}_{20}$, but increases $\mathrm{D}_{\text {fail }}$, the drift ratio at catastrophic failure.

The addition of rebar beyond the nominal single No.4 reinforcement generally leads to a larger $P_{\max }$, unchanged rate of strength degradation $\left(\mathrm{D}_{20}\right)$, and lower $\mathrm{D}_{\text {fail }}$.

The addition of confinement in the form of spiral wires or mesh hoops tends to have little effect on $\mathrm{P}_{\max }$, but appears to delay both $\mathrm{D}_{20}$ and $\mathrm{D}_{\text {fail. }}$.

The use of ECC concrete over PCC concrete appears to improve $\mathrm{P}_{\max }$ only marginally, but significantly improves both $\mathrm{D}_{20}$ and $\mathrm{D}_{\text {fail }}$.

\subsection{3: Faswall Specimen Specific Observations}

The presence of the form material increased $\mathrm{P}_{\max }$ by at least $45 \%$, but $\mathrm{D}_{20}$ and $\mathrm{D}_{\text {fail }}$ were significantly reduced.

Reinforcement placed at the edges of the Faswall cores resulted in an increased $\mathrm{P}_{\max }$, but decreased $\mathrm{D}_{20}$ and $\mathrm{D}_{\text {fail. }}$.

Mesh steel reinforcement appears to have only modestly increased the $\mathrm{P}_{\max }$ and $\mathrm{D}_{20}$. No conclusions may be drawn about $\mathrm{D}_{\text {fail }}$ due to support failure prior to core failure.

Use of ECC concrete appears to significantly improve $\mathrm{D}_{20}$ and $\mathrm{D}_{\text {fail }}$, but only sometimes improves $\mathrm{P}_{\max }$. 


\section{Chapter 5: Numerical ANAlysis ANd CoMputer Modeling}

\section{1: Hand Calculations}

As mentioned previously, the purpose of this project is to determine if the behavior of small-scale samples of both Faswall and Apex ICF grid walls can be generalized, scaled up, and applied to full-scale wall systems. To this end, to first understand the strength of the small specimens may help illuminate the strength and drift capacity of larger wall systems.

First, the most basic case is investigated: the small scale Apex ICF grid specimen with centrally placed No.4 rebar in each core and the form removed. The specimen and the corresponding hysteresis from testing are shown in Figure 38.
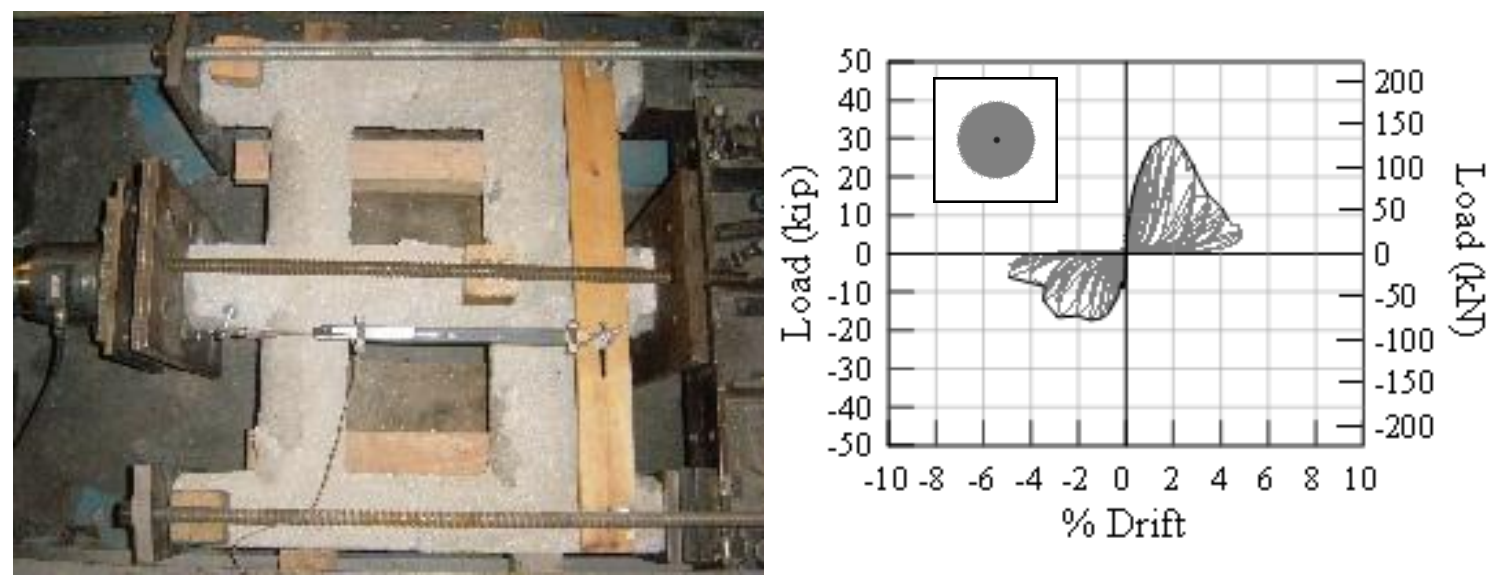

Figure 38: Apex Block small scale specimen and hysteresis

Due to the frame-like structure of ICF grid, and the Apex block especially, one might think to employ matrix structural analysis methods particularly well-suited for frames, which takes into account rotation and displacements of joints. Observations of the tests showed that flexural cracks at the member joints became fully developed at very 
low drift ratios, such that stiffness throughout each cycle and throughout an entire test is never constant. Therefore, matrix method analysis is likely not appropriate due to the difficulty, if not impossibility, of tracking the changes in stiffness as the test progresses. Even an initial stiffness estimate for very small drifts is likely to be inaccurate, as the 6 in diameter cores are only 10 in long between joints, they are far more likely to crack than to bend or cause joint rotation.

More emphasis is placed on behavior at much higher drift levels (2.5\% or more) for seismic response purposes, so more emphasis is placed on calculating $\mathrm{P}_{\max }$ at those levels, due to either shear or flexural modes of resistance. Assuming that flexural cracking has occurred thoroughly in the cores at the drift levels of interest, emphasis is placed on lateral force resistance due to the moment couple that exists when the vertical cores bear upon the horizontal cores and cause the steel to yield in tension, as illustrated previously in Figure 37.

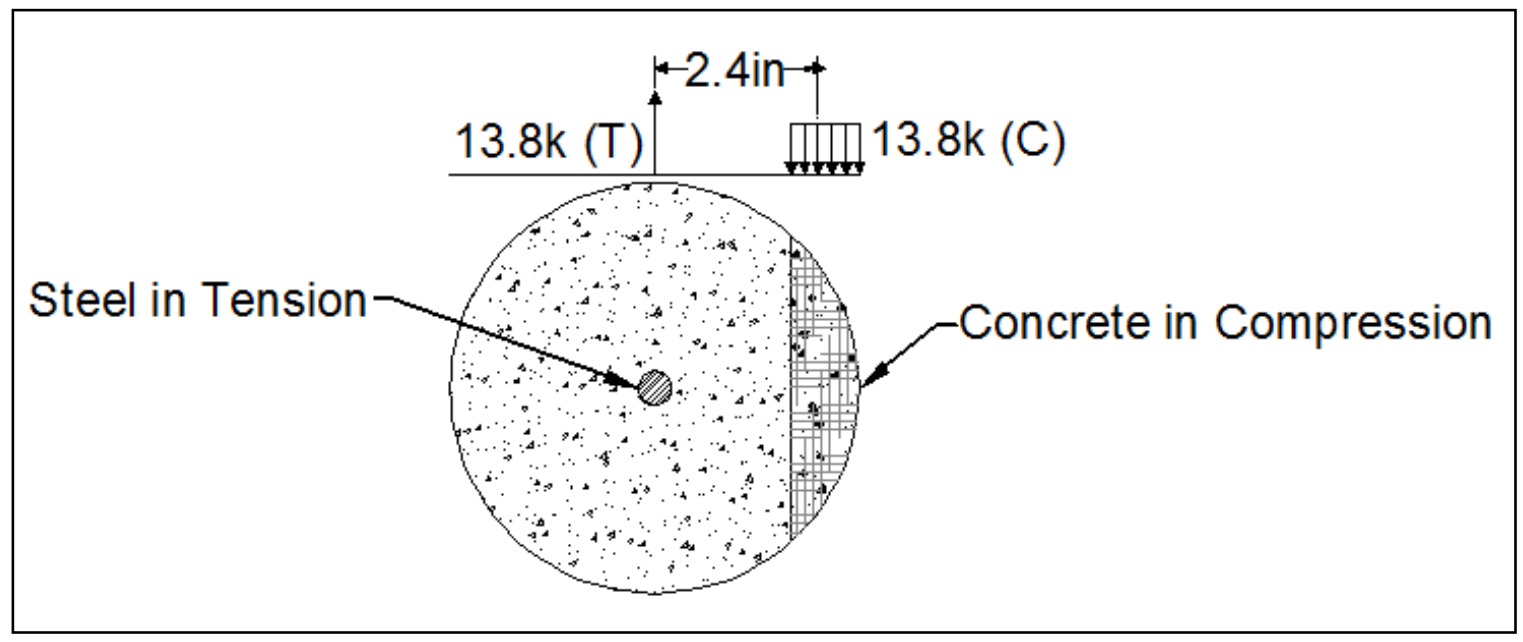

Figure 39: Idealized cross section of Apex core at deflection limits: $f_{y}=68 \mathrm{ksi}, \mathrm{f}_{\mathrm{c}}{ }_{\mathrm{c}}=7 \mathrm{ksi}$ 
Applying basic statics to a cracked Apex specimen that fully develops all eight moment couples results in a theoretical $\mathrm{P}_{\max }$ of 26.5 kip. As in the experimental tests, this is the force that would be applied to the middle longitudinal core of a specimen with the ICF form material removed; the affect of the material has not been considered. From the experimental data for similar Apex specimens, $P_{\max }$ often falls in the range of 17 kip to $23 \mathrm{kip}$, and in only one case is greater than $26.5 \mathrm{kip}$ (specimen A31R). The calculations therefore seem to overestimate the strength of the system, perhaps because they assume a highly ideal situation of the moment couple in all eight locations fully developing simultaneously. However, observations of the experimental specimens reveal that the cracks that formed were not identical, and hence were unlikely to simultaneously develop the maximum moment couple. Given that $\mathrm{P}_{\max }$ only once exceeded the calculated max of 26 kip during testing, this assumption seems reasonable.

Shear strength estimates were also calculated from ACI 318-08:

$$
V_{c}=2 \lambda \sqrt{f_{c}^{\prime}} b_{w} d
$$

Where:

$\lambda=1.0$ for normal weight concrete,

$f_{c}^{\prime}$ is the compressive strength of concrete in psi,

$b_{w}=$ the distance between the center of fibers in compression and the center of tension,

$\mathrm{d}=$ the diameter of the cross-section. 
The estimated shear strength for the reference Apex case with form removed was 7.3 kip, well below the observed $\mathrm{P}_{\max }$ observed experimentally. Table 4 shows calculated values for each Apex specimen, formulated from the reasoning and calculations above. In the table, $\mathrm{P}_{\text {moment }}$ is the maximum lateral force resistance due to flexural action, while $\mathrm{P}_{\text {shear }}$ is the maximum lateral force resistance due to shear strength. Each value was calculated considering the contribution of all four vertical cores.

\begin{tabular}{|c|c|c|c|c|}
\hline Apex Specimen & $\begin{array}{c}\text { Moment } \\
\text { Arm (in) }\end{array}$ & $\begin{array}{c}\mathrm{P}_{\text {moment }} \\
\text { (kip) }\end{array}$ & $\begin{array}{c}\mathrm{P}_{\text {shear }} \\
\text { (kip) }\end{array}$ & $\begin{array}{c}\text { Observed } \\
\mathrm{P}_{\text {max }} \text { (kip) }\end{array}$ \\
\hline Type 1 (7 ksi, 68 ksi) & 2.4 & 26.1 & 7.3 & 17 \\
\hline Type 1 (4 ksi, 63 ksi) & 2.1 & 23.2 & 6.2 & 15 \\
\hline Type 2 (4 ksi, 63 ksi) & 2.0 & 48.6 & 6.7 & $16-46$ \\
\hline Type 3 (4 ksi, 63 ksi & 4.1 & 41.3 & 15 & $16-46$ \\
\hline Type 4 (4 ksi, 63 ksi) & 2.1 & 23.2 & 8.2 & $18-28$ \\
\hline Type 4 (7 ksi, 68 ksi) & 2.4 & 26.1 & 9.3 & $19-24$ \\
\hline
\end{tabular}

Table 4: Maximum calculated lateral forces in Apex specimen from flexural and shear capacities

The specimen with two No.4 rebar in the center of the concrete core (Type 2) result in a theoretical $\mathrm{P}_{\text {moment }}=49 \mathrm{kip}$, while the specimen with dual No.4 rebar near the edges of the core result in a theoretical $\mathrm{P}_{\text {moment }}=41.3 \mathrm{kip}$. Once again, these values do not take into account the affect on $\mathrm{P}_{\max }$ due to the form material. In comparison to the results from the experiments performed with the forms in place (which generally appear to add approximately 10 kip to $\mathrm{P}_{\max }$ ), the hand calculations appear to again overestimate the strength of the small scale system of interest, during both the reverse and forward stroke of each cycle. A12a and A13a, considered to be acceptable test results, attain a $\mathrm{P}_{\max }-$ with forms in place-25\%-30\% lower than calculated by hand, with the forms removed. 
When shear is considered, the ACI equation appeared to underestimate the strength of each specimen, many times by approximately 50\%. The Apex cross-section however is not typical of members for which the ACI equation was intended rectangular beams with shear reinforcement and much moment arms twice as long for a given sample. The ACI equation is also conservative in general, thus the calculated value for shear capacity of the specimen is consistently low.

Similar calculations were also performed for the Faswall test specimens, and the results of which are tabulated in Table 5.

\begin{tabular}{|c|c|c|c|c|}
\hline Faswall Specimens & $\begin{array}{c}\text { Moment } \\
\text { Arm (in) }\end{array}$ & $\begin{array}{c}\mathrm{P}_{\text {moment }} \\
\text { (kip) }\end{array}$ & $\begin{array}{c}\mathrm{P}_{\text {shear }} \\
\text { (kip) }\end{array}$ & $\begin{array}{c}\text { Observed } \\
\mathrm{P}_{\max } \text { (kip) }\end{array}$ \\
\hline Type 1 (7 ksi, 68 ksi) & 4.3 & 39 & 14.4 & $18-36$ \\
\hline Type 2 (7 ksi 68 ksi) & 7.8 & 73 & 26.1 & $37-40$ \\
\hline Type 3 (7 ksi 68 ksi) & 4.3 & 39 & 14.9 & 35 \\
\hline
\end{tabular}

Table 5: Maximum calculated lateral forces in Faswall specimens from flexural and shear capacities

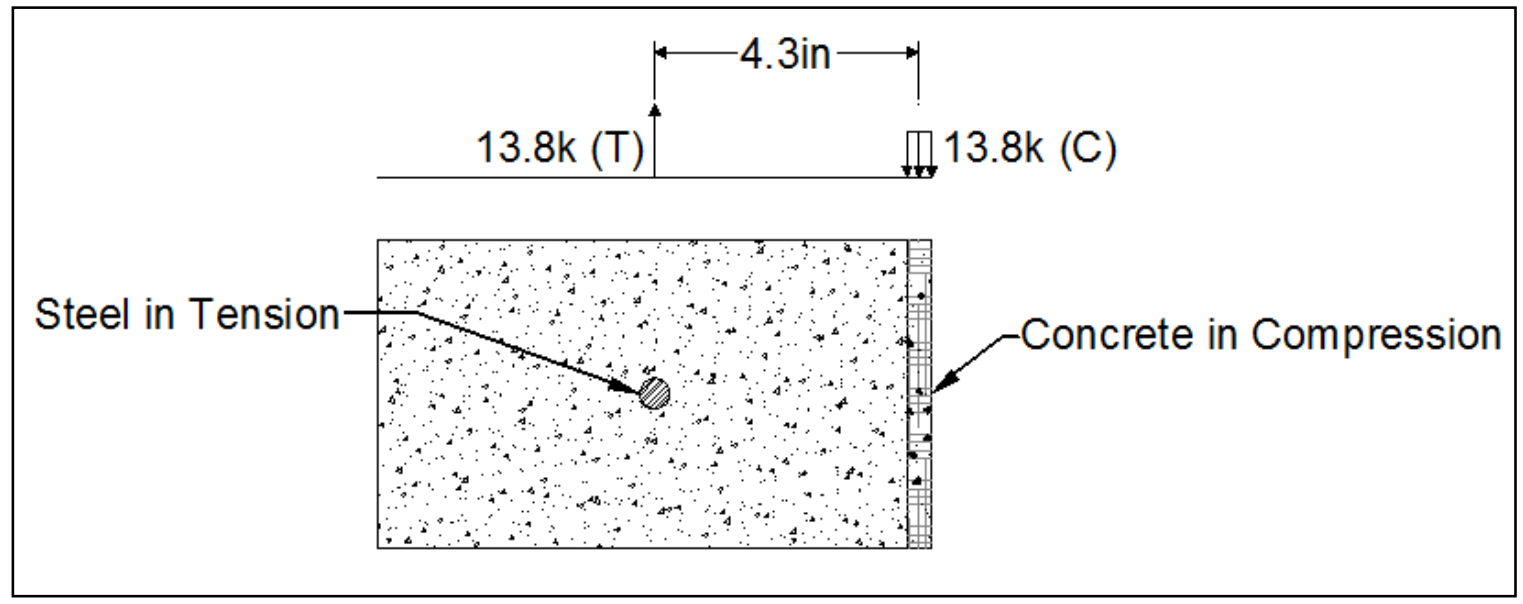

Figure 40: Idealized cross section of the reference Faswall core at deflection limits: $\mathrm{f}_{\mathrm{y}}=68 \mathrm{ksi}, \mathrm{f}_{\mathrm{c}}=7 \mathrm{ksi}$

The cross section of one nominally reinforced Faswall core as the concrete goes into compression and the steel is pulled into tension is shown in Figure 40. The resulting 
idealized moment couple resulted in $\mathrm{P}_{\text {moment }}=39$ kip. For the dual-reinforced Faswall specimen, $\mathrm{P}_{\text {moment }}$ increased to 73 kip due to the longer moment arm. Values for the peak lateral force resistance due to shear were also calculated per the ACI equation stated previously.

The experimental results of the nominally reinforced Faswall specimen were again less than the calculated values of $\mathrm{P}_{\text {moment }}$; the specimens that used PCC 2 concrete were half the calculated value, while the ECC saw a smaller decrease of $25 \%$ from the expected value. The specimens tested with the forms in place did exhibit a larger $\mathrm{P}_{\max }$ than calculated, whereas the Apex specimens did not.

In looking at the dual reinforced Faswall specimens, only the experimental results for the specimen tested with the form in place was near to the calculated $\mathrm{P}_{\text {moment }}$. The specimens tested with the forms removed exhibited a $P_{\max }$ that was $40 \%$ lower than calculated, regardless of the concrete type.

As with the Apex specimens, the hand calculation for the Faswall specimens assumes an ideal case in which the cracks at all eight flexural cracking locations are uniform and strength is fully developed during the limits of deflection. This ideal situation appears not to be the case in reality, and the calculations can be assumed to consistently overestimate the expected peak force resistance of the system by up to twice of that observed experimentally.

Again, as with the Apex specimens, the calculated force resistance for Faswall specimens due to shear strength, $\mathrm{P}_{\text {shear }}$, underestimated the range of observed values. The 
disparity was most likely again due again to the fact that the ACI equation is conservative and were developed for members including minimal shear reinforcement and rebar placed near the edges of the members instead of centered.

\section{2: Computer Modeling}

Maintained primarily by the University of California at Berkley, the Open System for Earthquake Engineering Simulations (OpenSees) is open source software designed to perform simulation of the flexural response of structural systems to a seismic event. OpenSees is a flexible script-driven program that uses the Tcl/Tk scripting language. OpenSees has no native graphical user interface. The software allows for monitoring and analyzing nonlinear response of systems, and can use a wide variety of materials with properties defined by the user. OpenSees uses a variety of iterative algorithms to calculate force, deformation, rotation, etc. during a simulation. A template script can be employed that uses the most efficient algorithm first, followed by more complex algorithms if the previous fails to converge on a solution. OpenSees can output a variety of data as defined by the user, which can then be analyzed. For purposes of this investigation, force and drift ratio data were generated, and subsequent plots of force versus drift ratio were readily made using Matlab or Grapher software programs, to which the experimental test data results were compared.

A description of building and analyzing a model of a simple Apex block small specimen is as follows: 
First, the model properties were defined. The geometrical properties included the number of dimensions and number of degrees of freedom in the system. The in-plane system of an ICF grid structure was two-dimensional, and had three degrees of freedom: translation in both transverse and longitudinal directions as well as rotation about that plane. Next, the nodal coordinates were defined (16 inches on-center for Apex block grids, as shown in Figure 41. The constraint conditions were also defined, constraining the top and bottom fixed supports from translating in the direction of force, but being allowed to breathe perpendicular to the force as the central member was being cycled.

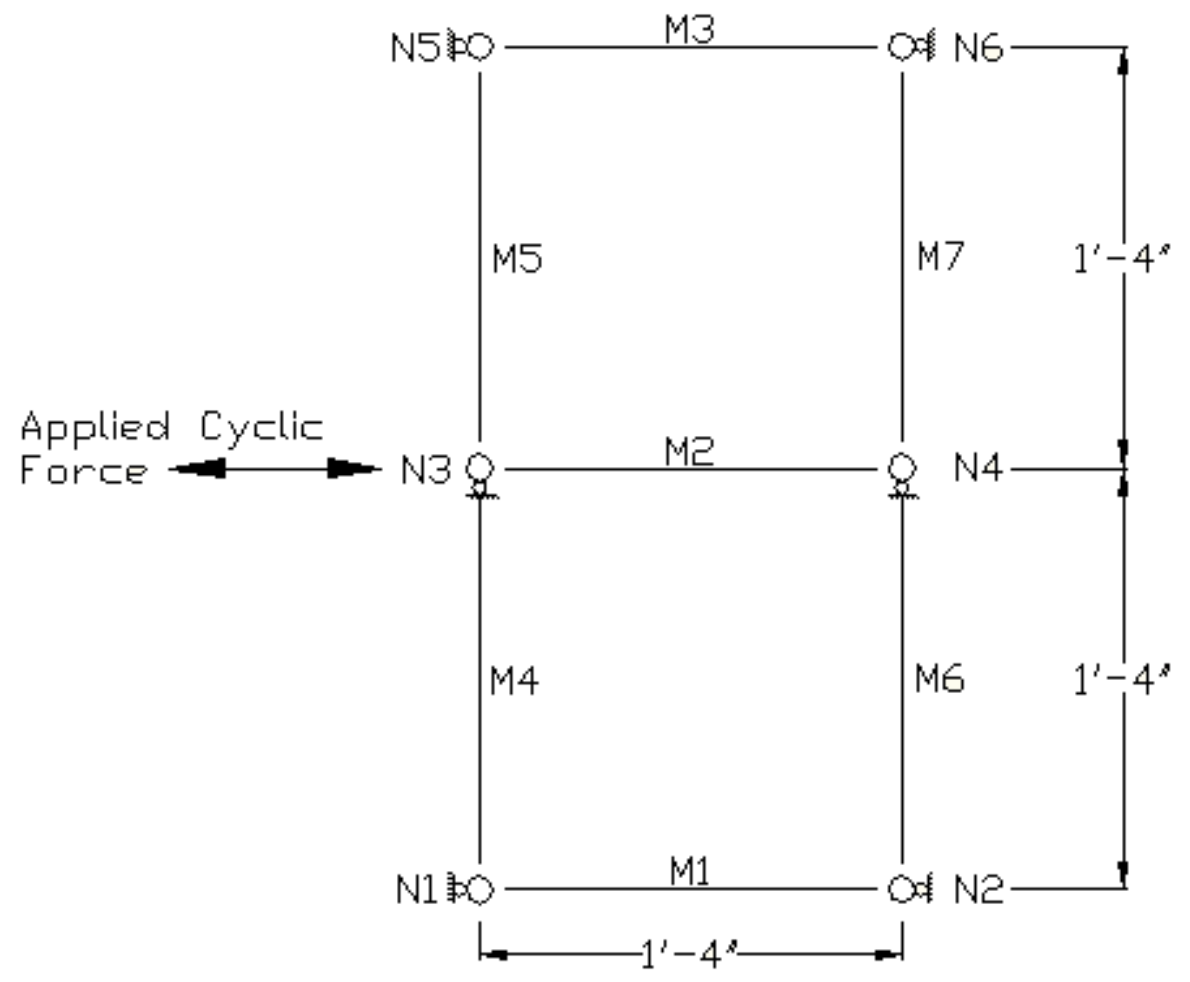

Figure 41: Nodes, members, and supports of Apex model 
Next, the material properties were defined, in which steel and concrete were chosen along with various specific parameters such as compressive strength, yield and fracture stresses, and moduli of elasticity. The general shape of the steel material used is illustrated in
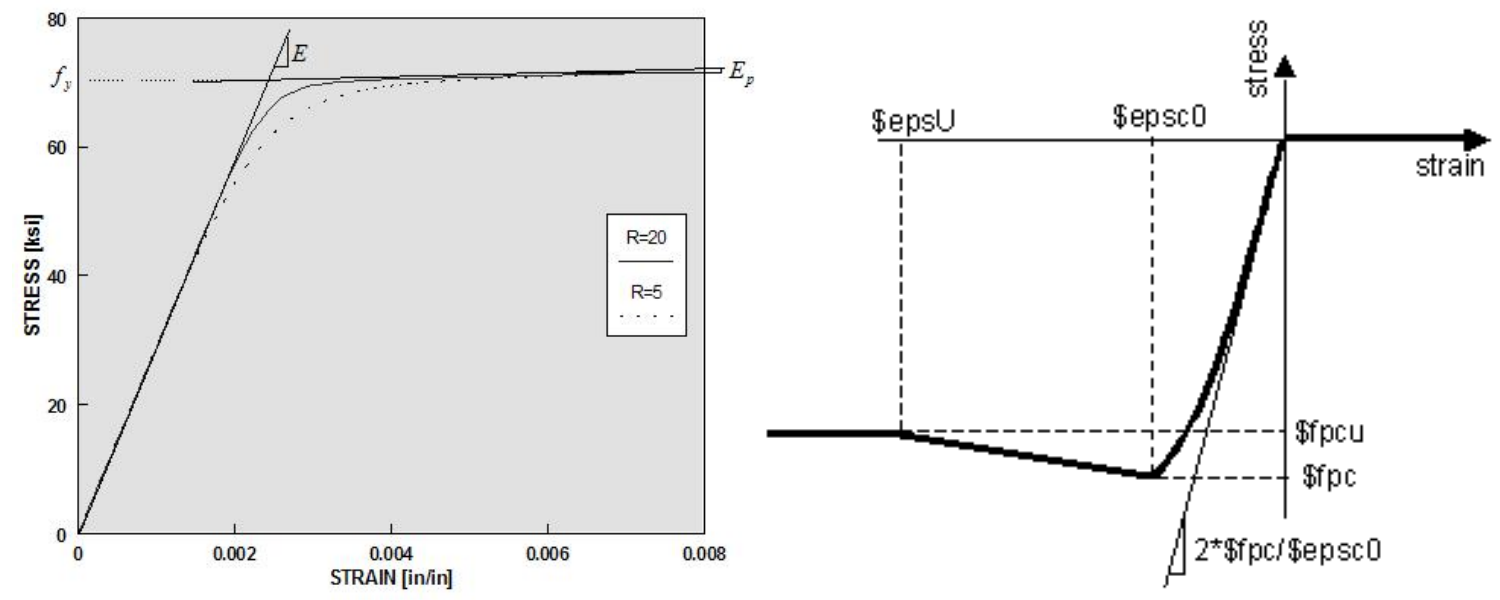

Figure 42: stress-strain diagram of OpenSees materials "stee102" (left), and "concrete01" (right)

Next, the geometry of a typical cross-section of each member was defined, which specified a six inch diameter unconfined concrete core with one centered piece of Grade 60 No.4 rebar. Finally, the connectivity of the individual core elements of the specimen were defined as having the previously defined cross sections connected to the appropriate nodal coordinates.

OpenSees treated the system as a stick model, where the interaction between members at each node was based upon member stiffness and the joint fixity, but did not take into account the confinement of material at the joint due to overlap of the members. Observations of the experimental test specimens showed that the flexural cracks that 
developed in the vertical members of interest did so away from the joint and the overlapping material of the horizontal members, as seen in Figure 43.
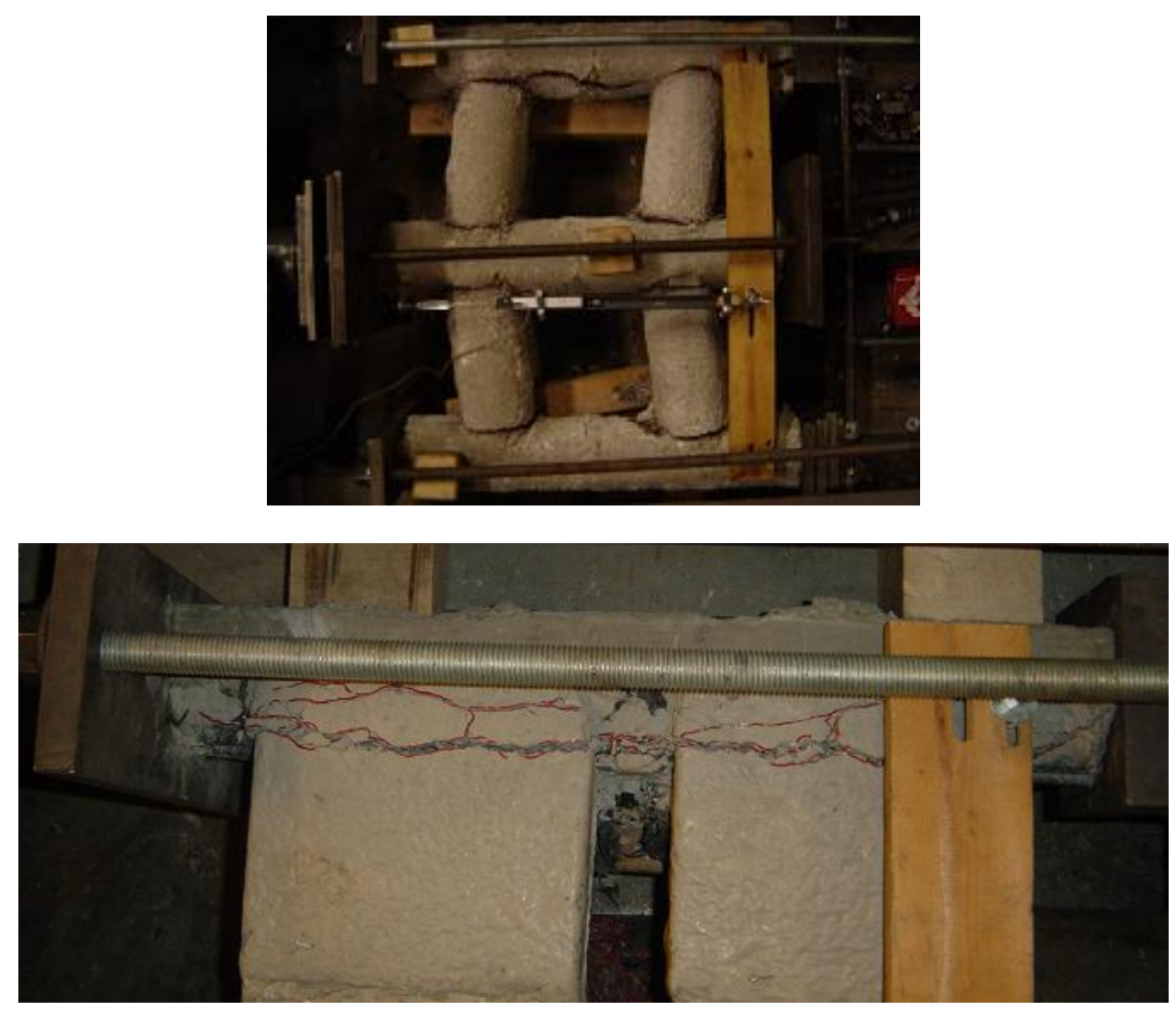

Figure 43: Crack development offset from center of joint for Apex (top) and Faswall (bottom) specimens

To account for the confinement within the joint and to force the flexural failure in the model to occur away from the joint, 3 in (for Apex) and 2 in (for Faswall) rigid offsets were specified at the end of each vertical member, which effectively eliminated any damage to the concrete within the joint.

While the use of joint offsets was deemed as the most physically accurate representation of the Faswall and Apex systems, each model was also run and analyzed as the basic stick model without any rigid joint offsets. The results, as seen in Appendix 
A, are notable for their results which are more similar to those of the experimental results than the joint-offset models.

To perform the in-plane cyclic analysis, another script was generated for instructing OpenSees to follow a drift-controlled cyclic loading program identical to that used in the experimental test program. First, data output files were specified for recording forces, deflections, drift ratio, support reactions, and stress and strain at particular locations. Next, the node to which the load was be applied was defined along with a vector that specified the drift ratio limits of each cycle. The number of cycles at each drift level was also defined, as well as the increment between consecutive steps of drift ratio within each cycle ( $0.001 \%$ drift, for instance). For each incremental step in displacement the support reactions, stresses, strains, and rotations were recorded and written to an appropriate digital data file.

Appendix B presents examples of the Apex and Faswall model scripts that were used to generate the data for the typically reinforced small scale specimens. Appendix B also includes scripts used in Matlab to extract and plot relevant data from the files output from OpenSees.

Once a working script was generated for a simple case, the script was easily adapted to a larger, more robust case. For instance, modeling a system identical to the previously reported small scale Apex ICF grid specimen was a simple six-node affair. Once that simulation was run successfully and the results deemed reasonable, modeling a full scale wall was only a matter of specifying additional nodal coordinates, connectivity, fixity, load location, and load direction. As such, modeling the small scale specimens 
from this experiment as well as the full scale walls tested by Dusicka and Kay should have resulted in some indication of the accuracy of the software to simulate peak in-plane force resistance, rate of strength degradation, and drift capacity.

Some limitations of the software include OpenSees' ability to only simulate the flexural nature of a system only, which necessitates a separate calculation of the shear capacity. While OpenSees tracks damage such as spalling of concrete in a model, OpenSees may not be able to simulate spalling of cover concrete followed by the buckling of reinforcing steel. As will be shown, the inability to track some types of damage and not others will call into question the accuracy of the models. Additionally, OpenSees does not provide material definitions for EPS foam or cementitiously-bonded wood chips, so including the ICF form material in the simulation proves difficult. As such, the simulated hystereses that follow are meant to model specimens with the ICF form material removed, and are, with two exceptions, compared to the experimental results of similarly configured test specimens.

\subsection{1: Modeling of Apex Block Small Scale Systems}

Several configurations of the Apex block systems were modeled for comparison to the physical subjects tested previously. The first run of Apex block small scale specimens, with 4000 psi concrete and 63 ksi reinforcing bars (as noted in the figures' captions) were modeled with their various reinforcement configurations. The second run

of Apex small scale systems were modeled as well, but with 7000 psi concrete and $68 \mathrm{ksi}$ 
steel. In either case, the ECC concrete, spiral wire reinforcement, and mesh wire reinforcement were simulated by using OpenSees default values for well-confined "core" concrete. All other specimens used default values for unconfined "cover" concrete, as shown previously.

Table 6 summarizes the results from the hysteresis obtained from the models, again with respect to the peak force $\left(\mathrm{P}_{\max }\right)$ and the drift ratio at which the force resistance has degraded by $20 \%\left(\mathrm{D}_{20}\right)$ from $\mathrm{P}_{\max }$. Table 7 shows the percent increase or decrease of the model's results with respect to the experimental results. An immediately evident shortcoming of the model is the absence of a well-defined point of failure that was seen in the physical experiments. The models were run to $10 \%$ drift ratios, and showed none of the substantial strength degradation seen in the physical tests following a total failure of one of the cores in a specimen.

\begin{tabular}{|c|c|c|c|c|c|c|c|}
\hline \multirow{2}{*}{ Specimen } & \multicolumn{2}{|c|}{$\mathbf{P}_{\text {max }}$, kip } & \multicolumn{2}{|c|}{$\mathrm{D}_{20}, \%$} & \multirow{2}{*}{$D_{\text {fail, }} \%$} & \multicolumn{2}{|c|}{ Max Drift $\left(D_{\text {end }}\right) \%$} \\
\hline & Forward & Reverse & Forward & Reverse & & Forward & Reverse \\
\hline A11R & 31.8 & 29.2 & $1.70 \%$ & $2.30 \%$ & $\mathrm{n} / \mathrm{a}$ & $10.0 \%$ & $10.0 \%$ \\
\hline $\mathrm{A} 12 \mathrm{R}$ & 50.1 & 49.2 & $0.85 \%$ & $1.00 \%$ & $\mathrm{n} / \mathrm{a}$ & $10.0 \%$ & $10.0 \%$ \\
\hline A13R & 88 & 87.5 & $\mathrm{n} / \mathrm{a}$ & $\mathrm{n} / \mathrm{a}$ & $\mathrm{n} / \mathrm{a}$ & $10.0 \%$ & $10.0 \%$ \\
\hline A14R & 34.7 & 31.2 & $3.20 \%$ & $5.10 \%$ & $\mathrm{n} / \mathrm{a}$ & $10.0 \%$ & $10.0 \%$ \\
\hline$A 21 R$ & 39.1 & 34.1 & $3.10 \%$ & $\mathrm{n} / \mathrm{a}$ & $\mathrm{n} / \mathrm{a}$ & $10.0 \%$ & $10.0 \%$ \\
\hline $\begin{array}{l}A 25 R / A 31 R \\
/ A 35 R\end{array}$ & 43.3 & 38.8 & $\mathrm{n} / \mathrm{a}$ & $\mathrm{n} / \mathrm{a}$ & $\mathrm{n} / \mathrm{a}$ & $10.0 \%$ & $10.0 \%$ \\
\hline
\end{tabular}

Table 6: OpenSees model results of Apex small scale specimens 


\begin{tabular}{|c|c|c|c|c|c|c|c|}
\hline \multirow{2}{*}{ Specimen } & \multicolumn{2}{|c|}{$P_{\text {max }}$, kip } & \multicolumn{2}{|c|}{$\mathrm{D}_{20}, \%$} & \multirow{2}{*}{$D_{\text {fail, }} \%$} & \multicolumn{2}{|c|}{ Max Drift $\left(D_{\text {end }}\right) \%$} \\
\hline & Forward & Reverse & Forward & Reverse & & Forward & Reverse \\
\hline $\mathrm{A} 11 \mathrm{R}$ & $43 \%$ & $134 \%$ & $-1 \%$ & $23 \%$ & $\mathrm{n} / \mathrm{a}$ & $371 \%$ & $321 \%$ \\
\hline $\mathrm{A} 12 \mathrm{R}$ & $9 \%$ & $70 \%$ & $-15 \%$ & $-50 \%$ & $\mathrm{n} / \mathrm{a}$ & $43 \%$ & $\mathrm{n} / \mathrm{a}$ \\
\hline A13R & $91 \%$ & $150 \%$ & $\mathrm{n} / \mathrm{a}$ & $\mathrm{n} / \mathrm{a}$ & $\mathrm{n} / \mathrm{a}$ & $43 \%$ & $43 \%$ \\
\hline A14R & $26 \%$ & $78 \%$ & $-3 \%$ & $-2 \%$ & $\mathrm{n} / \mathrm{a}$ & $43 \%$ & $43 \%$ \\
\hline$A 21 R$ & $29 \%$ & $97 \%$ & $11 \%$ & $\mathrm{n} / \mathrm{a}$ & $\mathrm{n} / \mathrm{a}$ & $108 \%$ & $108 \%$ \\
\hline $\begin{array}{l}\text { A25R / A31R } \\
/ A 35 R\end{array}$ & $34 \%$ & $63 \%$ & $\mathrm{n} / \mathrm{a}$ & $\mathrm{n} / \mathrm{a}$ & $\mathrm{n} / \mathrm{a}$ & $12 \%$ & $12 \%$ \\
\hline
\end{tabular}

Table 7: Percent increase or decrease of Apex model results over experimental results

The basic configuration, in which the Apex cores each contained one length of No. 4 rebar, is shown in Figure 44 . The model simulated $\mathrm{f}_{\mathrm{c}}=4 \mathrm{ksi}$ concrete and $\mathrm{f}_{\mathrm{y}}=63 \mathrm{ksi}$ steel. The OpenSees model results in Figure 44a showed increased $\mathrm{P}_{\max }$ values at a drift ratio similar to the experimental results (Figure 44b). The model's $\mathrm{P}_{\max }$ was approximately $25 \%$ greater than the hand calculations strength of 24 kip described previously, indicating that the calculation is most likely inadequate. The model's $\mathrm{D}_{20}$ benchmark of approximately $2 \%$ was within the range of $1.5 \%$ to $2.5 \%$ observed experimentally. The OpenSees model gave no indication of any core failure

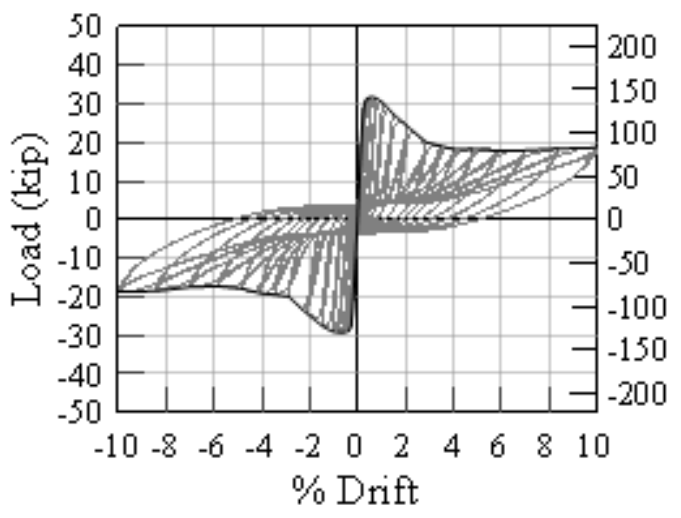

(a)

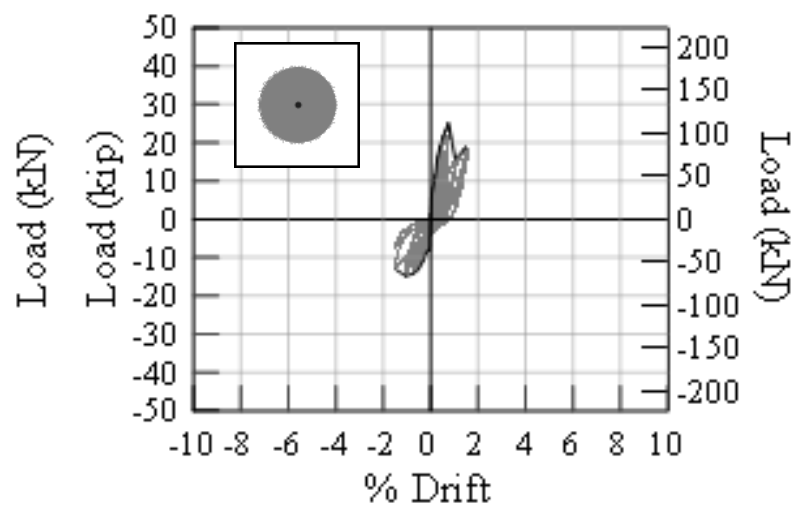

(b)

Figure 44: Apex small scale specimen A11R (4 ksi, 63 ksi): (a) model, (b) experimental result. 
that may occur, and thus $10 \%$ drift was readily_-if unrealistically_achieved in the model.

Generally, the models did not predict the behavior that was observed experimentally. $\mathrm{P}_{\max }$ was consistently overestimated, and the rate of reduction of strength was unreliable. Therefore this discussion is abbreviated as little useful information comes from comparing each model to the appropriate experimental result. The figures below illustrate the results of model versus the experimental results. One notable result was that the confined model of Figure 49(a) showed less degradation of strength after peaking, similarly to the observed experimental result of confined specimens. Also notable was rapid strength degradation predicted by the model of Figure 46, representing the dually reinforced (centered) Apex specimen. The model of the other dual reinforcement, with the rebar located near the edges of each core, as shown in Figure 47, shows increasing strength over the course of the test. Experimentally, that specimen's concrete spalled quickly and the rebar collapsed. OpenSees apparently cannot account for reinforcement buckling. 


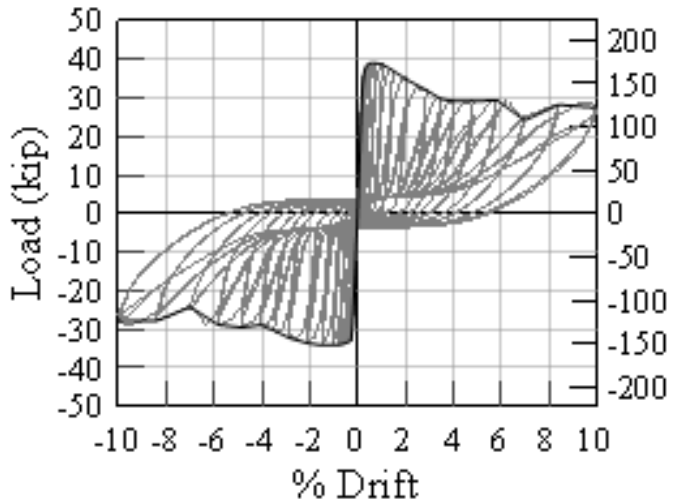

(a)

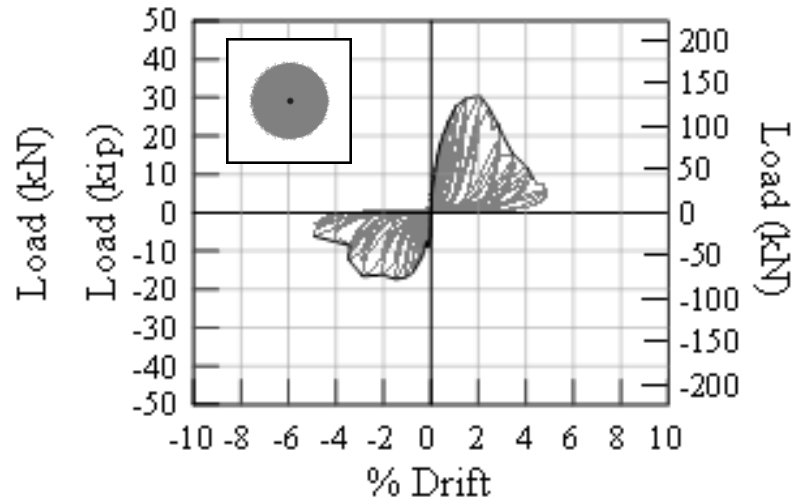

(b)

Figure 45: Apex small scale specimen A21R (7 ksi, 68 ksi): (a) model, (b) experimental result.

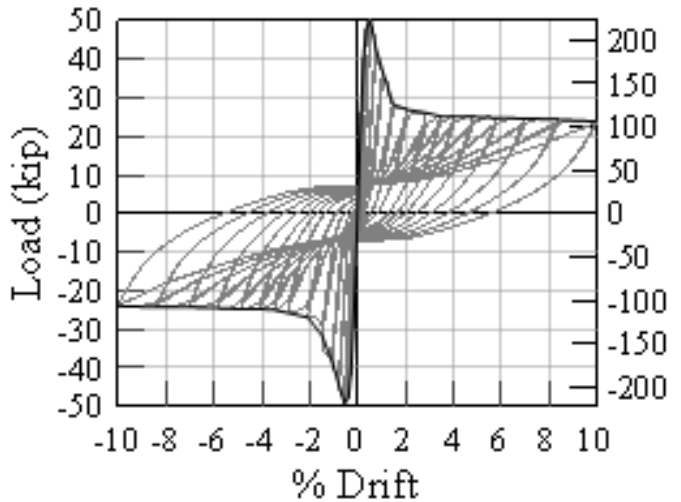

(a)

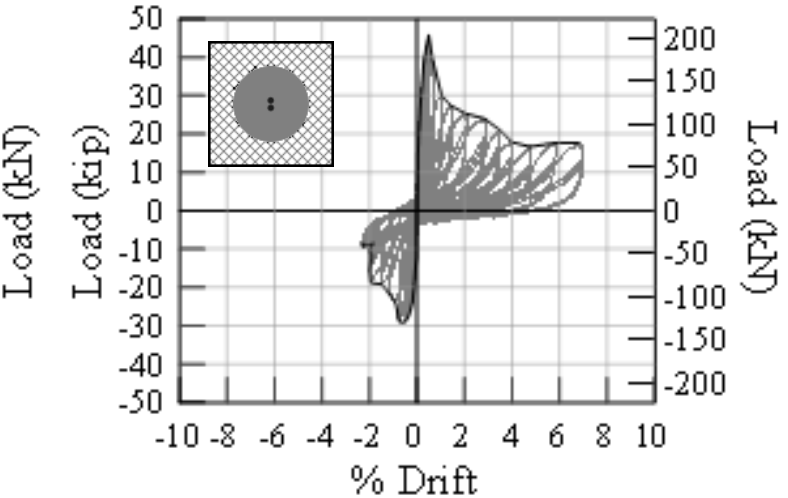

(b)

Figure 46: Apex small scale specimen A12 (4 ksi, 63 ksi): (a) model, (b) experimental result. 


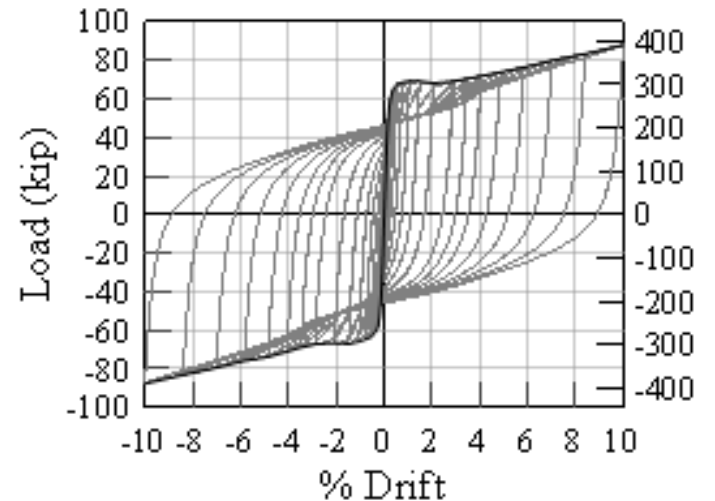

(a)

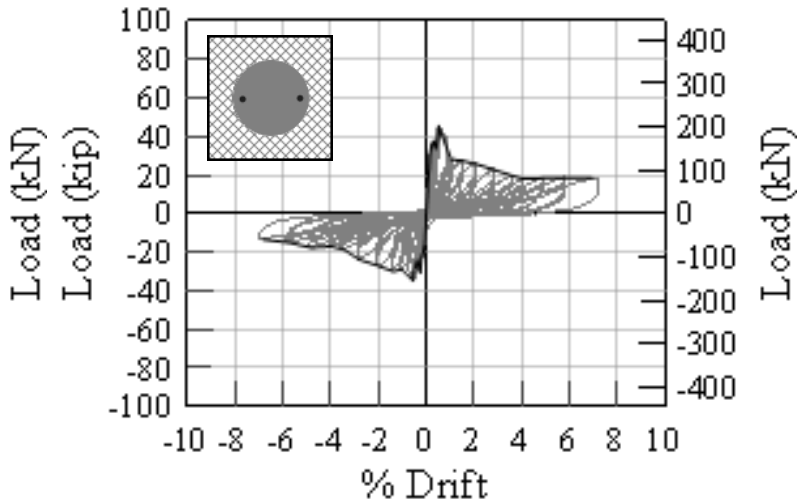

(b)

Figure 47: Apex small scale specimen A13 (4 ksi, $63 \mathrm{ksi}$ ): (a) model, (b) experimental result.

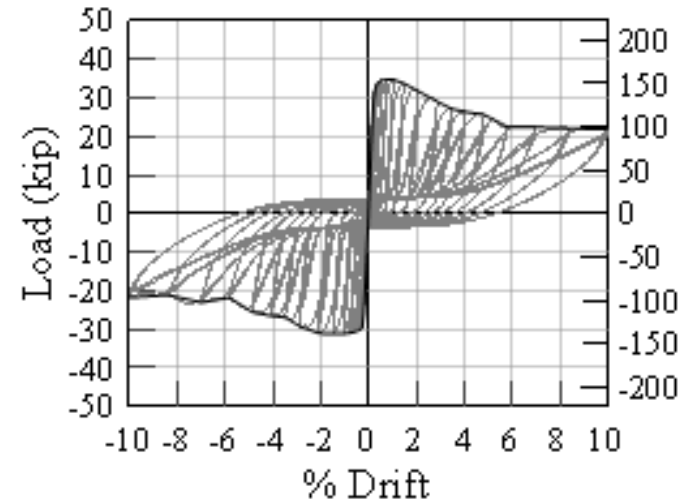

(a)

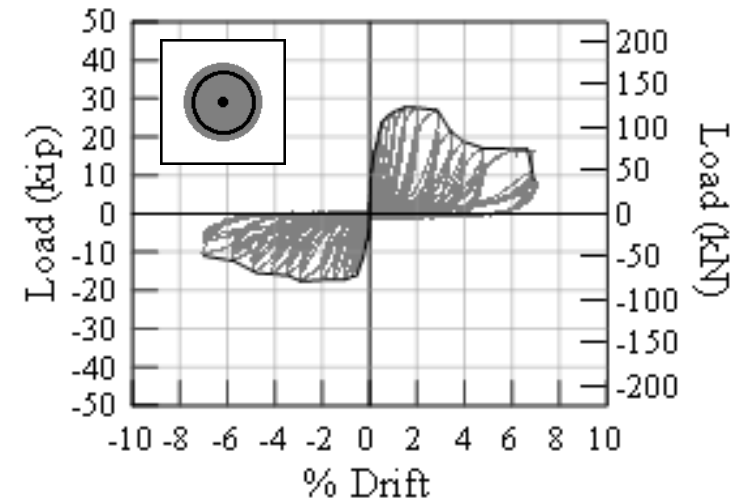

(b)

Figure 48: Apex small scale specimen A14R (4 ksi, 63 ksi): (a) model, (b) experimental result. 


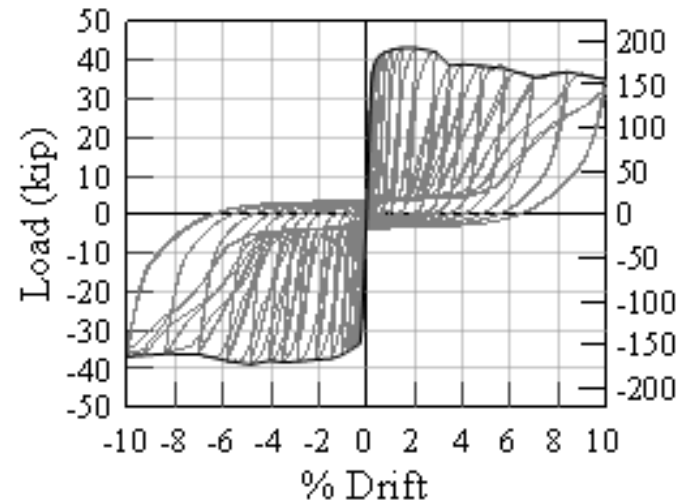

(a) confined model

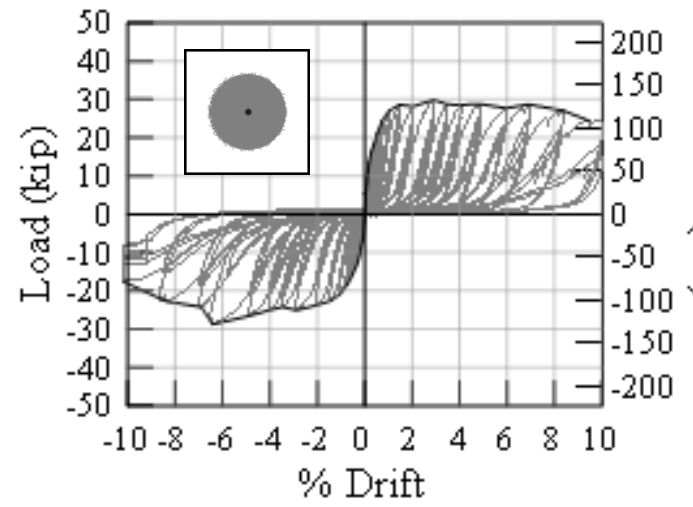

(c) A31R

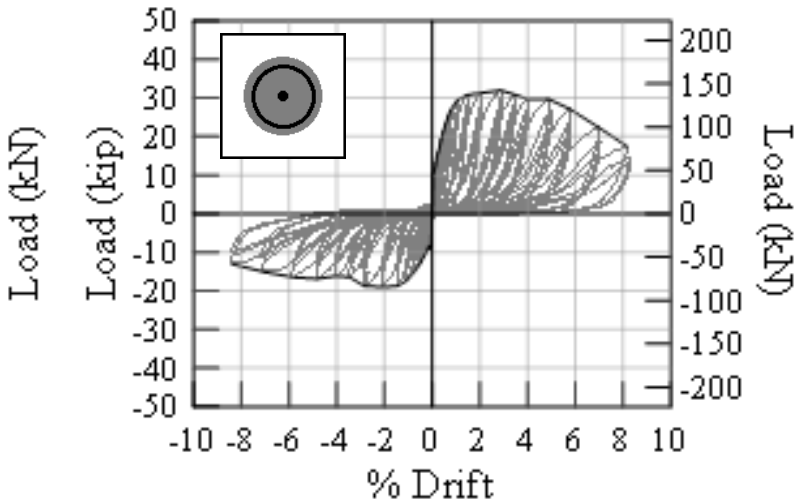

(b) A25R: mesh confinement

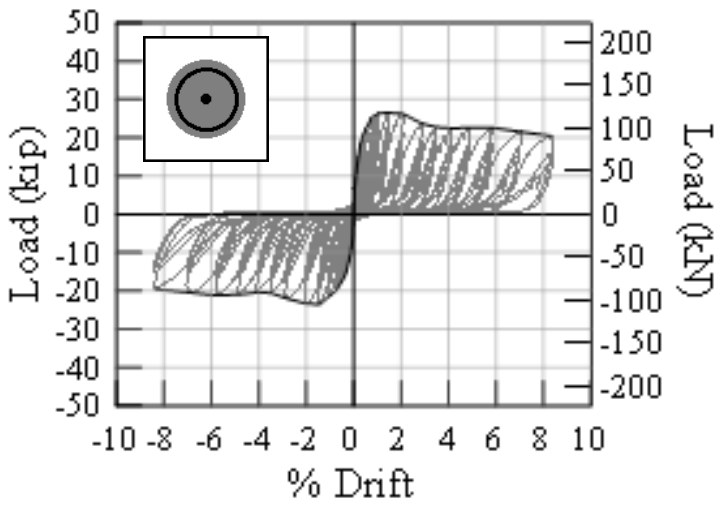

(d) A35R

Figure 49: Apex small scale confined specimens (7 ksi, 68 ksi): (a) model, (b) (c) \& (d) experimental results. 


\subsection{2: Modeling of Full Scale Apex Walls}

In addition to modeling the small scale specimens, models of the large scale walls tested by Kay and Dusicka were fairly easily constructed, merely requiring a larger nodal matrix, identical concrete and steel properties, and stating appropriate boundary conditions. As before, the collected data included drift ratios and the lateral force applied at the top of the wall. Unlike the small scale tests, additional data included the vertical reaction of each component at the footing location in order to compare to the previous hand calculations. Recall that the moment capacity of the wall is assumed to be controlled by the steel in tension; the compressive capacity of the outermost vertical core outweighs the tensile capacity of the steel in the remaining cores.

Figure 50 shows both the modeled and experimental results of the 10-ft 6-in high $\mathrm{x}$ 12-ft long wall with the form removed. In both positive and negative directions of the cycle, the model overestimates the strength by approximately $20 \%$, occurring at $0.5 \%$ drift, whereas the peak occurred near $1.5 \%$ experimentally. Again, the model does not

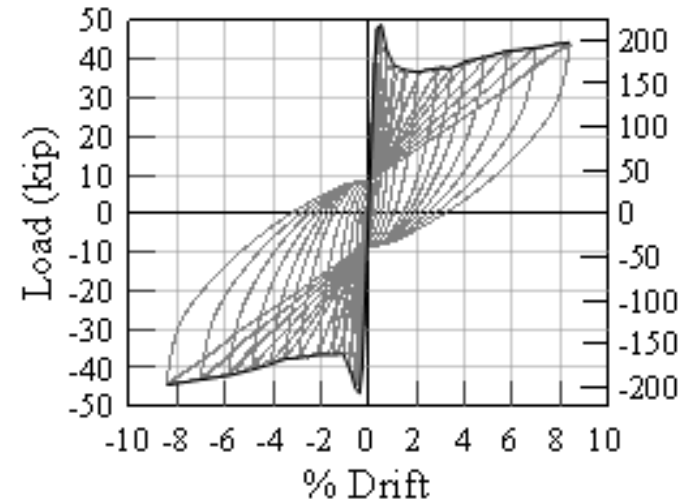

(a)

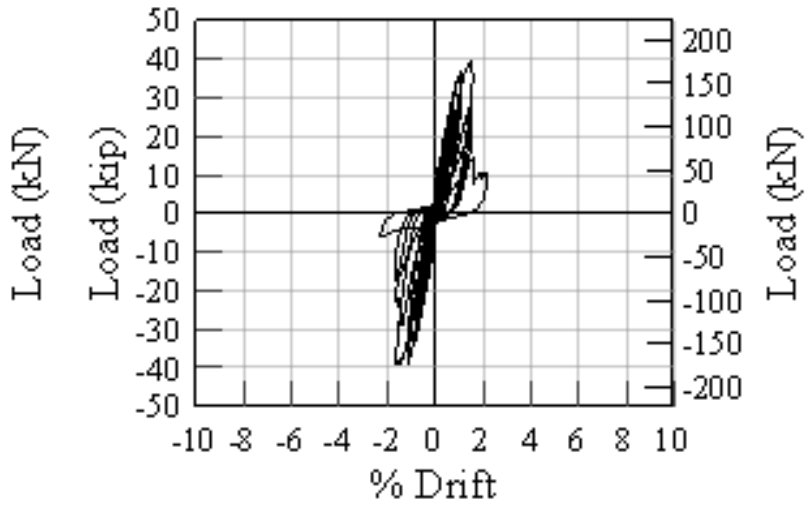

(b)

Figure 50: Apex full scale 10-ft 8-in x 12-ft wall (4.6 ksi, $60.5 \mathrm{ksi}$ ): (a) model, (b) experimental result. 
have the rapid degradation of strength that occurs following the failure of the vertical cores that precipitated the end of the experimental test. However, if $\mathrm{D}_{20}$ is the metric that suggests the structure's useful capacity, the results of the model beyond $2 \%$ drift ratio would generally be ignored. As was observed in the small scale models, this model's hysteresis loops appeared to be thicker than the experimental results, suggesting more energy dissipation than was actually observed experimentally.

As mentioned previously, the vertical reactions of each member are likely the most reliable indicator of flexural capacity, assuming that the shear capacity of concrete was adequate. Figure 51 shows the progression of the maximum axial forces in each member at select drift ratios for displacements to the right (indicated by blue bars) and to the left (indicated by red bars). The peak axial force at $0.38 \%-0.54 \%$ correlated to the peak lateral force applied in Figure 50a at the same drift ratios. A simple static analysis of the axial forces yields a coupled force of 65 kip separated by approximately 90 in. For a 128 in tall wall, this moment couple translated to a nominal lateral force of $45.7 \mathrm{kip}$, in agreement with the model's plot of force and drift. At drift ratios larger than $0.58 \%$, the compressive strength of the outer member appeared to diminish, and the adjacent interior members began to carry more of the compressive load. The total compressive load capacity of the system was decreased, as was the length of the couple, thus decreasing the wall's capacity for lateral force resistance at drift ratios over $0.58 \%$. The experimental results show a peak force of 40 kip occurring at approximately $1.5 \%$ drift ratio, followed by a rapid decrease of strength and overall wall failure due to the failure of concrete in individual vertical cores. 


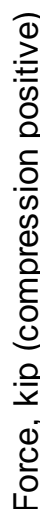

\% Drift:

0.1
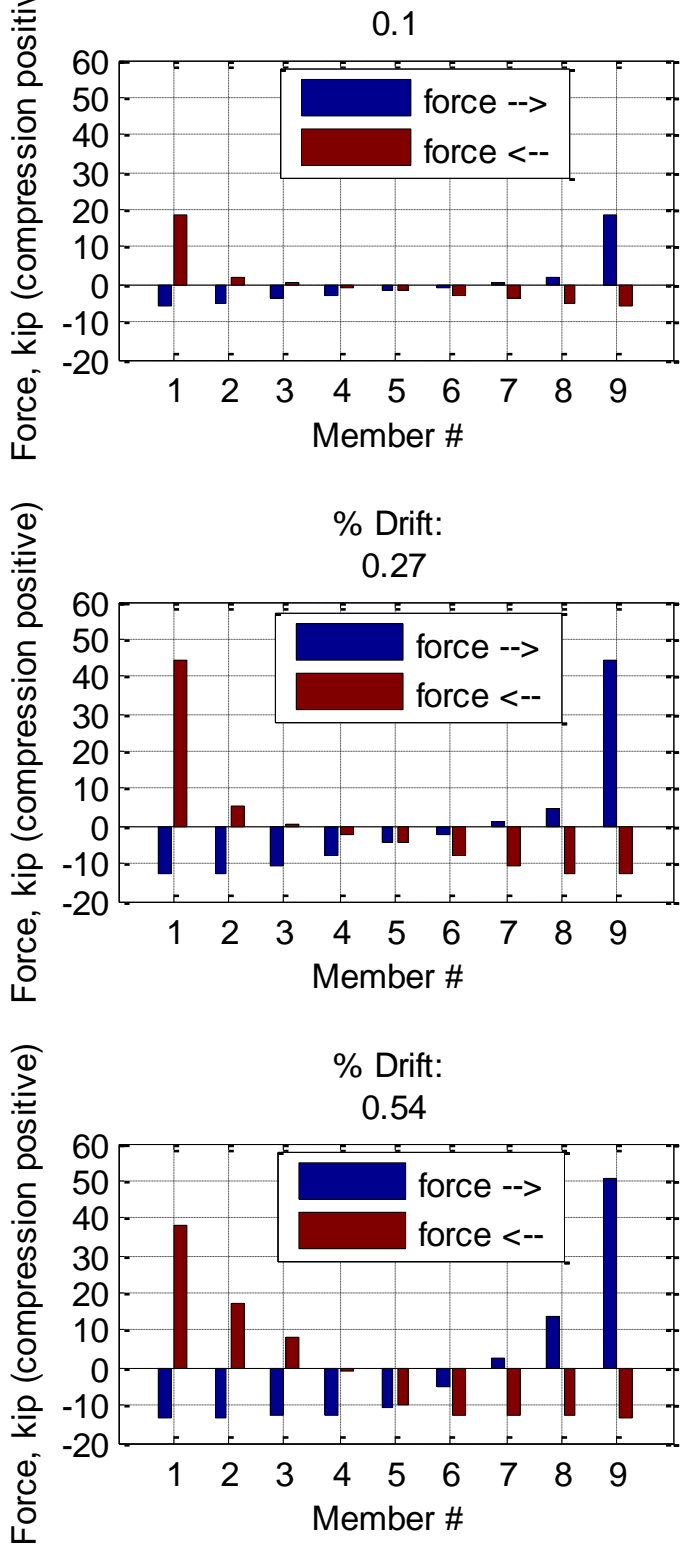
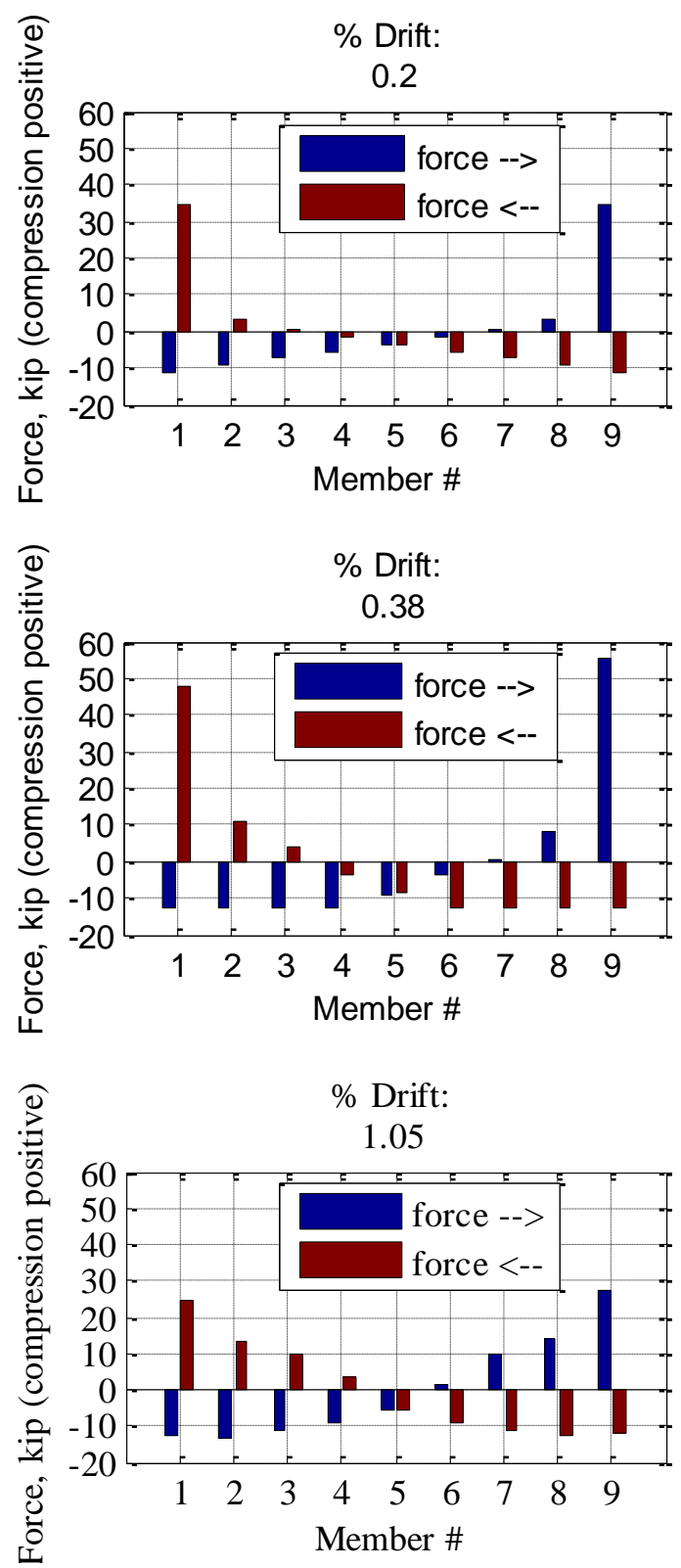

Figure 51: Peak axial loads in vertical members of 12ft Apex wall model at various drift ratios

(compression is positive)

\subsection{3: Modeling of Faswall Small Scale Specimens}

As with the Apex small scale specimen systems, the Faswall small scale specimens are also fairly easily modeled in OpenSees. The Faswall specimens are 
represented as six-node systems, restrained at the supports from lateral translation, with appropriately-sized members between the nodes. As with the Apex specimens, the model is a stick model by default, not taking into account the effect of overlap between vertical and horizontal members near the joints. Rigid joint offsets were again used in the areas of material overlap so that the damage to members occurred outside of the joint, as had been observed experimentally. Once again, with exception to the first model, OpenSees performed the cyclic loading program to the $10 \%$ drift ratio limit, not detecting any failure of the concrete or buckling of steel that was observed experimentally. In some cases, the strength of the model did not degrade to less than $80 \%$ of the observed peak, so $\mathrm{D}_{20}$ values were not recorded.

\begin{tabular}{|c|c|c|c|c|c|c|c|}
\hline \multirow[b]{2}{*}{ Specimen } & \multicolumn{2}{|c|}{$\mathbf{P}_{\max }$, kip } & \multicolumn{2}{|c|}{$D_{20}, \%$} & \multirow{2}{*}{$D_{\text {fail, }} \%$} & \multicolumn{2}{|c|}{ Max Drift $\left(D_{\text {end }}\right) \%$} \\
\hline & Forward & Reverse & Forward & Reverse & & Forward & Reverse \\
\hline F21R & 46.4 & 40.8 & $3.20 \%$ & $1.00 \%$ & $\mathrm{n} / \mathrm{a}$ & $10.0 \%$ & $10.0 \%$ \\
\hline $\mathrm{F} 22 \mathrm{R}$ & 99 & 124 & $\mathrm{n} / \mathrm{a}$ & $\mathrm{n} / \mathrm{a}$ & $\mathrm{n} / \mathrm{a}$ & $10.0 \%$ & $10.0 \%$ \\
\hline F23R & 47.2 & 40.3 & $2.90 \%$ & $0.50 \%$ & $\mathrm{n} / \mathrm{a}$ & $10.0 \%$ & $10.0 \%$ \\
\hline F31R & 48.8 & 41.2 & $\mathrm{n} / \mathrm{a}$ & $0.50 \%$ & $\mathrm{n} / \mathrm{a}$ & $10.0 \%$ & $10.0 \%$ \\
\hline F32R & 137 & 138.5 & $\mathrm{n} / \mathrm{a}$ & $\mathrm{n} / \mathrm{a}$ & $\mathrm{n} / \mathrm{a}$ & $10.0 \%$ & $10.0 \%$ \\
\hline
\end{tabular}

Table 8: Faswall small scale specimen result summary

Table 8 and Table 9 summarize the results of the model hystereses, and their comparison to the experimental results. Since many of the experimental test specimens failed in bearing or bending of the support, instead of the vertical members of interest, the experimental $\mathrm{D}_{20}, \mathrm{D}_{\text {fail }}$, and $\mathrm{D}_{\text {end }}$ benchmarks are not accurately known. However, some meaningful conclusions may still be drawn from the peak forces and the drift ratio at which they occur. 


\begin{tabular}{|l|c|c|c|c|c|c|c|}
\hline & \multicolumn{2}{|c|}{$\mathbf{P}_{\max }$, kip } & \multicolumn{2}{c|}{$\mathbf{D}_{\mathbf{2 0}}, \%$} & \multirow{2}{*}{$\mathbf{D}_{\text {fail, }} \%$} & \multicolumn{2}{c|}{ Max Drift $\left(\mathbf{D}_{\text {end }}\right) \%$} \\
Specimen & Forward & Reverse & Forward & Reverse & & Forward & Reverse \\
\hline F21R & $31 \%$ & $125 \%$ & $113 \%$ & $-59 \%$ & $\mathrm{n} / \mathrm{a}$ & $213 \%$ & $213 \%$ \\
F22R & $106 \%$ & $240 \%$ & $\mathrm{n} / \mathrm{a}$ & $\mathrm{n} / \mathrm{a}$ & $\mathrm{n} / \mathrm{a}$ & $809 \%$ & $809 \%$ \\
\hline F23R & $29 \%$ & $16 \%$ & $-3 \%$ & $-83 \%$ & $\mathrm{n} / \mathrm{a}$ & $245 \%$ & $245 \%$ \\
F31R & $25 \%$ & $127 \%$ & $\mathrm{n} / \mathrm{a}$ & $-80 \%$ & $\mathrm{n} / \mathrm{a}$ & $213 \%$ & $213 \%$ \\
F32R & $287 \%$ & $663 \%$ & $\mathrm{n} / \mathrm{a}$ & $\mathrm{n} / \mathrm{a}$ & $\mathrm{n} / \mathrm{a}$ & $213 \%$ & $213 \%$ \\
\hline
\end{tabular}

Table 9: Percent increase or decrease of Faswall model results with respect to experimental results

In the reference case of the Faswall specimen (one length of rebar per core, formwork removed, and PCC2 concrete used), as shown in Figure 52, the model once again overestimated the peak strength of the system, though more accurately predicted the drift ratio of just less than $1 \%$ at which the peak occurred. Beyond that critical drift ratio, the strength appeared to degrade similarly, albeit still at forces up to twice those observed experimentally.

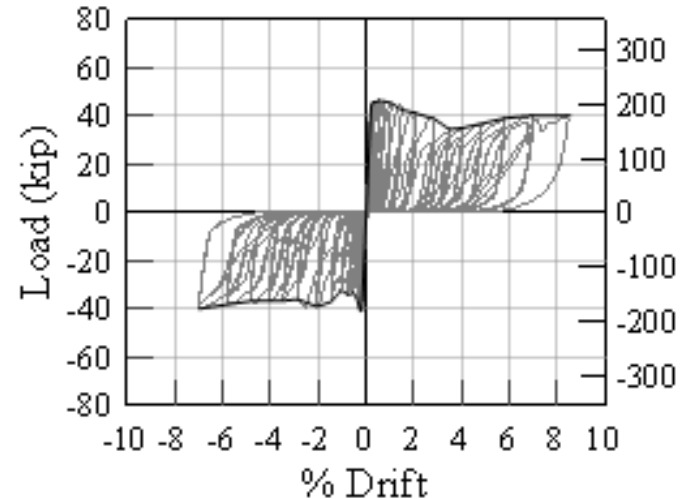

(a)

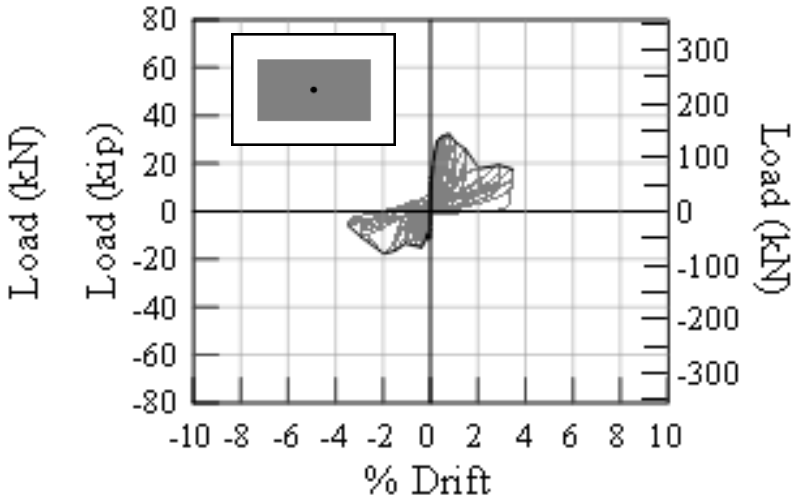

(b)

Figure 52: Faswall small scale specimen F21R: (a) model, (b) experimental result 


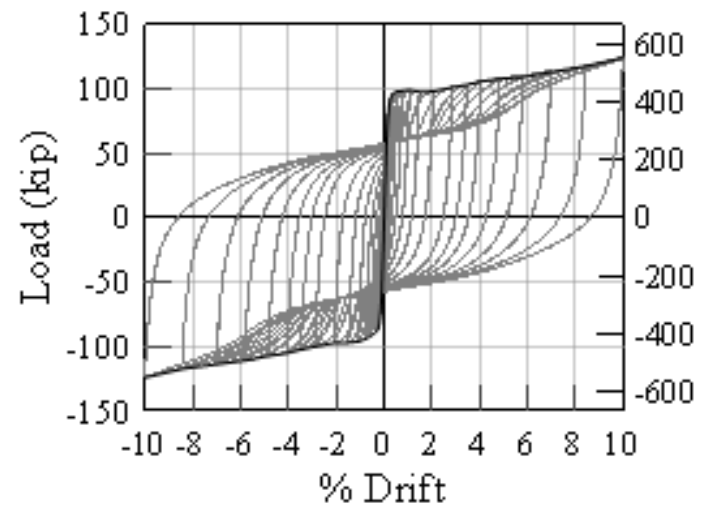

(a)

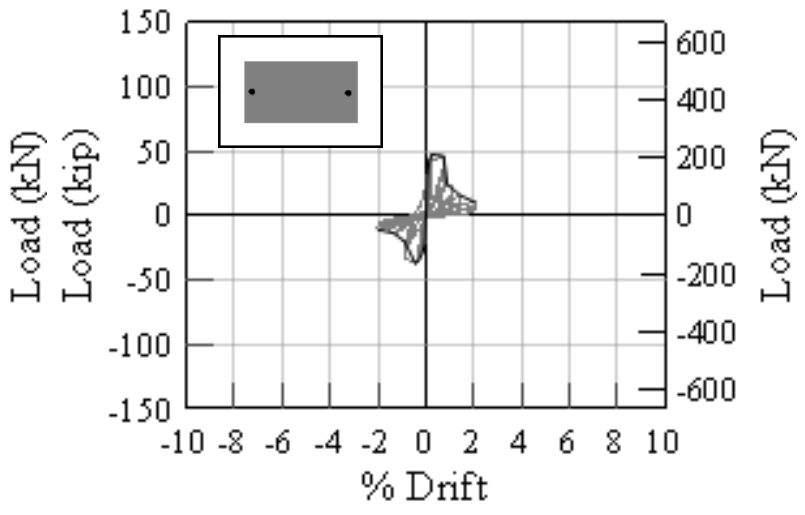

(b)

Figure 53: Faswall small specimen F22R: (a) model, (b) experimental result

When the reinforcement was doubled and moved to the outer edge of the core, an increased lateral force resistance capacity was expected due to the increased moment capacity in each core. The model bears out this expectation, as seen in Figure 53, and the hysteresis is much thicker due to the action of the reinforcement's plastic deformation during the cyclic loading. However, the physical experiment showed that the concrete cover was forced to spall long before reaching model's predicted $100 \mathrm{kip}$ of lateral force, followed by a rapid loss of strength before the test was ended at $2 \%$ drift. Again, the model was able to carry on to the imposed limit of $10 \%$ without detecting the catastrophic structural failure that is observed experimentally.

When the regularly reinforced Faswall sample used PCC2 concrete that was partially confined by the mesh wire hoops, the experimental results showed an improvement in the drift capacity. As shown in Figure 54, the peak force observed in the model was again greater than that seen experimentally by up to $30 \%$. On the positive stroke, $\mathrm{D}_{20}$ corresponds closely between model and experimental results, at $2.90 \%$ drift 
ratio. On the reverse stroke, $\mathrm{D}_{20}$ occurred at very low drift ratio - just $0.50 \%$, compared to $2.9 \%$ seen experimentally.

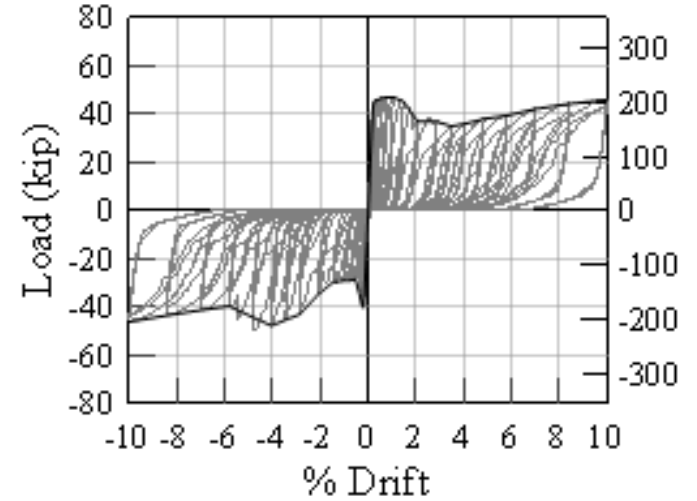

(a)

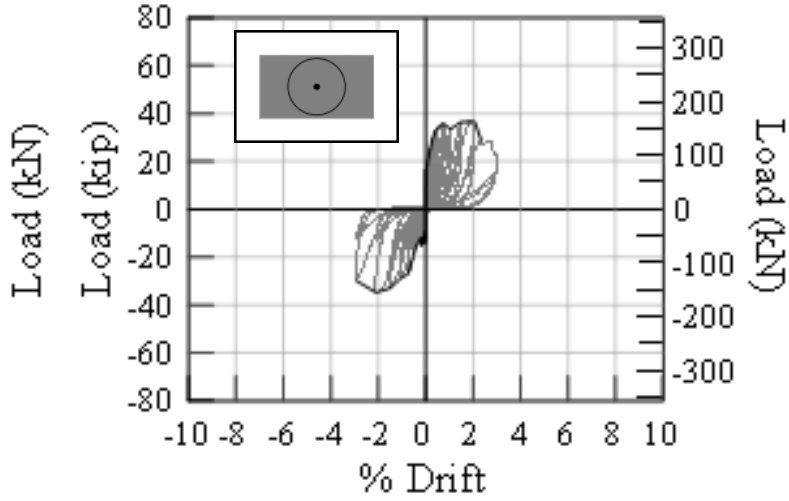

(b)

Figure 54: Faswall small scale specimen F23R: (a) model, (b) experimental result

As was found experimentally, the use of ECC concrete effectively confined the concrete in the entire cross section, in contrast to the 4.5 in diameter confined region in the previous plot. This confinement appears to have improved the drift capacity of the specimen, both in the modeled and experimental results. Figure 55 again indicates a very early peak strength in the reverse cycle, followed sharp loss of strength that results in a $\mathrm{D}_{20}$ of $0.5 \%$. 


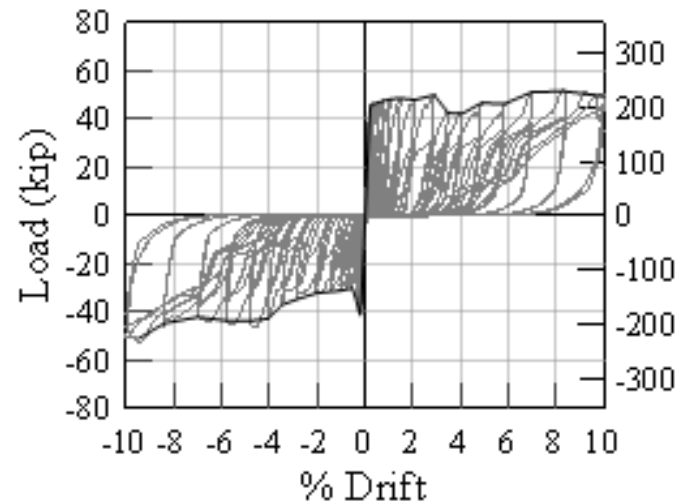

(a)

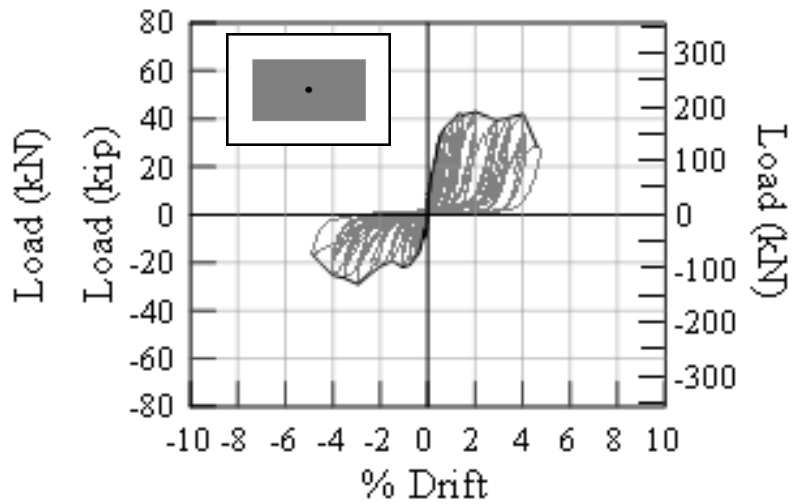

(b)

Figure 55: Faswall small scale specimen F31R (ECC): (a) model, (b) experimental result

While the peak force on the model's positive cycle was within $25 \%$ of the experimental results, the discrepancy between results in the negative cycle was again marked, with the model overestimating the strength by up to $127 \%$.

Figure 56 shows the model and experimental response of the dually reinforced Faswall specimen that used the ECC concrete. Similar to the PCC2 counterpart of Figure 53, the strength of the sample was largely due to the rebar, but ECC appeared to have a $10 \%$ increase of strength along the entire hysteresis. The model showed thick hysteresis loops that were not present in the experimental results. Again, when compared to the experimental results, a strength ceiling existed near $40 \mathrm{kip}$, after which the strength of the specimen degrades. $\mathrm{D}_{20}$ between the model and experimental results is incomparable since the model never loses strength. 


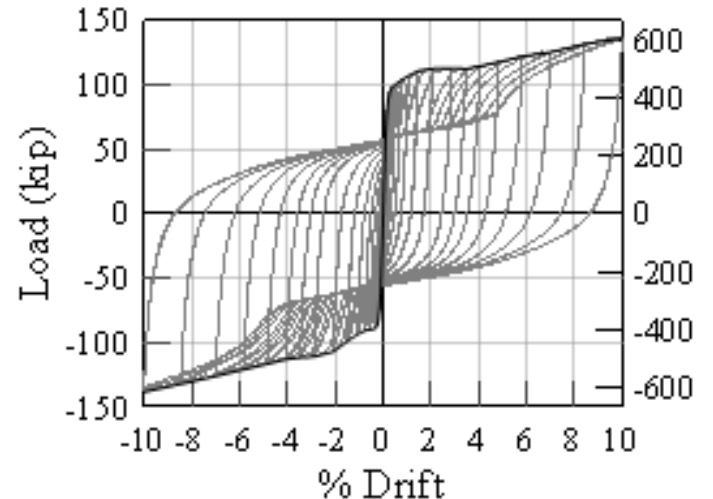

(a)

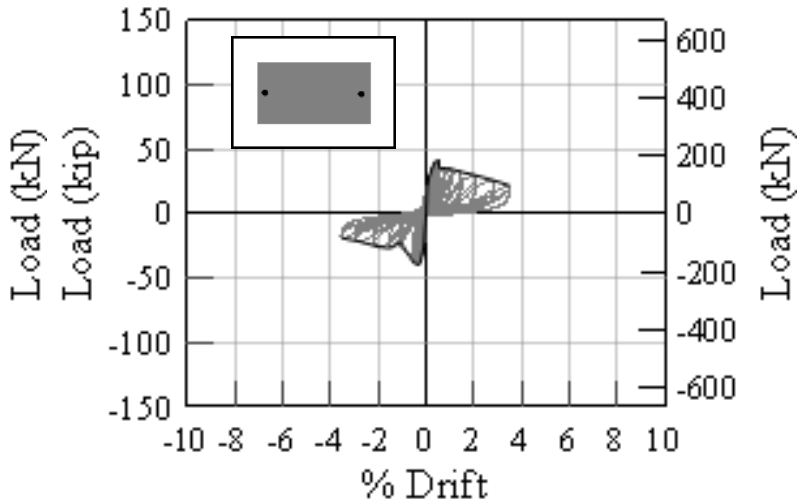

(b)

Figure 56: Faswall small scale specimen F32R (ECC): (a) model, (b) experimental result 


\section{CHAPTER 6: CONCLUSIONS \& RECOMMENDATIONS}

\section{1: Conclusions}

During the course of this ICF investigation, many of the goals were reached, yet some will require further research. In general, the determination was made that several variables affected the strength and ductility of ICF systems.

\subsection{1: Apex ICF Experimental Test Results}

When compared to test specimens tested with the ICF formwork removed, the presence of the form material tended to increase $\mathrm{P}_{\max }$ by $25-50 \%$, did not appreciably increase $\mathrm{D}_{20}$, but did delay $\mathrm{D}_{\text {fail, }}$, the drift ratio at which one core's total failure was observed.

The addition of rebar beyond the nominal single No.4 reinforcement generally led to a doubling of $\mathrm{P}_{\max }$, but $\mathrm{D}_{20}$ was decreased by up to $50 \%$ and $\mathrm{D}_{\text {fail }}$ was not improved. However, visual comparison of the hysteresis of the dually reinforced Apex specimen shows thicker hysteresis loops, which would indicate more energy dissipation and slightly better stiffness when compared to the singly reinforced specimens.

The addition of confinement in the form of spiral wires or mesh hoops tended to cause a negligible increase of $\mathrm{P}_{\max }$, but appeared to improve both $\mathrm{D}_{20}$ and $\mathrm{D}_{\text {fail }}$ substantially, in some cases by up to $250 \%$ over unconfined test specimens. 
The use of ECC concrete over PCC concrete appeared to improve $\mathrm{P}_{\max }$ only marginally, but significantly improved both $\mathrm{D}_{20}$ and $\mathrm{D}_{\text {fail }}$, a similar affect to that of the confinement provided by the inclusion of wire mesh hoops or wire spirals.

In each case where confinement was used and the drift ratio benchmarks were improved, the hystereses were still highly pinched, which indicated non-ideal energy dissipation. Additionally, the slope of the transition region between the extremes of each drift cycle is nearly horizontal; for large drift cycles, for example at $8 \%$ drift, the slope of the middle $\pm 5 \%$ drift approaches zero, meaning the system stiffness is nearly nonexistent within that range.

From the experimental results, the ceiling of the maximum force resisted by four Apex cores under cyclic loading appeared to be approximately 45 kip with form in-place, and approximately $30 \mathrm{kip}$ with the form-removed. That, despite the calculated range of values for the flexural or shear controlled strengths of 23 kip - 26 kip and 7.3 kip - 9.3 kip, respectively.

The shear force calculation was performed from ACI 318-08 equation 11-3, a conservative formula that arose empirically from a wide range of shear strength data. In the equation, ACI assumed a distance of $80 \%$ of the diameter of the section as the distance from the compression fibers to center of tension reinforcement, which is typical for common circular columns. The ICF reinforcement was typically located at half that distance. Accordingly, the approximation of shear strength in most cases was halved, and may not be applicable to a typical ICF member's cross section. 


\subsection{2: Faswall ICF Experimental Test Results}

The presence of the wood chip form material increased $\mathrm{P}_{\max }$ by $45 \%-150 \%$, but the affect upon $\mathrm{D}_{20}$ and $\mathrm{D}_{\text {fail }}$ was unknown due to premature failure of the support members when the form was in place and the forces were large.

Reinforcement placed at the edges of the Faswall cores resulted in an increased $\mathrm{P}_{\max }$, but decreased $\mathrm{D}_{20}$ and $\mathrm{D}_{\text {fail }}$ by up to $80 \%$ due to premature spalling of the concrete cover and buckling of the reinforcement.

The inclusion of mesh steel hoops appeared to increase $\mathrm{P}_{\max }$ in one case and decreased $\mathrm{P}_{\max }$ in another, making any conclusion on the effect uncertain. Due to premature support failure, comparisons of $\mathrm{D}_{20}$ and $\mathrm{D}_{\text {fail }}$ between the samples were also impossible.

When the ECC concrete was used in the specimens tested with the forms removed, $\mathrm{P}_{\max }$ was increased by up to $70 \%$ and $\mathrm{D}_{20}$ increased by $73 \%-100 \%$, when compared to the Faswall specimens made from PCC2 concrete.

The ceiling of the maximum force resisted by four Faswall cores under cyclic loading appeared to be approximately 70 kip with form in-place, and approximately 40 kip with the form removed. The calculated moment capacity of the specimens with forms removed was 39 kip, very close to the observed value. The maximum shear force, as calculated for four member using ACI 318-08 equation 3-11, was estimated to be 14.4 kip for the reference reinforcement configuration, and 26.1 kip for the dual reinforcement configuration. The estimate was lower than the observed maximum force, and may again 
be attributed to a conservative formulation of the ACI equation along with the atypical location of tension reinforcement within the member cross section when compared to a typical beam or column.

\subsection{3: Computer Model Results}

The computer model representations of the small scale specimens often overestimated the lateral strength that was shown experimentally, sometimes by $200 \%$ or more. The most egregious overestimates occurred in models that included reinforcement at the edges of the cores (A13, F22, F32). In these cases, the lateral force resistance due to flexural was unrealistically large, as the experimental tests showed that the concrete cover would spall and the rebar would buckle long before forces of the magnitude predicted by the model were allowed to develop.

For many instances of the Faswall geometry, OpenSees was unable to predict any appreciable degradation of strength, whereas the equivalent experimental test specimen results showed significant and steep strength losses, sometimes at drift ratios under $2 \%$.

When joint offsets were used in the Apex ICF models to more accurately represent the confinement of concrete within a specimen's joints, the results were less accurate than those with no joint offsets, which proved to be more accurately representative of the experimental test results.

Because the models showed unreliable correlation to experimental results, the models should not be used to predict the ICF system's lateral capacities without further development and testing. 


\section{2: Suggestions for Future Research}

\section{1.) Confinement of concrete by various means}

While the experimental investigation of this thesis sought to understand the performance characteristics of a very small ICF structure in hopes of applying those results to larger structures, still smaller components could be tested to further understand the elemental mechanics of screen grid insulated concrete forms.

Yland's investigation showed a dramatic increase in the compressive strength of EPS-confined concrete which could not be attributed to the compressive strength of the EPS alone. Those observations may have been skewed by confining a small 2 in diameter concrete cylinder within an inordinately large 6-in x 6-in form of EPS. A more accurate understanding of the confinement offered by an ICF form would arise from testing samples that use a typical cross section of concrete and ICF that would be found in a full scale wall (i.e. 2 in of cover on all sides for Faswall geometry and 10-in x 16-in form for Apex geometry).

In addition to the confinement introduced by the formwork, the effect of the mesh wire hoops, 3/16 in wire spirals, and ECC concrete should also be tested and compared to control specimens having identical concrete but no confinement. Those tests would quantify and differentiate the efficacy of each method, and perhaps indicate the superiority of one method over another with respect to performance, cost, and labor intensity. 
The incorporation of those confinement effects into a computer model may allow more accurate comparisons to between a model and the results from walls tested with the ICF forms in place.

\section{2.) Perform more full scale wall tests with forms removed}

Only one cyclic test exists for a wall tested after the EPS had been removed. Performing more tests would add to the depth of knowledge of crack propagation and failure modes of walls with different aspect ratios. These tests would preferably include ICF grid walls from a variety of manufacturers to account for differences in geometry.

\section{3.) Perform full scale wall tests with additional confinement}

The findings of the small scale specimen investigation showed that adding spiral wire, wire mesh hoops, or using ECC concrete all improved the drift ratio at which failure occurs, $\mathrm{D}_{20}$. Since the computer modeling does not appear to be reliably accurate, testing these confinement techniques in larger walls in a lab may be the only way to reliably predict the effect on the systems performance characteristics.

\section{4.) Repeat the reference small scale form-in-place Faswall specimen tests}

Consideration should also be given to altering the method for securing the test specimen to the frame - perhaps in the form of a roller bearing - so the test specimen may breathe freely with minimal resistance from friction at the supports.

New specimens should be made that retain the same vertical core reinforcement but increase the moment capacity in the horizontal support members, and use spiral wires or mesh hoops in the concrete near the bearing plates to offer confinement and prevent 
them from failing prematurely. Also, since the specimens with reinforcement located at the outer edges of each core failed prematurely due to flexural capacity in excess of shear capacity, the No.4 rebar in those samples could be replaced by No.3 in order to decrease the flexural strength, but still possibly provide improved ductility over the standard reinforcement. Confinement from mesh wire or simple ties could also be provided to prevent the reinforcement from buckling and causing premature strength degradation. The resulting hystereses should be inspected not only for improved Pmax and D20, but for less pinching, more energy dissipation, and less degradation of the system stiffness between the extents of the larger drift cycles.

\section{5.) Improve the Model Accuracy}

The OpenSees models used to predict the strength and deformation characteristics should be revisited and the various assumptions questioned. Those assumptions would include support condition fixity, use of joint offsets at the ends of each member, and the specification of confined and unconfined concrete material parameters, as well as reinforcing steel material parameters. 


\section{REFERENCES}

American Concrete Institute Building Code Requirements for Structural Concrete (ACI 318-08) and Commentary [Book]. - Farmington Hills, MI : American Concrete Institute, 2008. - ISBN 978-0-87031-264-9.

ASTM, International Standard Test Methods for Cyclic (Reversed) Load Test for Shear Resistance of Vertical Elements of the Lateral Force Resisting Systems for Buildings [Report]. - West Conshoohocken, PA : ASTM, International, 2008. - ASTM E 2126-08.

Hawkins N. and Ghosh S. Acceptance Criteria for Special Precast Concrete Structural Walls Based on Validation Testing [Journal]. - [s.1.] : PCI Journal, Sept-Oct 2004. - pp. 78-92.

ICC Evaluation Service, Inc. ES Report: Apex Block Interlocking System [Report]. September 2008.

Kay T. and Dusicka P. Reversed Cyclic Deformation Tests on Insulated Concrete Form Walls Using the APEX Blocks Interlocking System [Report]. - Portland, OR : [s.n.], 2009.

LaManna L. and Thoen C. Building With the Apex Block Interlocking System. Winchester : [s.n.], January 2007.

Li V. C. and Lepech M. General Design Assumptions for Engineered Cementitious Composites (ECC) [Conference] // International RILEM Workshop on High Performance Fiber Reinforced Cementitous Composites (HPFRCC) in Structural Applications. Honolulu, Hawaii : [s.n.], 2005. - pp. 269-277. 
Li V. C. On Engineered Cementitious Composites (ECC); A Review of the Material and its Applications [Journal] // Journal of Advanced Concrete Technology. - November 2003. - 3 : Vol. 1. - pp. 215-230.

Mehrabi A. In-Plane Lateral Load Resistance of Wall Panels in Residential Buildings [Report]. - Skokie, IL : Portland Sement Association, 2000. - PCA R\&D Serial No. 2403. NAHB Research Center, Inc. In-Plane Shear Resistance of Insulating Concrete Form Walls [Report]. - Upper Marlboro, MD : [s.n.], 2001.

Tingley D. Test Result Summary of Shelterworks Faswall Wallform Building Material Properties [Report]. - Philomath, OR : [s.n.], 2008.

Worrell E. [et al.] Carbon Dioxide Emissions from the Global Cement Industry [Journal] // Annual Review of Energy and the Environment. - 2001. - Vol. 26. - pp. 303329.

Yland C. Experimental and Analytical Studies of the Structural Performance of Innovative Structural Grid Walls (Doctoral Dissertation) [Report]. - Irvine, CA : [s.n.], 2000. 


\section{APPENDIX A: RESUlTS OF APEX ICF COMPUTER MODELS WiTHOUt JOINT OFFSETS}

As mentioned earlier, the OpenSees models included joint offsets to more accurately physically represent the small scale test specimens. However, the results of the plane stick model using no joint offsets produce quite good results despite being less rigorously representative. The results that follow are only for the Apex specimens, as the Faswall specimen models showed little difference when the offsets were removed.

\begin{tabular}{|c|c|c|c|c|c|c|c|}
\hline \multirow[b]{2}{*}{ Specimen } & \multicolumn{2}{|c|}{$P_{\text {max }}$, kip } & \multicolumn{2}{|c|}{$D_{20}, \%$} & \multirow{2}{*}{$D_{\text {fail, }} \%$} & \multicolumn{2}{|c|}{ Max Drift $\left(D_{\text {end }}\right) \%$} \\
\hline & Forward & Revere & Forward & Reverse & & Forward & Reverse \\
\hline $\mathrm{A} 11 \mathrm{R}$ & 23.2 & 20.4 & $3.10 \%$ & $4.00 \%$ & $\mathrm{n} / \mathrm{a}$ & $10.00 \%$ & $10.00 \%$ \\
\hline A12R & 31.8 & 31.5 & $1.80 \%$ & $1.90 \%$ & $\mathrm{n} / \mathrm{a}$ & $10.00 \%$ & $10.00 \%$ \\
\hline A13R & 60 & 58.5 & $\mathrm{n} / \mathrm{a}$ & $\mathrm{n} / \mathrm{a}$ & $\mathrm{n} / \mathrm{a}$ & $10.00 \%$ & $10.00 \%$ \\
\hline A14R & 25.8 & 21.6 & $5.60 \%$ & $8.50 \%$ & $\mathrm{n} / \mathrm{a}$ & $10.00 \%$ & $10.00 \%$ \\
\hline $\mathrm{A} 21 \mathrm{R}$ & 29.7 & 23.7 & $3.90 \%$ & $8.70 \%$ & $\mathrm{n} / \mathrm{a}$ & $10.00 \%$ & $10.00 \%$ \\
\hline $\begin{array}{l}\text { A25R / A31R } \\
\text { / A35R }\end{array}$ & 32.8 & 25 & $10.00 \%$ & $\mathrm{n} / \mathrm{a}$ & $\mathrm{n} / \mathrm{a}$ & $10.00 \%$ & $10.00 \%$ \\
\hline
\end{tabular}

Table A1: Summary of Apex small scale specimen model results

\begin{tabular}{|c|c|c|c|c|c|c|c|}
\hline \multirow[b]{2}{*}{ Specimen } & \multicolumn{2}{|c|}{$P_{\max }$, kip } & \multicolumn{2}{|c|}{$D_{20}, \%$} & \multirow{2}{*}{$D_{\text {fail, }} \%$} & \multicolumn{2}{|c|}{ Max Drift $\left(D_{\text {end }}\right) \%$} \\
\hline & Forward & Reverse & Forward & Reverse & & Forward & Reverse \\
\hline $\mathrm{A} 11 \mathrm{R}$ & $5 \%$ & $63 \%$ & $80 \%$ & $113 \%$ & $\mathrm{n} / \mathrm{a}$ & $371 \%$ & $321 \%$ \\
\hline $\mathrm{A} 12 \mathrm{R}$ & $-31 \%$ & $9 \%$ & $80 \%$ & $-5 \%$ & $\mathrm{n} / \mathrm{a}$ & $43 \%$ & $\mathrm{n} / \mathrm{a}$ \\
\hline $\mathrm{A} 13 \mathrm{R}$ & $30 \%$ & $67 \%$ & $\mathrm{n} / \mathrm{a}$ & $\mathrm{n} / \mathrm{a}$ & $\mathrm{n} / \mathrm{a}$ & $43 \%$ & $43 \%$ \\
\hline A14R & $-6 \%$ & $23 \%$ & $70 \%$ & $63 \%$ & $\mathrm{n} / \mathrm{a}$ & $43 \%$ & $43 \%$ \\
\hline $\mathrm{A} 21 \mathrm{R}$ & $-2 \%$ & $37 \%$ & $39 \%$ & $156 \%$ & $\mathrm{n} / \mathrm{a}$ & $108 \%$ & $108 \%$ \\
\hline $\begin{array}{l}\text { A25R / A31R } \\
\text { / A35R }\end{array}$ & $1 \%$ & $5 \%$ & $29 \%$ & $\mathrm{n} / \mathrm{a}$ & $\mathrm{n} / \mathrm{a}$ & $12 \%$ & $12 \%$ \\
\hline
\end{tabular}

Table A2: Percent increase or decrease of Apex model results over experimental results

Table A1 and Table A2 summarize the performance of various models and compare those results to the experimental results, respectively. Of specific note is the percentage difference between the model and experimental results for $\mathrm{P}_{\max }$ in the reversed 
portion of the cycle. The model predicts $\mathrm{P}_{\max }$ that are within $6 \%$ of the experimental results (note that $\mathrm{A} 12 \mathrm{R}$ and $\mathrm{A} 13 \mathrm{R}$ are modeled without forms, while the experimental results did have forms). Values of $\mathrm{D}_{20}$, while still overstated here, are closer to the experimental values than the joint-offset models. As before, the model can be computed to $10 \%$ drift without catastrophic failure, so the $\mathrm{D}_{20}$ benchmark is again useful for gauging the point where the system is considered to have failed.

The basic configuration, in which the Apex cores each contain one axial No.4 rebar, is shown in Figure 44. The model simulates concrete with $f_{c}{ }^{\prime}=4 \mathrm{ksi}$, and $\mathrm{f}_{\mathrm{y}}=63 \mathrm{ksi}$. The OpenSees model (Figure A1(a)) appears to show similar $\mathrm{P}_{\max }$ values at a drift ratio similar to the experimental results (Figure A1(b)). The model's $\mathrm{P}_{\max }$ is approximately $30 \%$ less than the hand calculations described previously, indicating that the calculation is most likely inadequate. The model's $\mathrm{D}_{20}$ benchmark, signifying a $20 \%$ degradation from $\mathrm{P}_{\max }$, is delayed to $4 \%$ drift, compared to the $1.5 \%-2.5 \%$ drift observed experimentally. The OpenSees model gives no indication of any core failure that may occur, and is thus $10 \%$ drift is readily - if not yet somewhat unrealistically-modeled. 


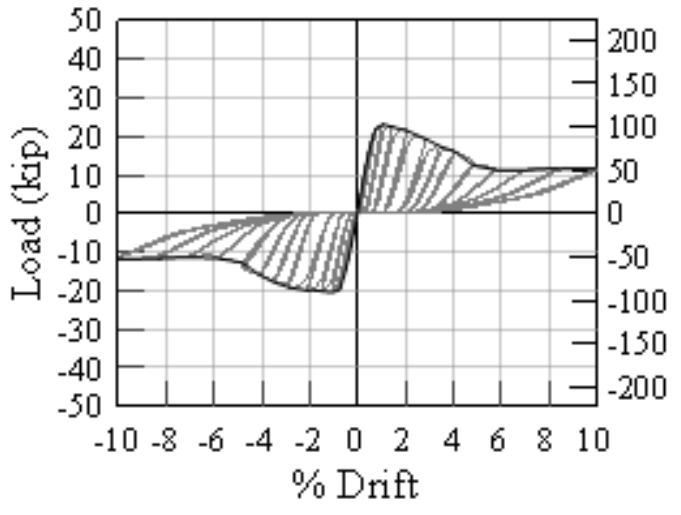

(a)

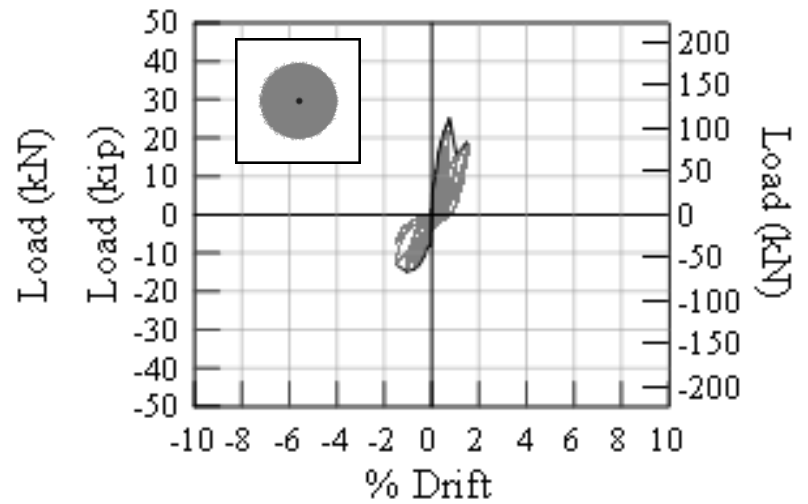

b

Figure A1: Apex small scale specimen A11R (4 ksi, 63 ksi): (a) model, (b) experimental result.

The second batch of Apex specimens also contain a unit with the basic rebar configuration, but with $\mathrm{f}_{\mathrm{c}}{ }^{\prime}=7 \mathrm{ksi}$, and $\mathrm{f}_{\mathrm{y}}=68 \mathrm{ksi}$. As shown in Figure A2(a), the model shows increased $\mathrm{P}_{\max }$ over the weaker materials of the prior model, and appears to fairly closely simulate the force and drift at $\mathrm{P}_{\max }$, especially on the positive stroke. However, the degradation of strength is much less drastic in the model, where $\mathrm{D}_{20}$ on the reverse stroke is delayed to $8.7 \%$ drift versus $3.4 \%$ experimentally. Again, the model apparently cannot predict catastrophic core failure that precedes a rapid reduction in strength.

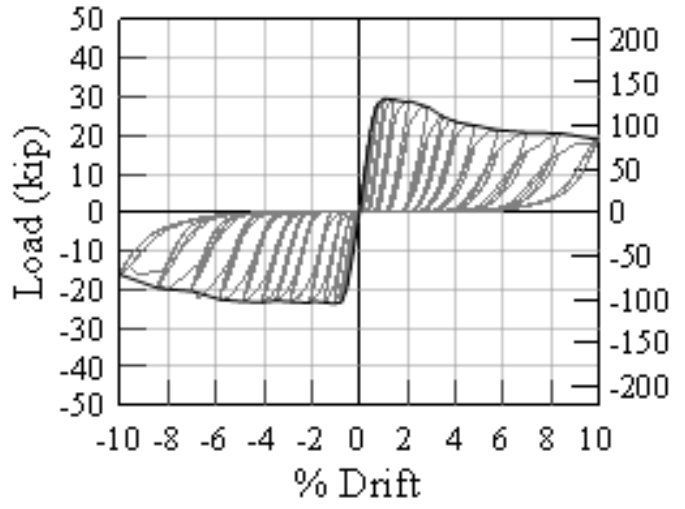

(a)

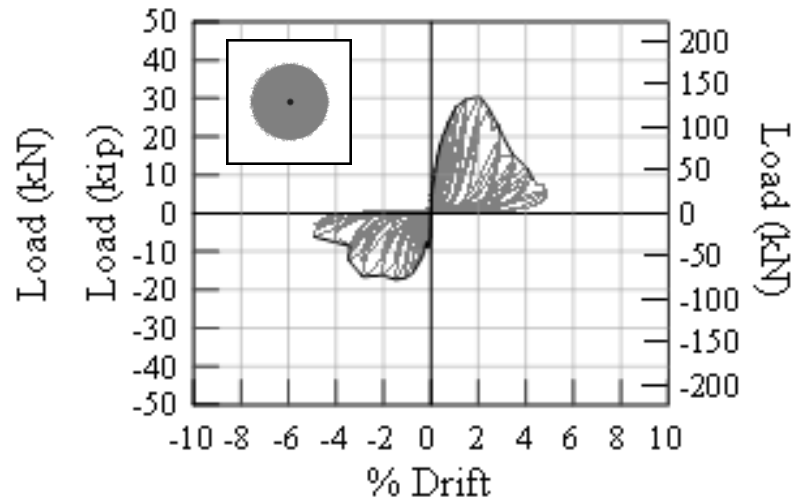

(b)

Figure A2: Apex small scale specimen A21R (7 ksi, $68 \mathrm{ksi}$ ): (a) model, (b) experimental result. 


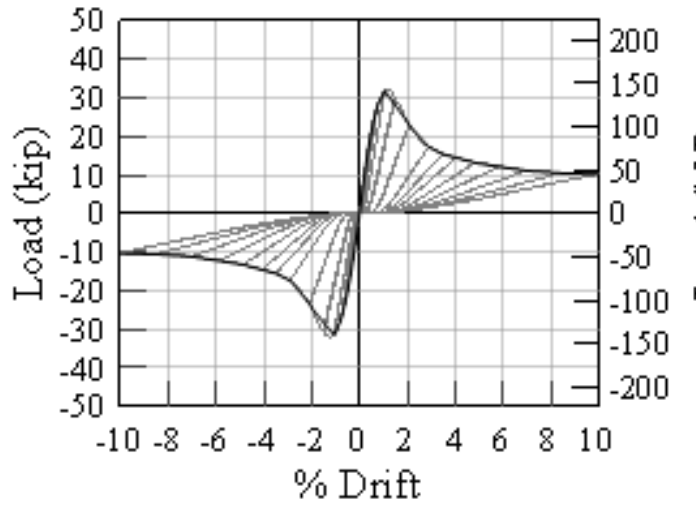

(a)

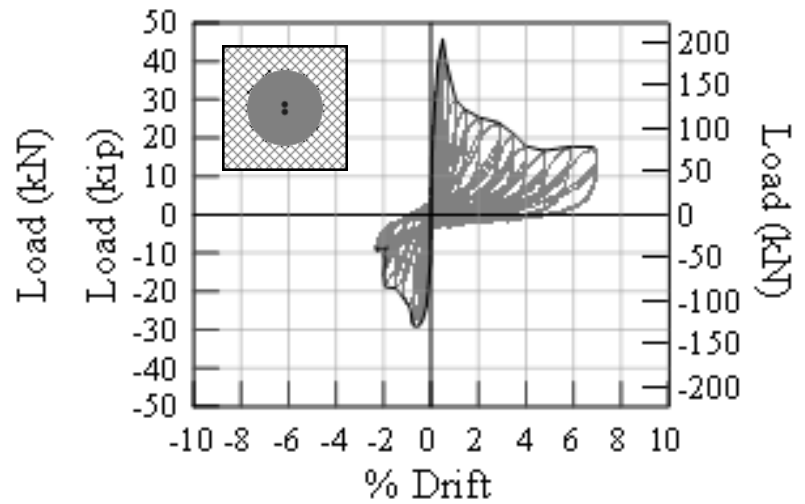

(b)

Figure A3: Apex small scale specimen A12 (4 ksi, 63 ksi): (a) model, (b) experimental result.

Figure A3 compares a model of the A12 specimen (double reinforcement centered in each vertical core) with the form removed to the experimental specimen tested with the form in place. Consistent with observations during testing, the form provides additional strength to the sample, but the high force is followed by a rapid degradation of strength. The model has notable strength degradation, but not as dramatic as seen experimentally. $\mathrm{P}_{\max }$ and $\mathrm{D}_{20}$ both occur earlier in the drift cycle experimentally than in the simulation. Both results may indicate that additional rebar does not improve the behavior of the sample, but increasing the strength of concrete, helps curb rapid strength degradation.

If the dual rebars are moved to the outer edges of the core, as in the A13 Apex specimen of Figure A4, they should create a moment couple with twice the moment capacity of the reference case, as noted above. As with the prior double reinforced system, the high early strength shown experimentally results in a rapid strength degradation thereafter. The reinforcement may be providing flexural capacity that exceeds the shear capacity of the system, thus resulting in a brittle failure that yields a 
sharp decline in strength. Observation of any such brittle failure was made impossible by the presence of the form during testing.

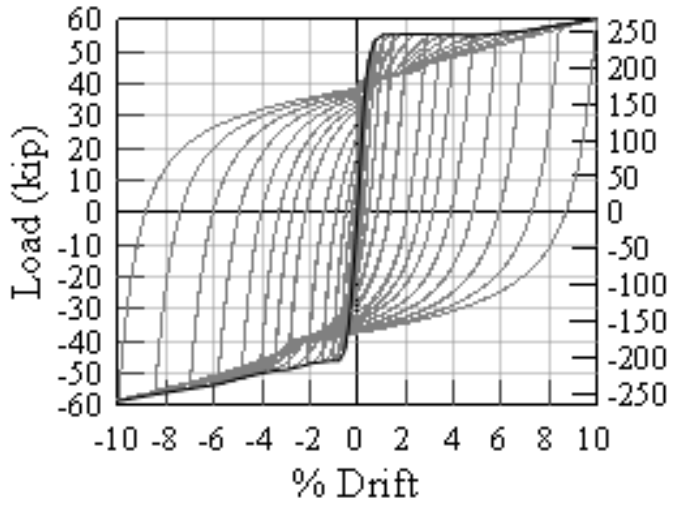

(a

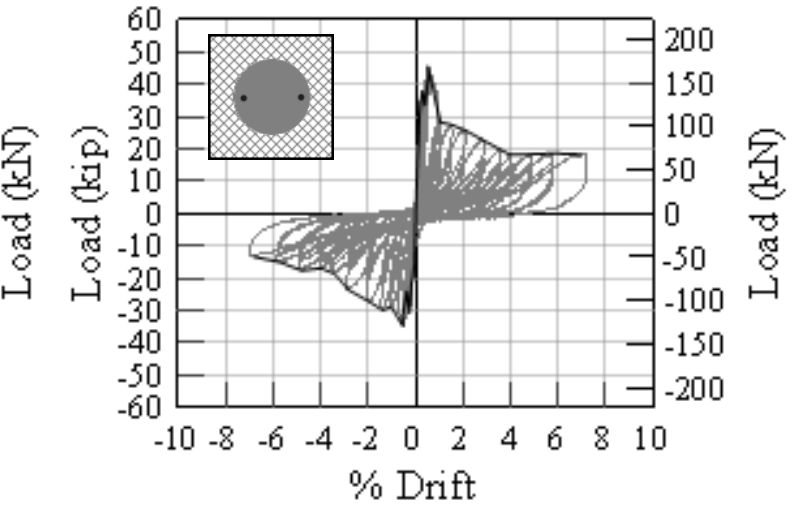

(b)

Figure A4: Apex small scale specimen A13 (4 ksi, 63 ksi): (a) model, (b) experimental result.

OpenSees does not account for shear capacity, and thus predicts an inaccurately high and sustained $\mathrm{P}_{\max }$. Also notable is the thickness of the hysteresis, indicating much higher energy dissipation during each cycle than for the single reinforced specimen, for which the hystereses are generally much more pinched.

As seen in Figure A5 and Figure A6, OpenSees simulates the confined specimens (either by spiral wire, ECC concrete, or mesh hoops) quite well, simply by defining the concrete as confined, whereas the concrete from prior specimens were all unconfined.

For the lower strength case of Figure A5, $\mathrm{P}_{\max }$ is similar in the positive and reverse stroke of the cycle, and occurs at about $1 \%$ drift in both the simulation and the experiment. On the negative stroke backbone, the strength degradation of the model is slightly slower, but the general similarity between the two is encouraging. 


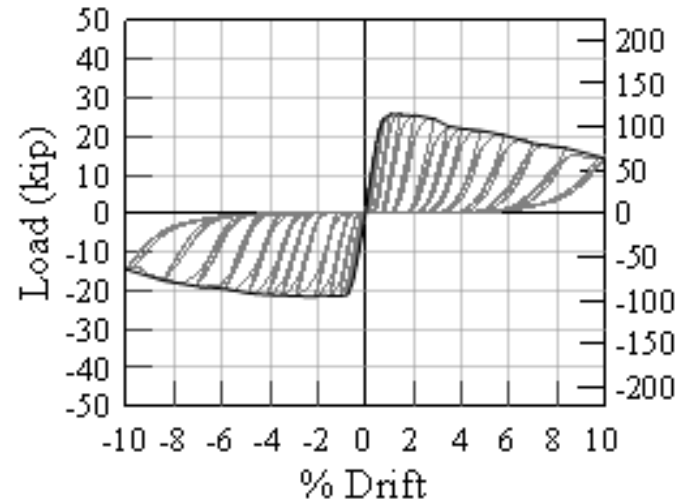

(a)

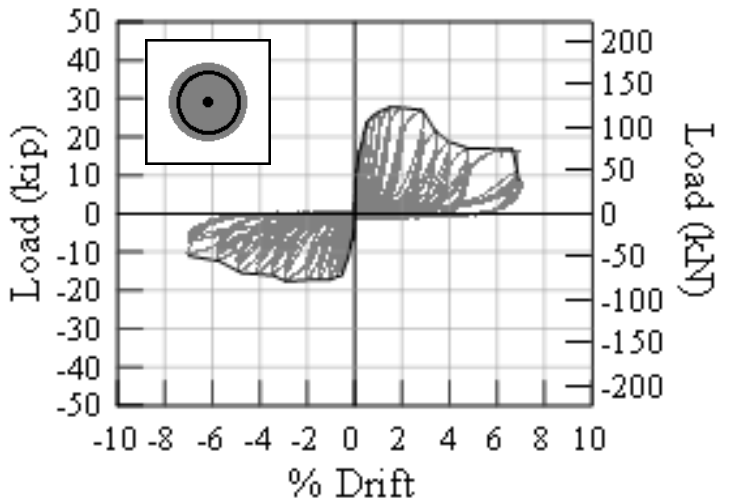

(b)

Figure A5: Apex small scale specimen A14R (4 ksi, 63 ksi): (a) model, (b) experimental result.

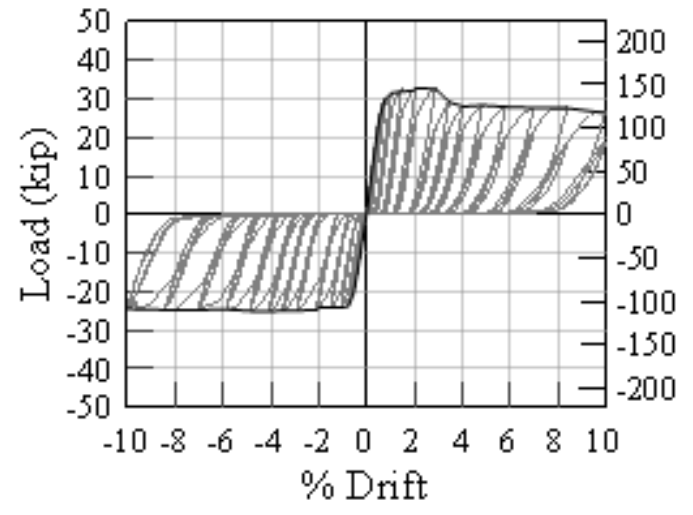

(a) confined model

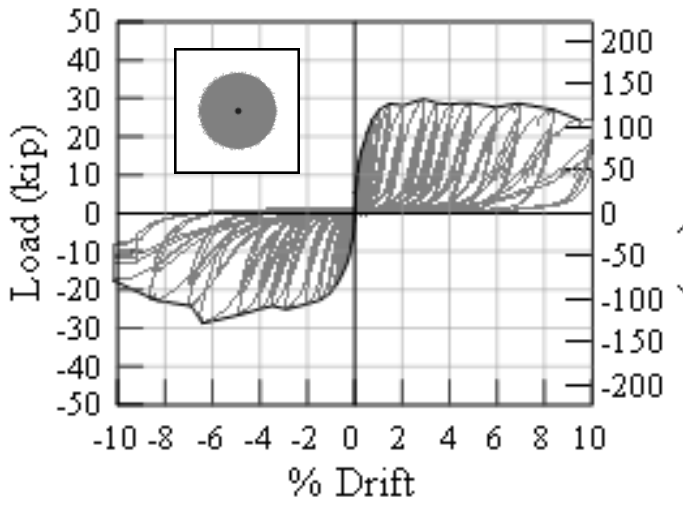

(c) A31R

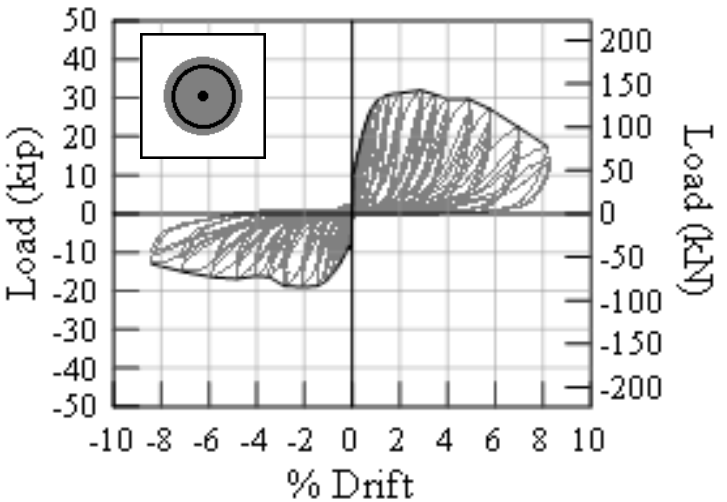

(b) A25R: mesh confinement

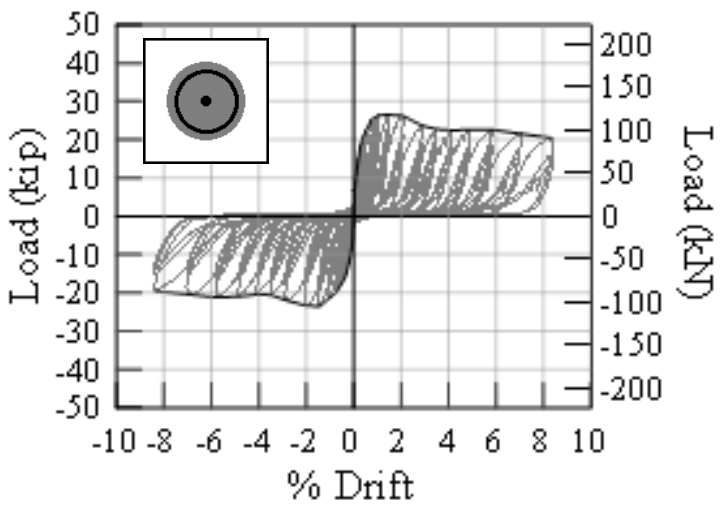

(d) A35R

Figure A6: Apex small scale specimen A25R (7 ksi, 68 ksi): (a) model, (b) (c) \& (d) experimental results. 
For the higher strength case of Figure A6, the model predicts a slower degradation of strength than for the unconfined case as well as both confined and unconfined lower strength cases. Again, the model predicts the experimental results for $\mathrm{P}_{\max }$ and $\mathrm{D}_{20}$ quite well on the negative stroke, especially for the ECC cases.

For the full scale walls that were investigated by Kay and Dusicka at PSU, the model of the 4-foot-wide predicted lower strengths than were seen experimentally, and justifiably so since the experimental results were collected with the form in place. The model showed no indication of loss of strength, whereas the real wall reached $\mathrm{D}_{20}$ and was considered failed at $4 \%$ drift. The model merely reached a plateau before the model ceased at $10 \%$ drift, as shown in Figure A7.

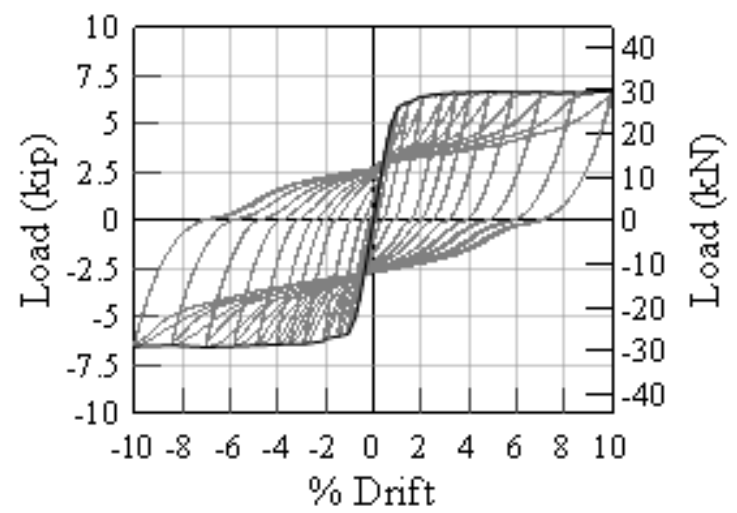

(a)

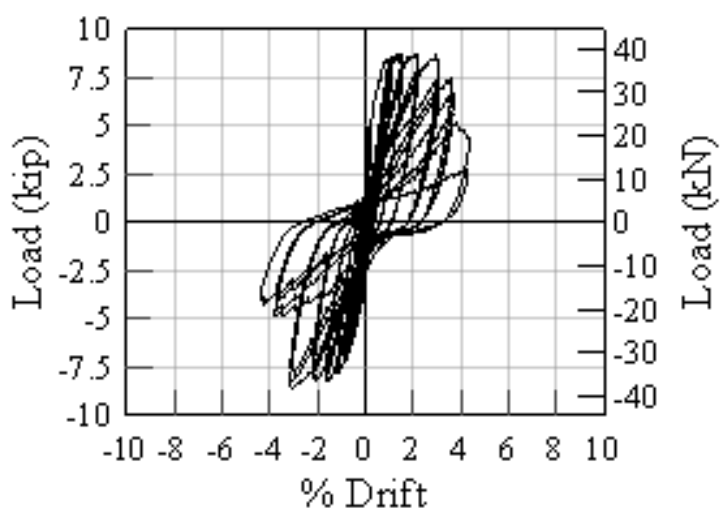

(b)

Figure A7: Apex full scale 10-ft 6-in x 4-ft wall: (a) model, (b) experimental result.

The only full scale wall tested in the PSU investigation that was tested with the form removed was one 12 -ft wide by 10 -ft 8 -in tall specimen. The model results and experimental results of this wall are shown in Figure A8(a) and Figure A8(b), 
respectively. At drift ratios below $2 \%$, the model is uncannily similar to the experimental results. In both positive and negative portions of the cycle, $\mathrm{P}_{\max }$ is nearly indistinguishable between the two in both magnitude and drift ratio. Both results indicate failure at $2 \%$ drift.

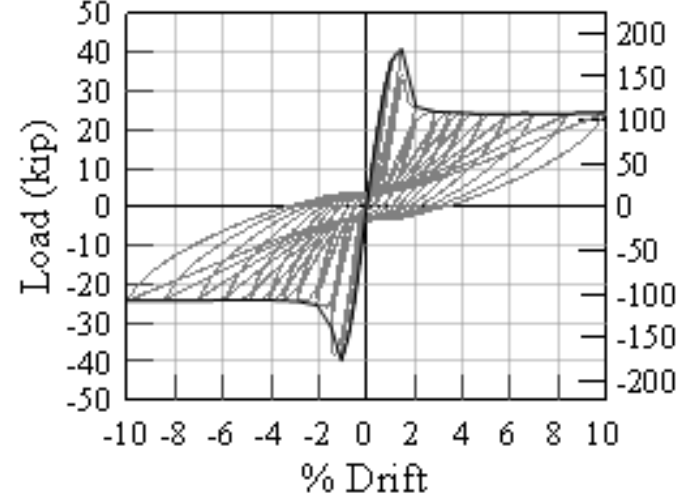

(c)

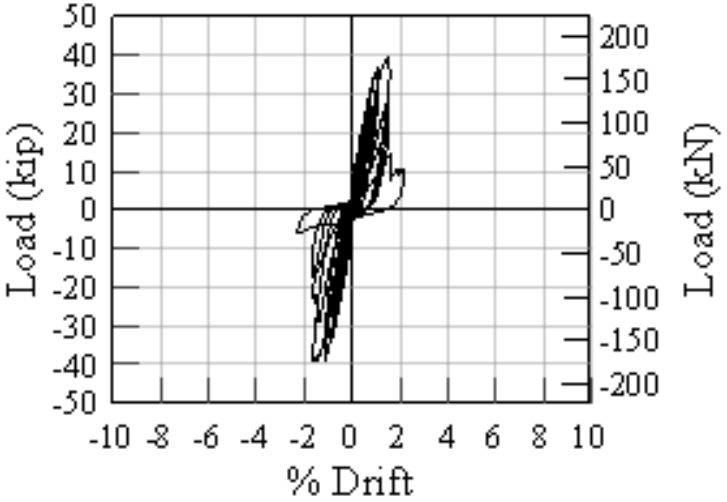

(d)

Figure A8: Apex full scale 10-ft 6-in x 12-ft wall: (a) model, (b) experimental result.

As mentioned previously, the model results here do not employ the more physically rigorous representation of joint offsets as the primary model results of Chapter 5 , but the results were compelling enough to include for consideration here. 


\section{APPENDIX B: CONCRETE MIX DESIGNS:}

\section{PCC1: Unavailable}

\section{PCC2:}

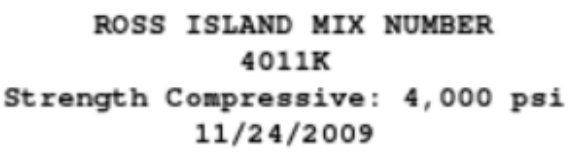

ROSS ISLAND MIX NUMBER

$4011 \mathrm{~K}$

Strength Compressive: 4,000 psi

$11 / 24 / 2009$

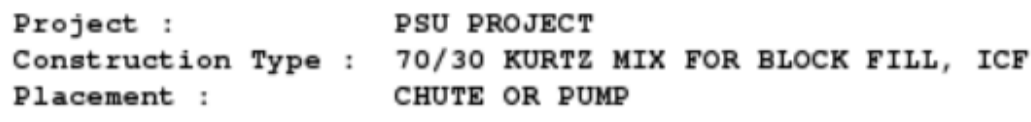

Prepared by :

ROSS ISLAND TECHNICAL SERVICES 
ECC:

\begin{tabular}{|l|c|c|c|r|r|r|} 
1. Material & $\begin{array}{c}\text { 2. Spec. } \\
\text { Grav. }\end{array}$ & $\begin{array}{c}\text { 3. Rec'd } \\
\text { Proportion } \\
\text { by weight }\end{array}$ & $\begin{array}{c}\text { 4. } \\
\text { Volume } \\
\left(\mathrm{ft}^{3}\right)\end{array}$ & $\begin{array}{c}\text { 5. Volume } \\
\text { req'd (ft3): }\end{array}$ & $\begin{array}{r}\text { 6. Weight } \\
\text { req'd (lb): }\end{array}$ & kg \\
\hline Cement & 3.15 & 1 & 0.0051 & 5.2 & 1028 & 467 \\
\hline Sand & 2.833 & 0.8 & 0.0045 & 4.7 & 822 & 374 \\
\hline Slag/Fly Ash & 2.89 & 1.2 & 0.0067 & 6.8 & 1233 & 561 \\
\hline Water & 1 & 0.58 & 0.0093 & 9.6 & 596 & 271 \\
\hline SuperPlast. & 1.09 & 0.013 & 0.0002 & 0.196 & 13 & 6 \\
\hline ECC-PVA & & $2 \%$ by vol. & 0.0005 & 0.536 & 0 & 0 \\
\hline & & Total: & 0.0263 & 27.000 & & 1678 \\
\hline
\end{tabular}




\section{APPENDIX C: SAMPLE COMPUTER SCRIPTS}

\section{C1: Script for Modeling Small Scale Faswall Test Specimen in OpenSees}

Filename: "FasWall.BuildAnalyze.type1.tcl"

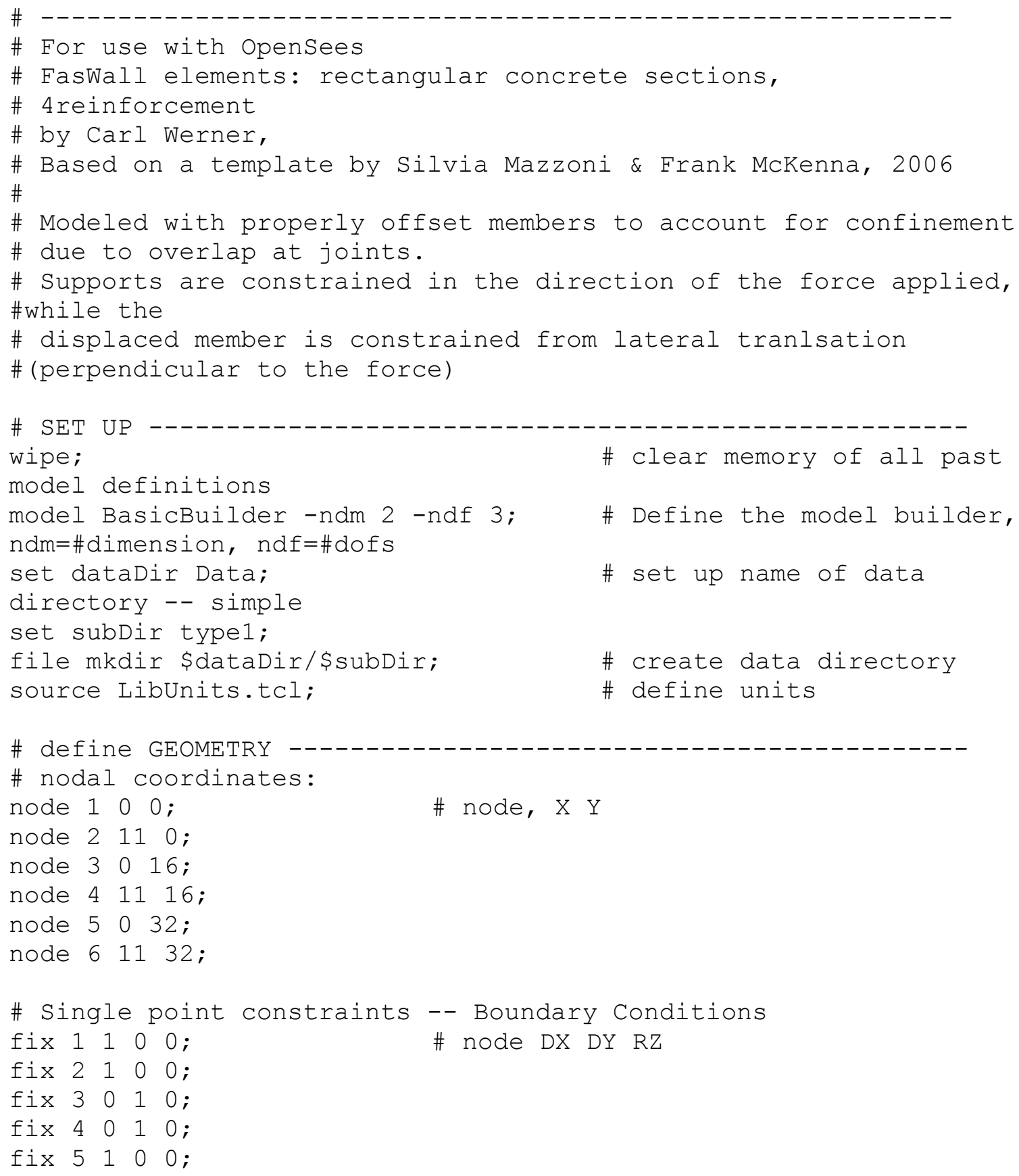




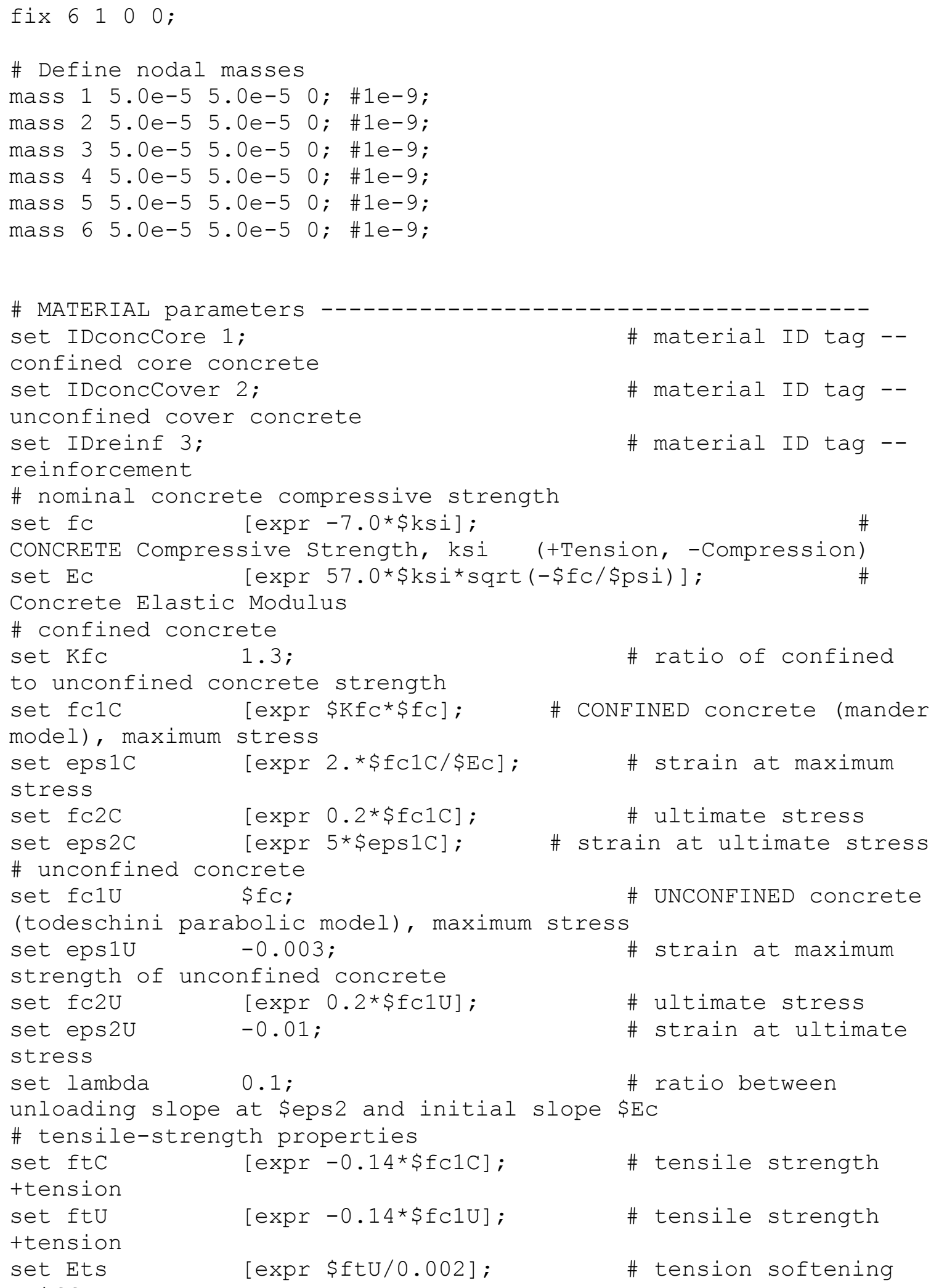




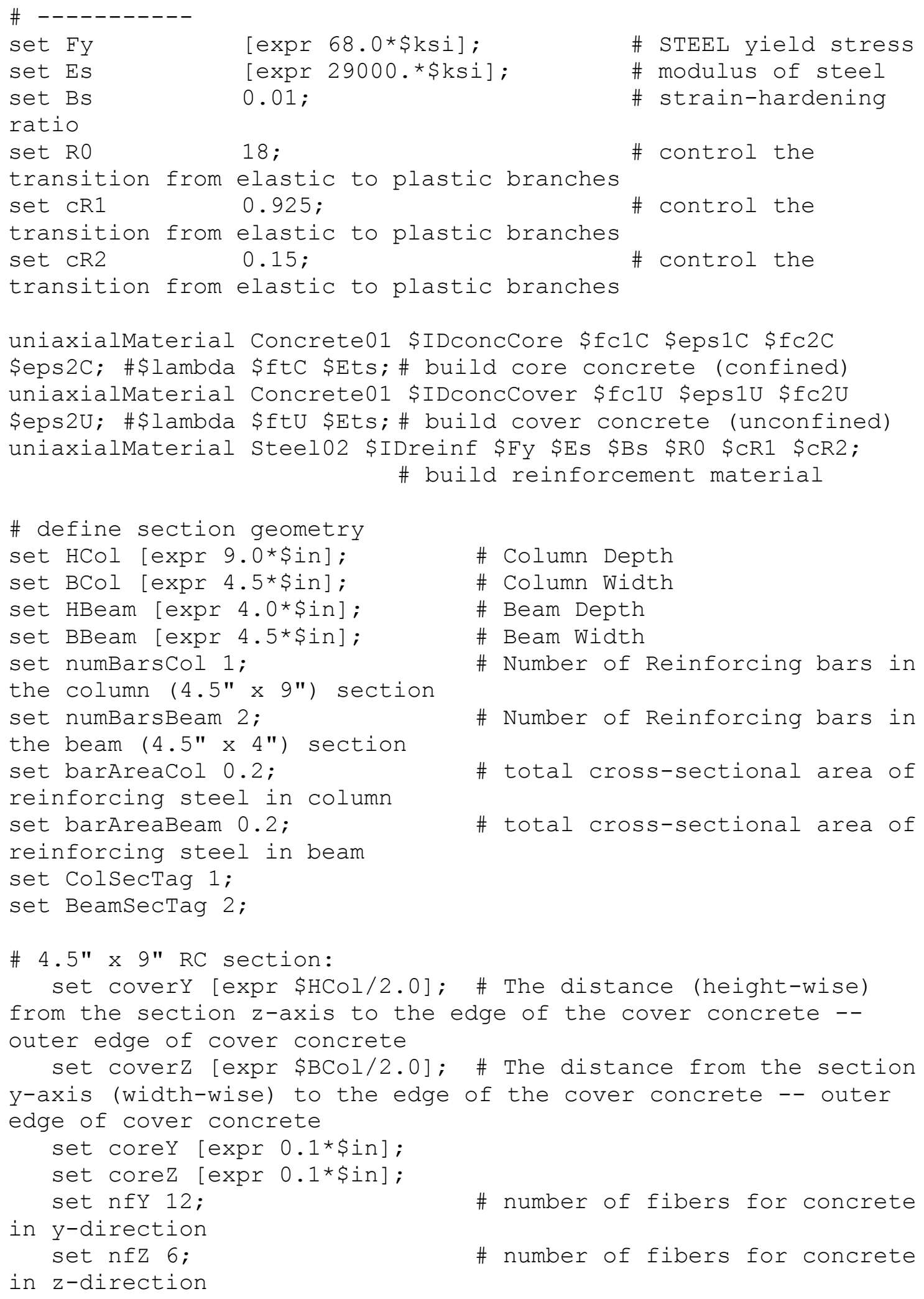




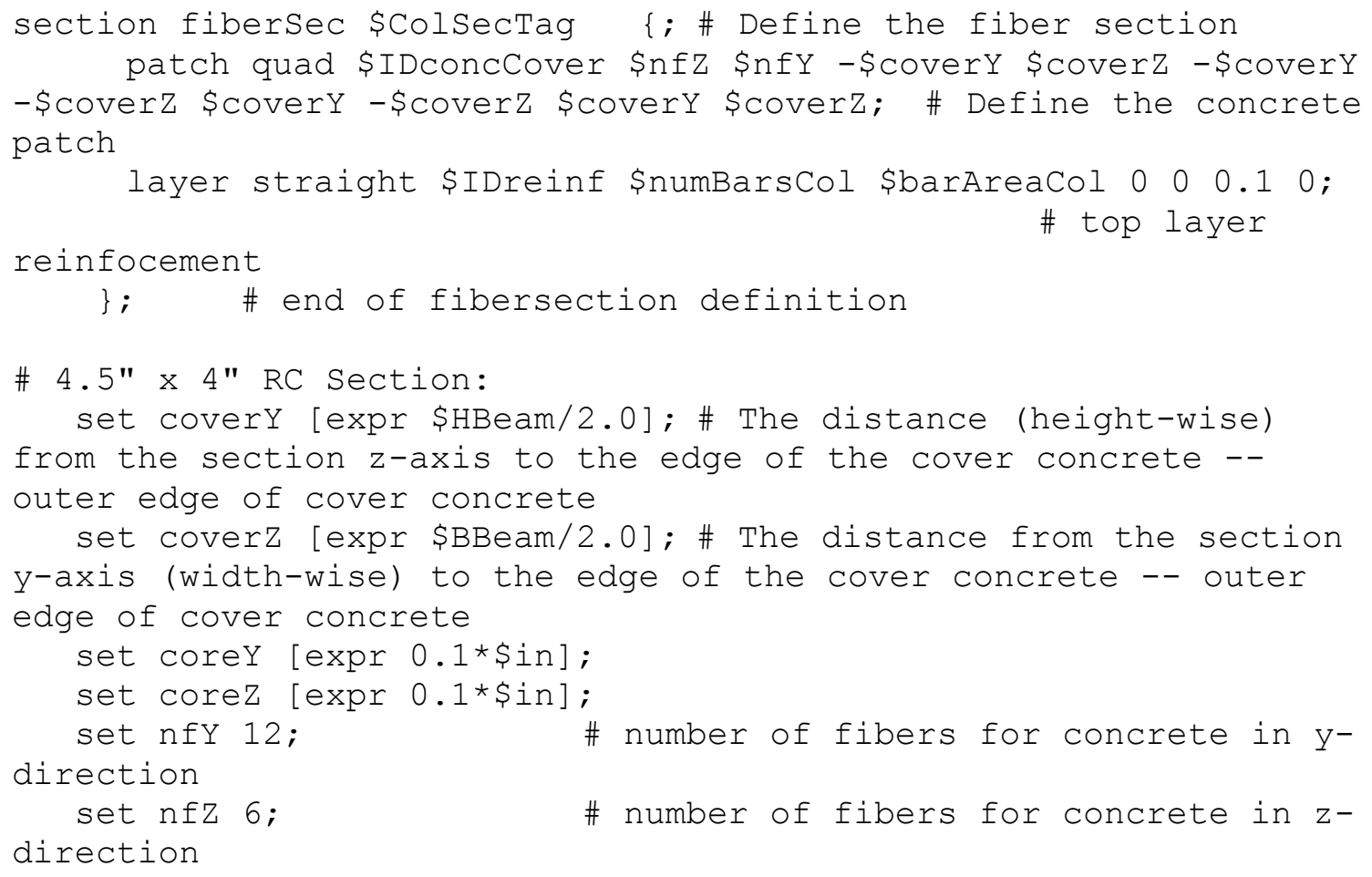




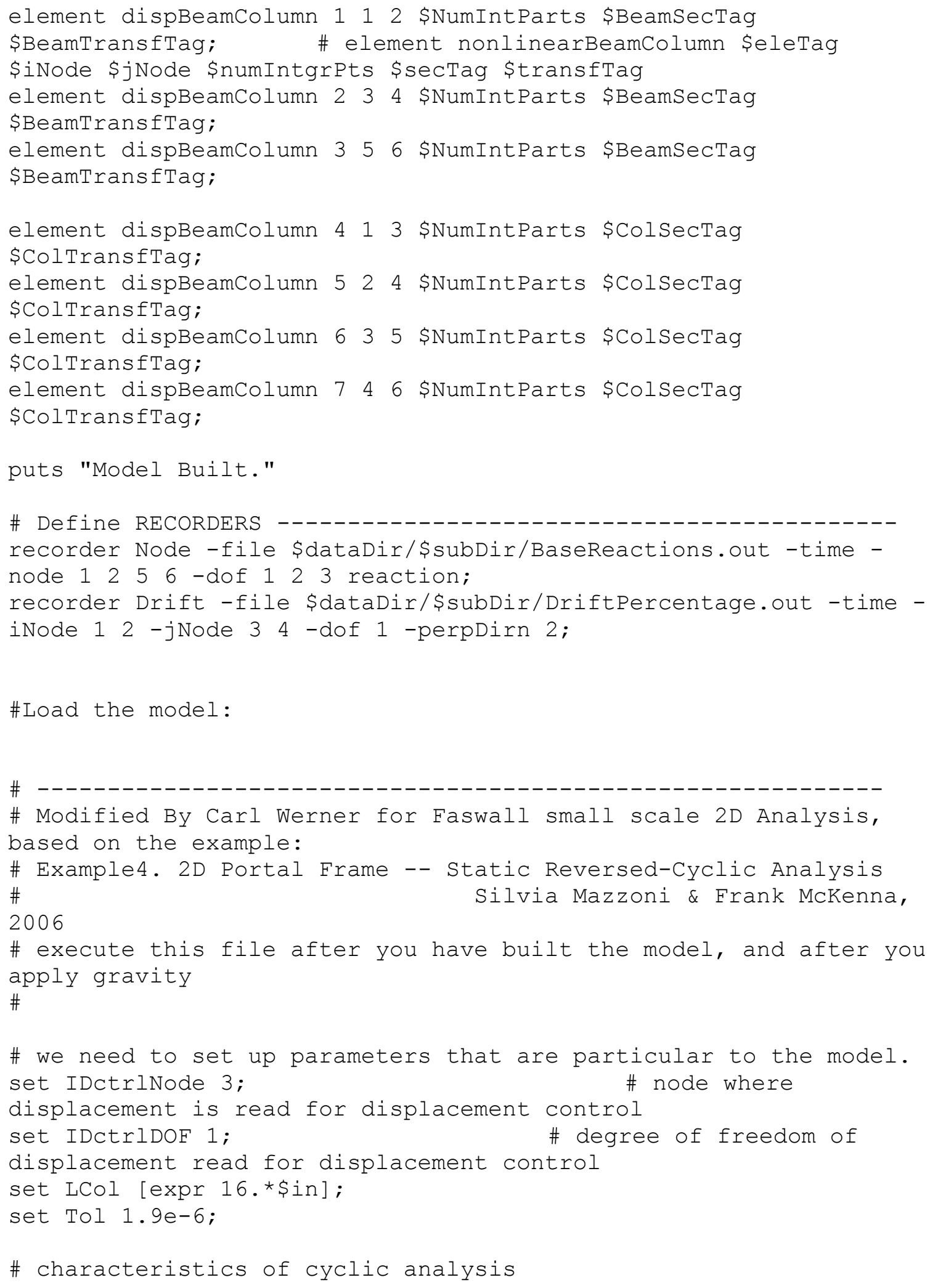




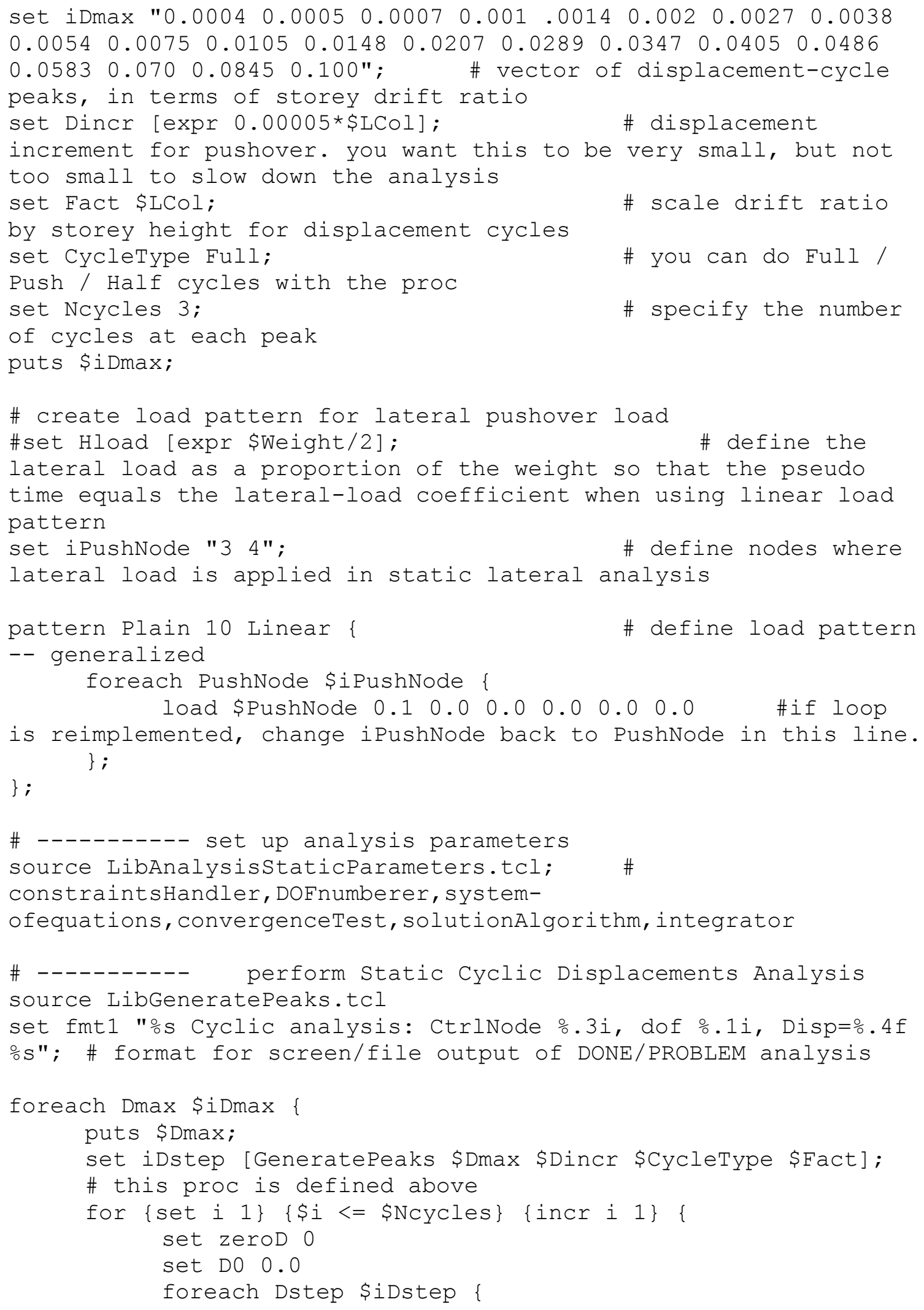




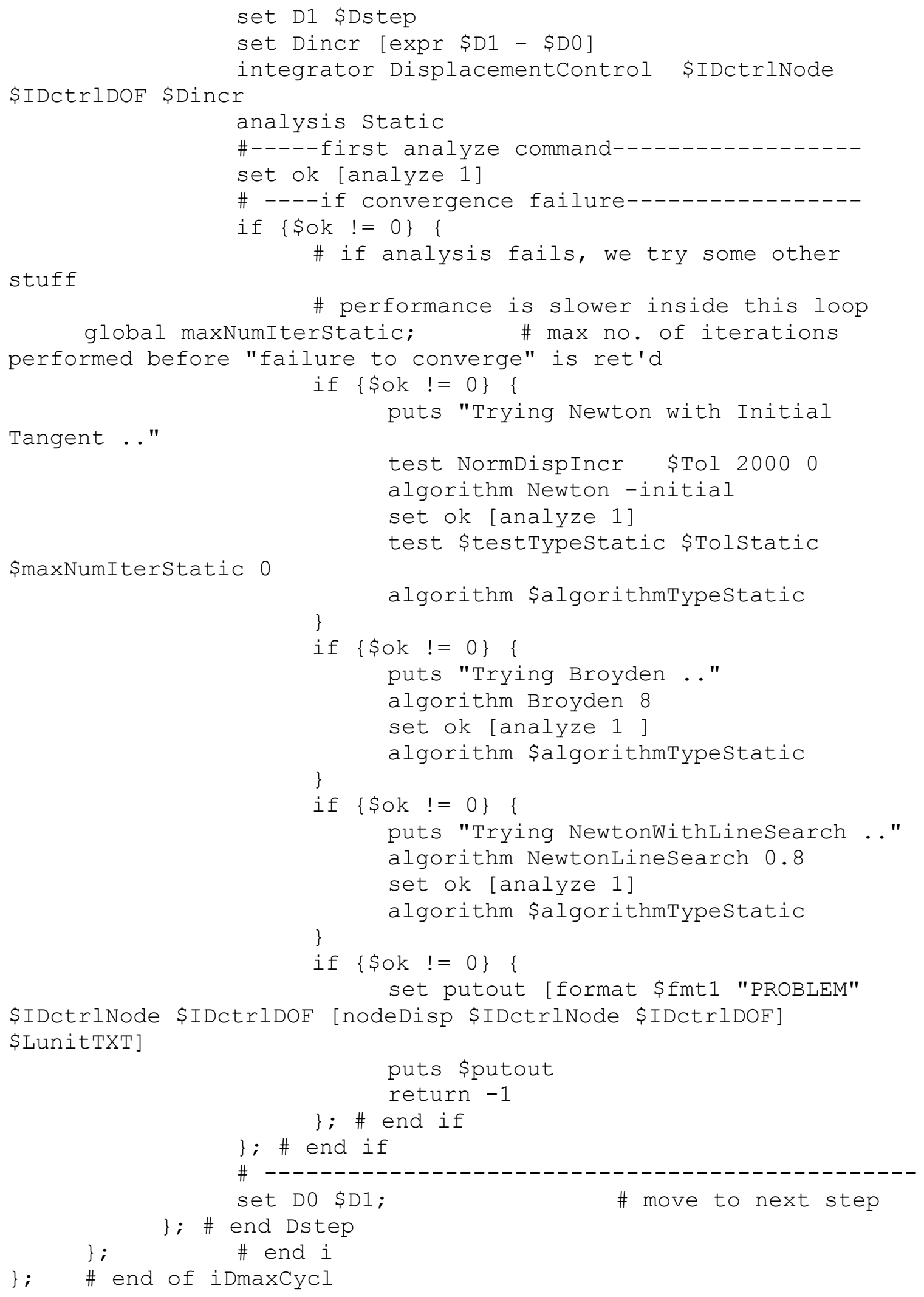




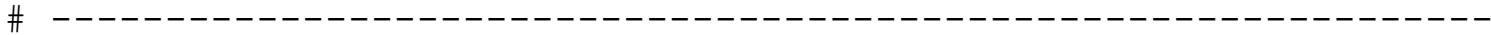

if $\{\$ o k \quad !=0\} \quad\{$

puts [format \$fmt1 "PROBLEM" \$IDctrlNode \$IDctrlDOF

[nodeDisp \$IDctrlNode \$IDctrlDOF] \$LunitTXT]

\} else \{

puts [format \$fmt1 "DONE" \$IDctrlNode \$IDctrlDOF [nodeDisp \$IDctrlNode \$IDctrlDOF] \$LunitTXT]

\} 


\section{C2: Script for Modeling Small Scale Apex Test Specimen in Opensees}

Filename: "Apex.BA.type1.7ksi.68ksi.tcl”

\#this model uses the 6-node specification, with 3" offsets at the end of each member.

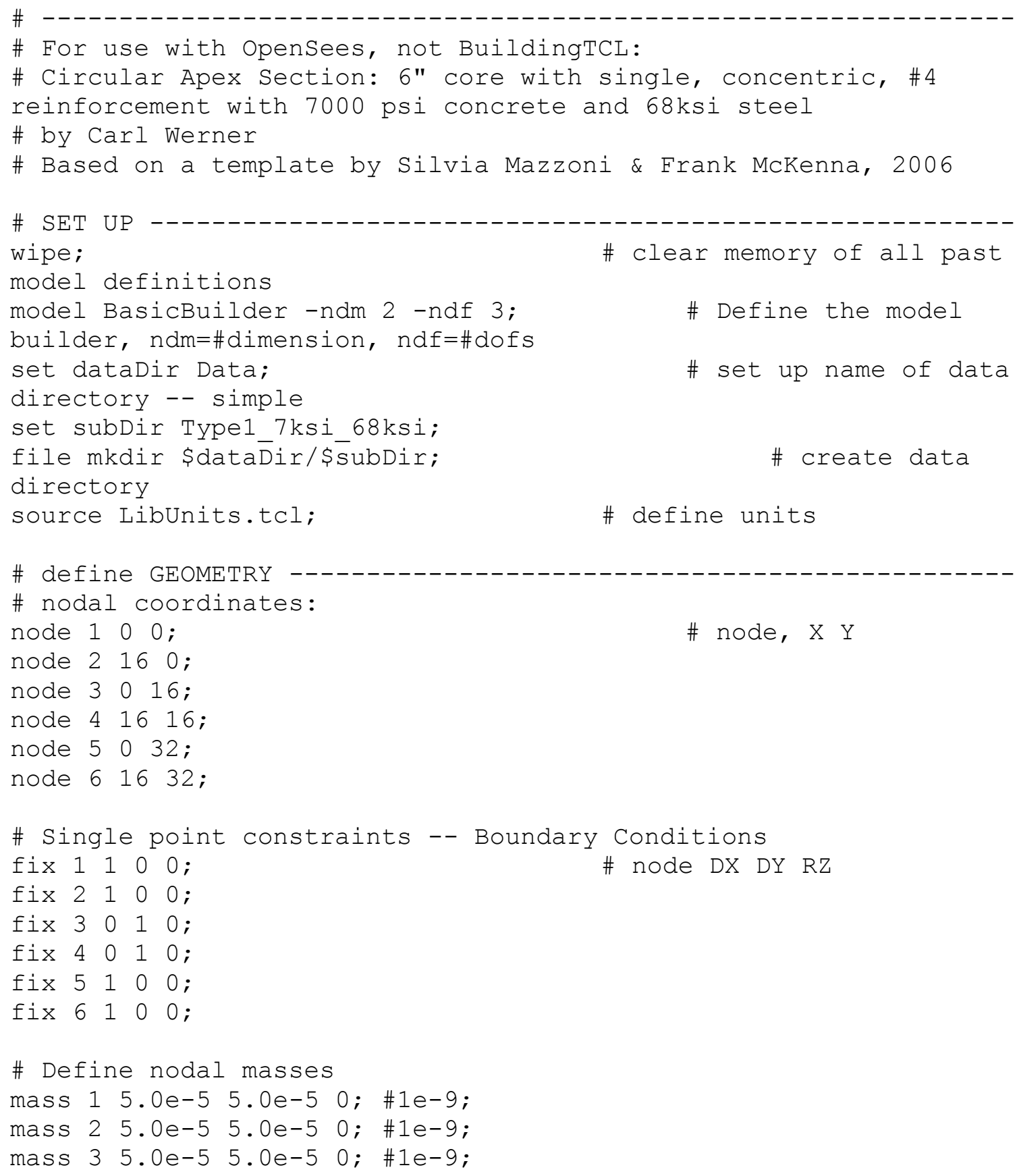




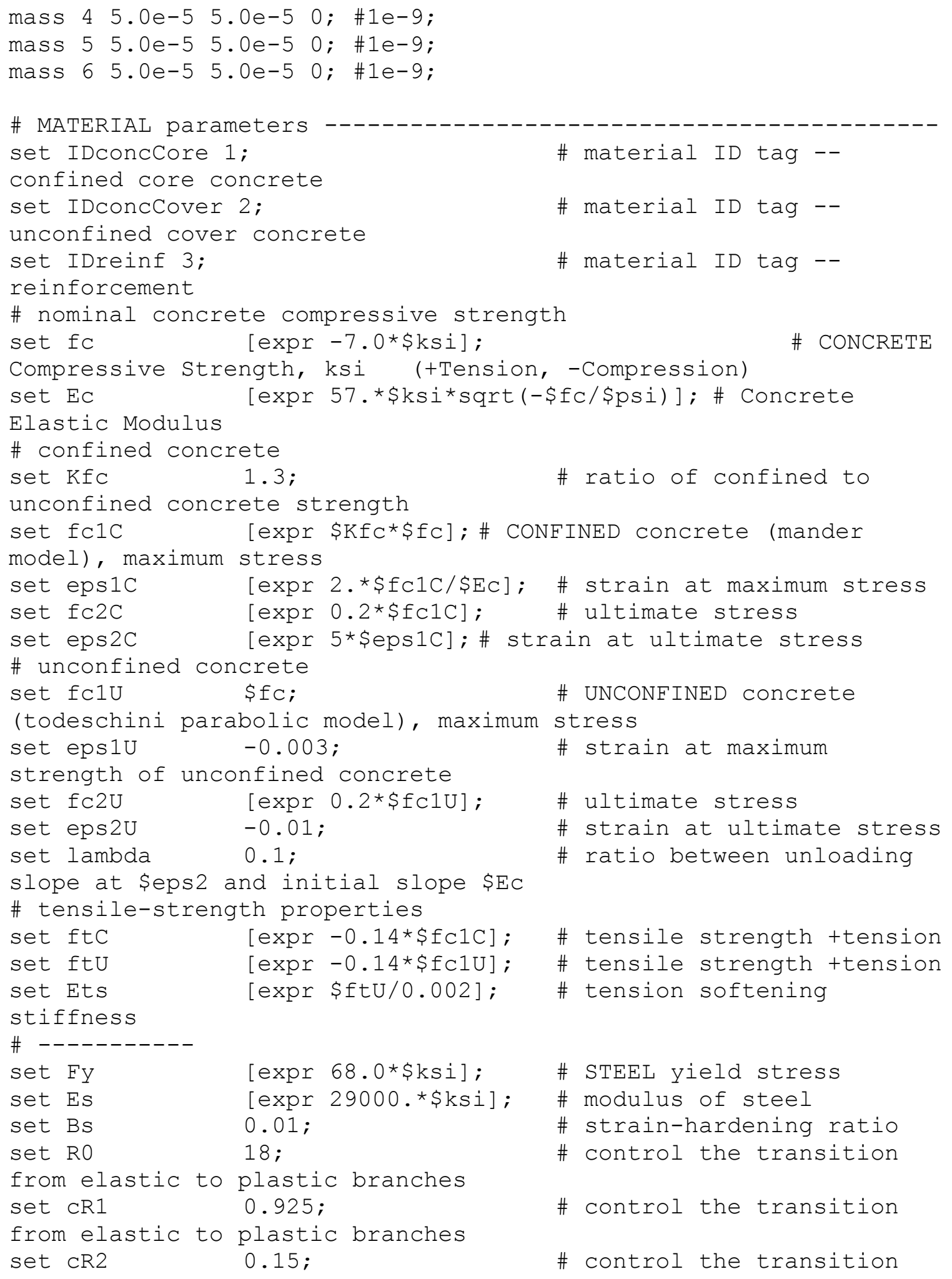




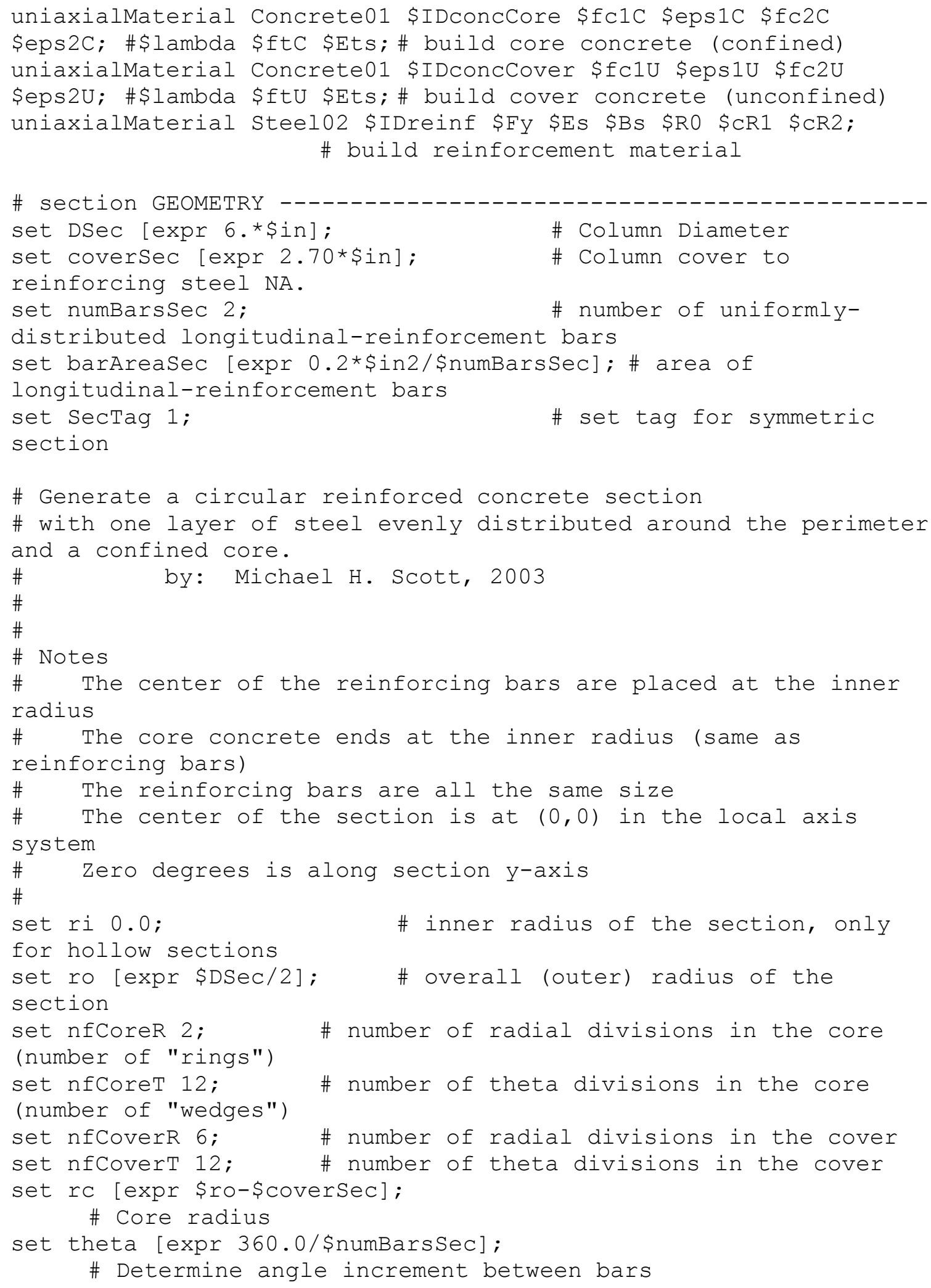




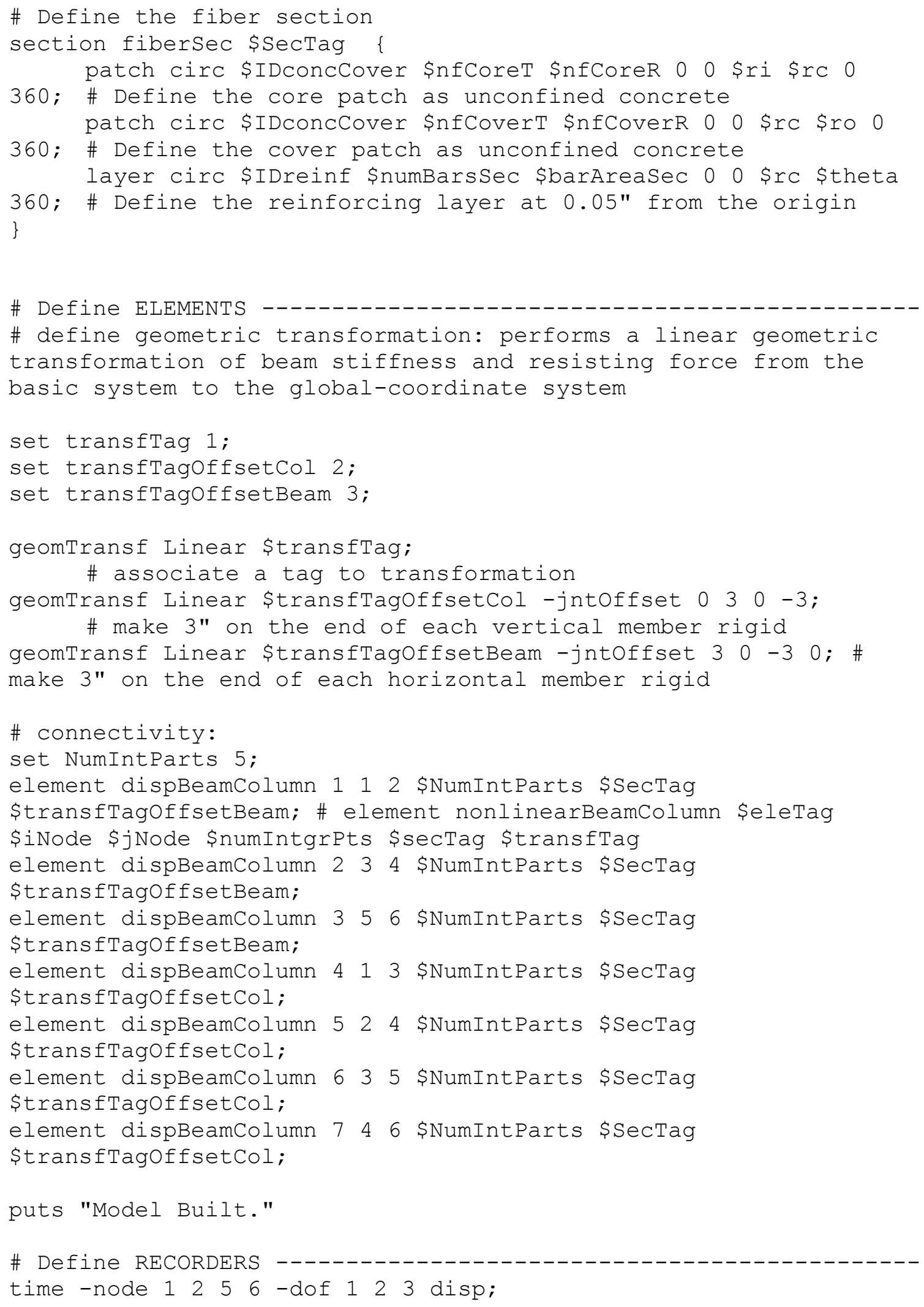


recorder Node -file \$dataDir/\$subDir/BaseReactions.out -time node $125 \quad 56$-dof 123 reaction;

recorder Drift -file \$dataDir/\$subDir/DriftPercentage.out -time iNode 12 -jNode 34 -dof 1 -perpDirn 2;

\#The model's built, so now we test it:

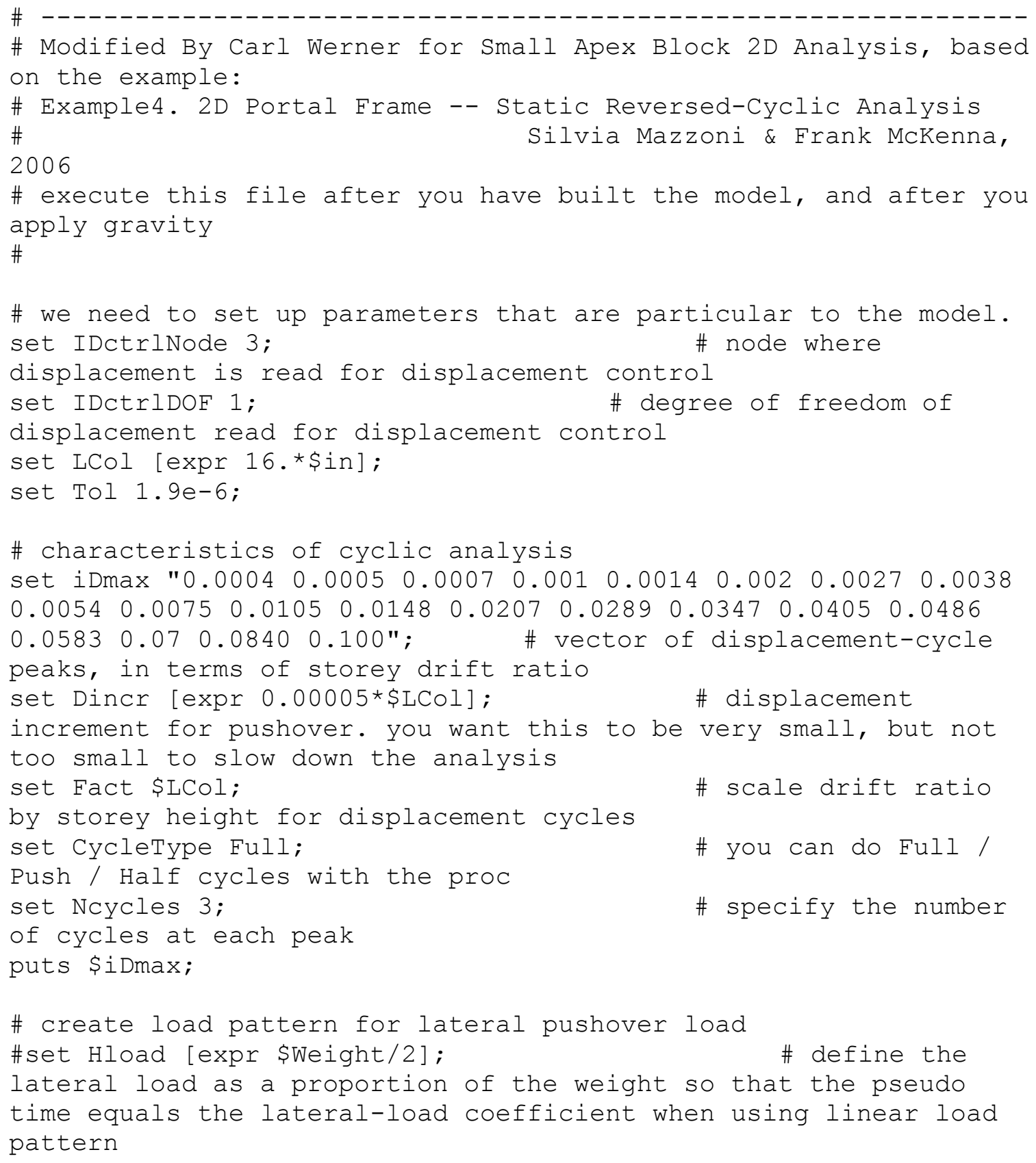




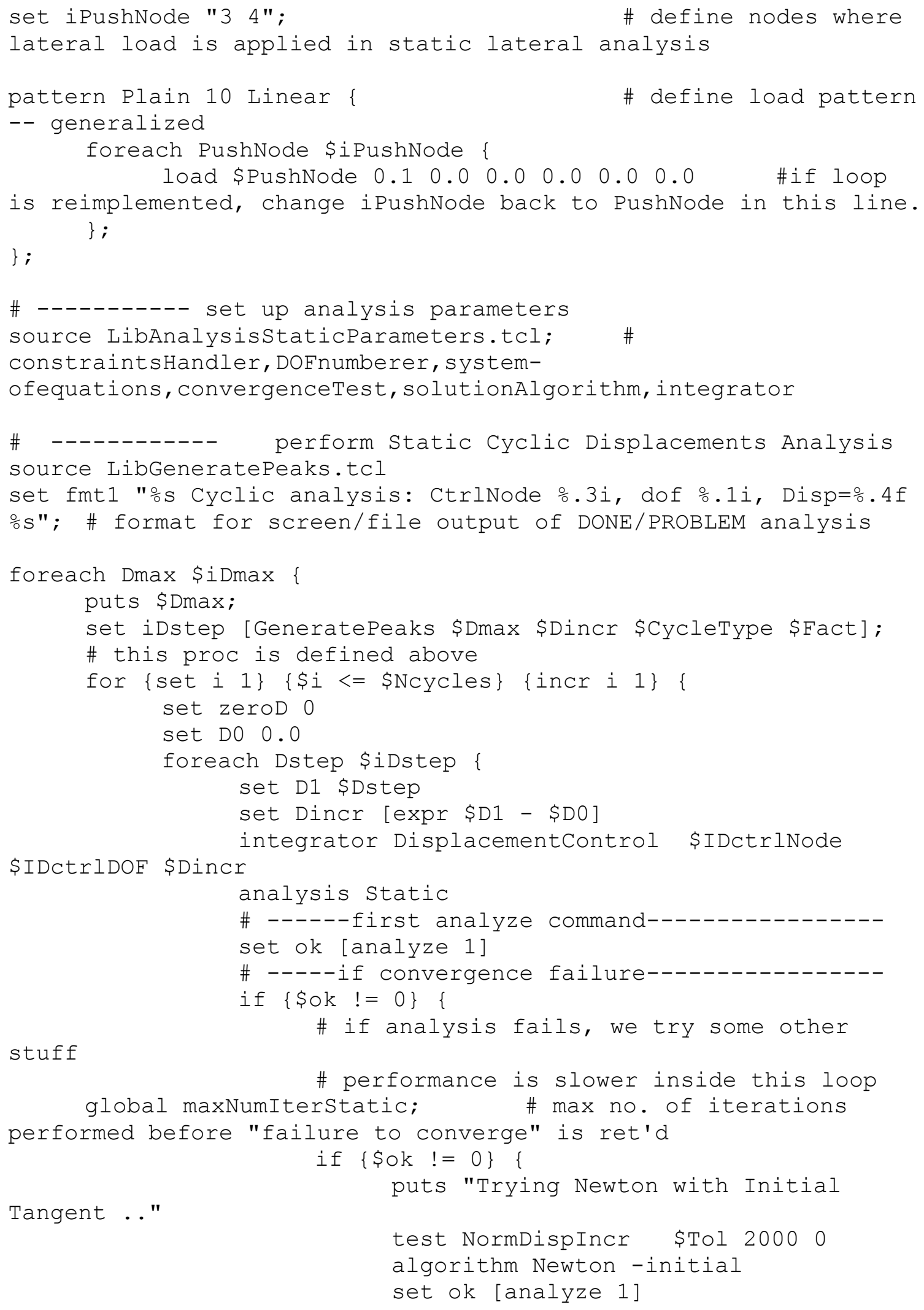




\title{
C3: Matlab Script for Generating Plots Results of OpenSees Models
}

\author{
Filename: OpenSeesGraphGenerator.m
}

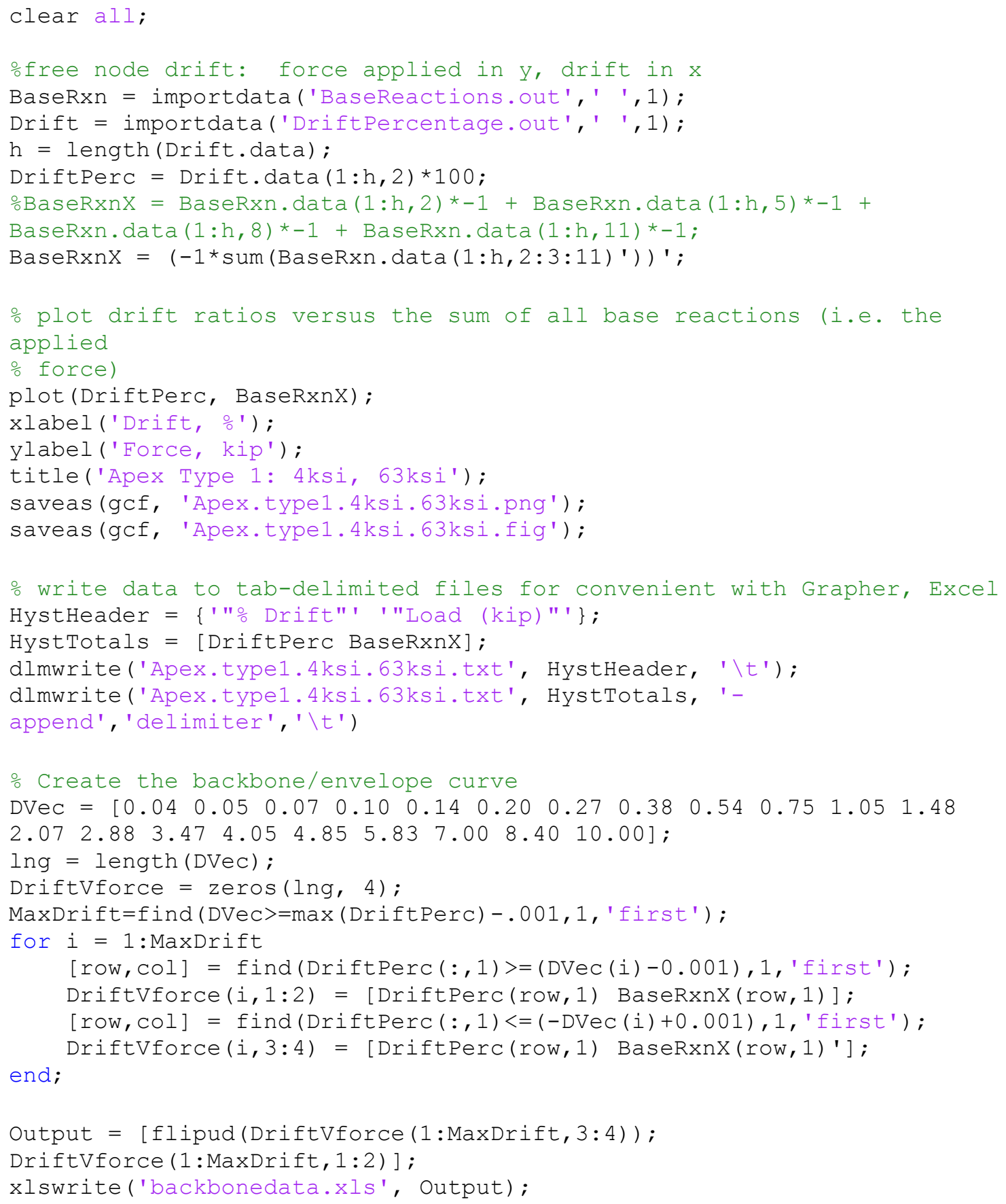

